ãoDasSimulações7.155Tempos de execução das simulaçõestable.caption.34

Inácio Guerberoff Lanari Bó

\title{
Influência da complexidade da representação de estratégias em modelos evolucionários para o Dilema do Prisioneiro com $\mathbf{n}$ jogadores
}

\author{
Dissertação apresentada à Escola Po- \\ litécnica da Universidade de São Paulo \\ para obtenção do Título de Mestre em \\ Engenharia Elétrica.
}


Inácio Guerberoff Lanari Bó

\section{Influência da complexidade da representação de estratégias em modelos evolucionários para o Dilema do Prisioneiro com n jogadores}

Dissertação apresentada à Escola Politécnica da Universidade de São Paulo para obtenção do Título de Mestre em Engenharia Elétrica.

Área de concentração:

Sistemas Digitais

Orientador:

Prof. Dr. Jaime Simão Sichman 
Este exemplar foi revisado e alterado em relação a versão original, sob responsabilidade única do autor com a anuência de seu orientador.

São Paulo, 15 de janeiro de 2008.

Assinatura do autor

Assinatura do orientador

\section{Ficha Catalográfica}

Bó, Inácio Guerberoff Lanari

Influência da complexidade da representação de estratégias em modelos evolucionários para o Dilema do Prisioneiro com n jogadores. São Paulo, 2008. 116 p. CD-ROM em Anexo.

Dissertação (Mestrado) — Escola Politécnica da Universidade de São Paulo. Departamento de Engenharia de Computação e Sistemas Digitais.

1. Teoria dos Jogos. 2. Sistemas Multiagentes. 3. Autômatos Finitos. 4. Simulação de Sistemas I. Universidade de São Paulo. Escola Politécnica. Departamento de Engenharia de Computação e Sistemas Digitais. II. Título. 


\section{Agradecimentos}

Gostaria inicialmente de agradecer ao meu orientador, Prof. Dr. Jaime Simão Sichman, por me guiar pelo complexo mundo da ciência, indicando a direção correta da clareza e me ajudando a desviar das diversas armadilhas que surgem pelo caminho.

Gostaria também de agradecer à minha mãe, ao meu irmão, à minha avó e a todos os meus familiares, por sempre me apoiarem nas escolhas, às vezes tortuosas, que me trouxeram até aqui. Tudo seria muito mais difícil sem essa força!

Um agradecimento especial aos meus colegas da época da UFPR, em especial aos colegas Luciano Carvalho, Luciano Gabriel, Rodrigo Lobo e Fábio Ono, assim como aos professores Ramón Fernandez e José Luis Oreiro. Meus interesses, anseios e pensamentos definitivamente não seriam os mesmos não fossem os debates, conversas e momentos compartilhados com vocês.

Agradeço aos colegas do LTI Antônio, Marcelo, Valdinei, Valguima, Alan, André, Lucas, Rodrigo, Bianchi, Anna, Diana, Luciano, Gustavo e à minha "irmã por parte de orientador" Priscilla, pelas diversas ajudas nos momentos de sufoco, bate-papos, bandejões, cafezinhos e churrascos compartilhados, assim como sugestões e críticas em apresentações.

Agradeço muito a ajuda dos amigos Alberto Sciessere e Bruno Favaretto, por tratarem como filhas as simulações que ficaram executando enquanto eu viajava, e da amiga Thais Semprebom pela paciência e rigor aplicados à cansativa tarefa de revisar este texto.

Gostaria ainda de agradecer à Dra. Anarosa Brandão e ao Prof. Dr. Eleutério Prado por aceitarem o convite para participarem da minha banca.

Agradeço ao Prof. Dr. João José Neto, do PCS/EP pela ajuda na compreensão e desenvolvimento do modelo de autômatos adaptativos, ao Prof. Dr. Pablo Ferrari, do MAE/IME pela ajuda e apoio na busca por uma solução para as análises numéricas, e em especial à Profa. Dra. Airlane Alencar, do MAE/IME pela preciosa ajuda na elaboração das análises estatísticas. 
Por fim, agradeço ao $\mathrm{CNPq}$ pela bolsa oferecida, viabilizando o desenvolvimento deste trabalho. 


\section{Resumo}

Em Teoria dos Jogos, o Dilema do Prisioneiro para N Participantes (DPNP) é o problema que representa, em sua forma elementar, o paradoxo que gera as dificuldades existentes na formação da cooperação entre mais de dois agentes. Diversos trabalhos foram e continuam sendo feitos sobre esse tema, no sentido de compreender melhor os fatores que influenciam o surgimento e a evolução da cooperação numa sociedade. Neste trabalho, o objetivo principal é o de analisar o impacto do poder expressivo de um modelo de representação de estratégias neste surgimento e evolução. Para tal, foi desenvolvido um modelo computacional de jogos evolutivos, onde agentes participam repetidamente do DPNP. Nele, as estratégias que definem qual será a jogada de um determinado agente são desenvolvidas e selecionadas através de mecanismos de mutação e reprodução daquelas que obtiveram melhores resultados nas iterações anteriores, e implementadas através de duas representações com diferentes poderes computacionais: autômatos finitos e autômatos adaptativos. Este modelo foi implementado num sistema denominado $\boldsymbol{S}_{\mathbf{2}} \boldsymbol{E}_{\mathbf{2}}$ onde foram executados diversos experimentos de simulação. Através da comparação dos resultados obtidos para ambas as representações, verificou-se que em ambos os casos a sociedade consegue atingir, após um período inicial, um nível de cooperação relativamente alto e estável. A análise das estratégias utilizadas pelos agentes, entretanto, mostrou que o uso de autômatos adaptativos resulta em uma pequena vantagem, embora estatisticamente não significativa, pois permite surgir estratégias que visam retornar a uma situação de cooperação. 


\section{Abstract}

In Game Theory, the n-Players Prisoner's Dilemma (NPPD) is a problem that represents, in its elementary form, the paradox that leads to the existing difficulties in the development of cooperation between two or more agents. Many works were and are still being done about this subject, trying to better understand the factors that influence the development and evolution of cooperation in a society. In this work, the main objective is to analyze the impact of the expressive power of the strategies representation model in this development and evolution. In order to do so, a computational model of evolutionary games was developed, where agents are spatially distributed and participate on the NPPD with five participants, interacting only with their neighbors. In this model, the strategies that define the agent's decisions are developed and selected through mutation and reproduction of those strategies that obtained better results in the last iterations, and they are implemented by two representations with different computational power: finite automata and adaptative automata. This model was implemented in a system called $\boldsymbol{S}_{\mathbf{2}} \boldsymbol{E}_{\mathbf{2}}$ and several simulation experiments were carried on. Comparing the results obtained in those experiments, it was verified that after an initial period of time in both cases the society achieved a relatively high and stable level of cooperation. On the other hand, the analysis of the strategies used by the agents showed that the use of adaptative automata resulted in a slight advantage, although not statistically significative, because they allow the emergence of strategies that return to a situation of cooperation. 


\title{
Sumário
}

\section{Lista de Figuras}

\author{
Lista de Tabelas
}

\section{Lista de Abreviaturas}

1 Introdução 1

1.1 Motivação . . . . . . . . . . . . . . . . . . . . . . . . . 1

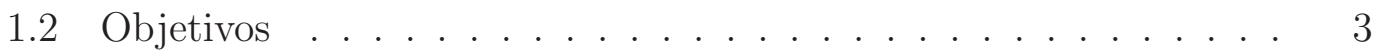

1.3 Resultados esperados . . . . . . . . . . . . . . . . . . . . 4

1.4 Método ........................ . . . 4

1.5 Descrição do documento . . . . . . . . . . . . . . . 6

$\begin{array}{llr}2 & \text { Teoria dos jogos } & 8\end{array}$

2.1 Introdução . . . . . . . . . . . . . . . . . . . . . . . 8

2.2 Dilema do prisioneiro . . . . . . . . . . . . . . . . . 8

2.2.1 Matriz de ganho . . . . . . . . . . . . . . 9

2.2 .2 Versão iterada . . . . . . . . . . . . . . . . . . . 10

2.3 Dilema do prisioneiro para $n$ participantes . . . . . . . . . . 12

2.4 Jogos evolutivos . . . . . . . . . . . . . . . . . . . . . . . . . . 14

2.5 Considerações finais . . . . . . . . . . . . . . . . . . . . . 15

$\begin{array}{lll}3 & \text { Autômatos finitos e autômatos adaptativos } & 17\end{array}$

3.1 Autômatos finitos . . . . . . . . . . . . . . . . . . . 17

3.2 Autômatos adaptativos . . . . . . . . . . . . . . . . . . . . . 19

3.3 Considerações finais . . . . . . . . . . . . . . . . . . . . . 22 
4.1 Ambiente evolutivo e espacial . . . . . . . . . . . . . . 24

4.2 Representação de estratégias . . . . . . . . . . . . . . . . 27

4.3 Mutação de estratégias . . . . . . . . . . . . . . . . . . . 28

4.4 Resultados obtidos . . . . . . . . . . . . . . . . . 29

5 Extensão do modelo de Lindgren e Johansson 31

5.1 Introdução . . . . . . . . . . . . . . . . . . . . . . . . 31

5.2 Modelo simplificado de autômatos adaptativos . . . . . . . . . . . 32

5.3 Complexidade de estratégias possíveis . . . . . . . . . . . . 35

5.4 Funcionamento dos modelos . . . . . . . . . . . . . . . 38

6 Sistema $S_{2} E_{2} \quad 44$

6.1 Escolha do ambiente de desenvolvimento . . . . . . . . . . . . . . 44

6.2 Arquitetura do software ................. 45

6.2 .1 Núcleo de simulação . . . . . . . . . . . . . . . . . 46

6.2 .2 Ambiente espacial . . . . . . . . . . . . . 47

6.2.3 Agentes e estratégias . . . . . . . . . . . . . . 49

6.2 .4 Depósito de dados . . . . . . . . . . . . . . . . . 49

6.2 .5 Interface ........................ 50

7 Experimentos realizados $\quad 53$

7.1 Descrição dos experimentos . . . . . . . . . . . . . . 53

7.2 Experimentos com o modelo JE+AF . . . . . . . . . . . . . 55

7.2.1 Primeira bateria de testes . . . . . . . . . 56

7.2.2 Segunda bateria de testes . . . . . . . . . . . 63

7.2 .3 Síntese dos resultados . . . . . . . . . . . . . . 65

7.3 Experimentos com o modelo JE+AA . . . . . . . . . . . . 68

7.3.1 Primeira bateria de testes . . . . . . . . . 68 
7.3.2 Segunda bateria de testes . . . . . . . . . . 75

7.3.3 Síntese dos resultados . . . . . . . . . . . . . . . . 78

7.4 Análise comparativa . . . . . . . . . . . . . . . . . . 79

7.4 .1 Análise qualitativa . . . . . . . . . . . . . . . . 79

7.4.2 Análise quantitativa . . . . . . . . . . . . . 83

7.5 Considerações finais . . . . . . . . . . . . . . . . 8 85

8 Conclusões $\quad 86$

$\begin{array}{ll}\text { Apêndices } & 90\end{array}$

A Estratégias predominantes no modelo JE+AA 90

$\begin{array}{lll}\text { B Análise estatística } & 104\end{array}$

B.1 Análise de correlação serial das utilidades das simulações amostradas a cada 10 gerações após o equilíbrio . . . . . . . . . . . . . 104

B.2 Resultado da aplicação do método de Tukey . . . . . . . . . . . . 104

$\begin{array}{lr}\text { Referências Bibliográficas } & 114\end{array}$ 


\section{Lista de Figuras}

2.1 Matriz de ganho DP . . . . . . . . . . . . . . . . 9

3.1 Exemplo de $\mathrm{AF} \ldots \ldots \ldots \ldots$. . . . . . . . . . . . . . . 17

3.2 Exemplo de remoção de estados inalcançáveis . . . . . . . . . . . 19

3.3 Exemplo de combinação de estados equivalentes . . . . . . . . . . 19

3.4 Autômato antes da execução da função adaptativa $\omega_{0}$. . . . . . . 21

3.5 Autômato após a execução da função adaptativa $\omega_{0}$. . . . . . . . 21

3.6 Exemplo de representação de autômato sem todas as transições 23

4.1 Exemplo de reticulado e vizinhança . . . . . . . . . . . . . . 25

4.2 Vizinhança no limite e toro . . . . . . . . . . . . . 25

4.3 Vizinhança extendida . . . . . . . . . . . . . . . . . . 26

4.4 Representação de estratégias por Lindgren \& Johansson . . . . . . 27

4.5 Resultado da simulação feita por Lindgren \& Johansson (LINDGREN; JOHANSSON, 2003) . . . . . . . . . . . . . . . . . . . . . . 29

4.6 Estratégia $\mathbf{U} \ldots \ldots \ldots$

4.7 Estratégia predominante após 1000 gerações na simulação feita por Lindgren \& Johansson . . . . . . . . . . . . . . . . . . . . 30

5.1 Estrutura inicial do autômato . . . . . . . . . . . . . . 36

5.2 Estrutura do autômato no início da rodada $2 \ldots . . . .37$

5.3 Estrutura do autômato no início da rodada 3 . . . . . . . . . 37

5.4 Estrutura do autômato no início das rodadas 4,5,6,7,8 e 9 . . . . 37

6.1 Estrutura do sistema $\boldsymbol{S}_{\mathbf{2}} \boldsymbol{E}_{\mathbf{2}} \ldots \ldots \ldots \ldots$

6.2 Diagrama de classes - núcleo de simulação . . . . . . . . . . . . 47

6.3 Diagrama de classes - ambiente espacial . . . . . . . . . . . . . . . 47

6.4 Diagrama de classes - agentes . . . . . . . . . . . . . . . . 48 
6.5 Diagrama de classes - estratégias . . . . . . . . . . . . 48

6.6 Diagrama de classes - depósito de dados . . . . . . . . . . . . . . 49

6.7 Interface para realização dos experimentos . . . . . . . . . . . 50

7.1 Estratégia inicial TT5 para a bateria 2 de simulações de 5000

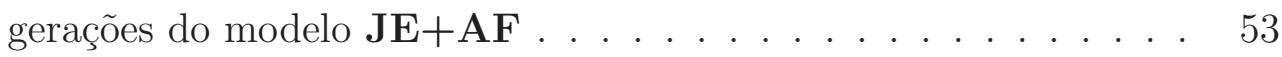

7.2 Utilidade total dos agentes para a simulação 1 da bateria 1 de 8000

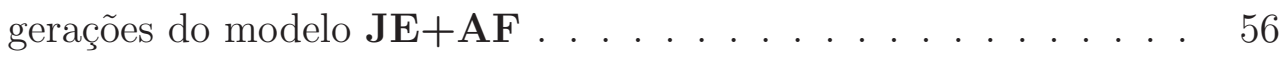

7.3 Utilidade total dos agentes para a simulação 2 da bateria 1 de 8000

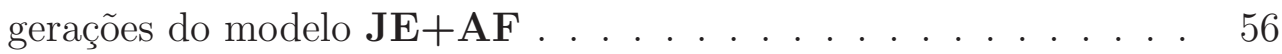

7.4 Utilidade total dos agentes para a simulação 3 da bateria 1 de 8000 gerações do modelo $\mathbf{J E}+\mathbf{A F} \ldots . . . . . . .57$

7.5 Jogadas feitas pelos agentes para a simulação 1 da bateria 1 de 8000 gerações do modelo $\mathbf{J E}+\mathbf{A F}$. . . . . . . . . . . . . . . . 57

7.6 Jogadas feitas pelos agentes para a simulação 2 da bateria 1 de 8000 gerações do modelo $\mathbf{J E}+\mathbf{A F}$. . . . . . . . . . . . . . . . 58

7.7 Jogadas feitas pelos agentes para a simulação 3 da bateria 1 de 8000 gerações do modelo $\mathbf{J E}+\mathbf{A F}$. . . . . . . . . . . . . . . . 58

7.8 População de estratégias da simulação 1 da bateria 1 de 8000 gerações do modelo $\mathbf{J E}+\mathbf{A F}$. . . . . . . . . . . . . . . . . . . . 59

7.9 Mapas de jogadas e da localização das mutações para a simulação 1 da bateria 1 de simulações de 8000 gerações do modelo $\mathbf{J E}+\mathbf{A F} \quad 60$

7.10 População de estratégias da simulação 2 da bateria 1 de 8000 gerações do modelo $\mathbf{J E}+\mathbf{A F}$. . . . . . . . . . . . . . . . . . . . 61

7.11 População de estratégias da simulação 3 da bateria 1 de 8000 gerações do modelo $\mathbf{J E}+\mathbf{A F}$. . . . . . . . . . . . . . . . . . . . 62

7.12 Utilidade total dos agentes para a simulação 1 da bateria 2 de 5000

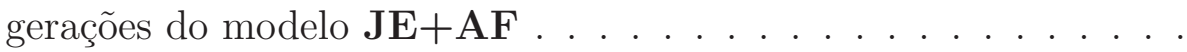

7.13 Utilidade total dos agentes para a simulação 2 da bateria 2 de 5000 gerações do modelo $\mathbf{J E}+\mathbf{A F}$. . . . . . . . . . . . . . . . . . . . 64

7.14 Jogadas feitas pelos agentes para a simulação 1 da bateria 2 de 5000 gerações do modelo $\mathbf{J E}+\mathbf{A F}$. . . . . . . . . . . . . . . . . . 64 
7.15 Jogadas feitas pelos agentes para a simulação 2 da bateria 2 de 5000 gerações do modelo $\mathbf{J E}+\mathbf{A F}$. . . . . . . . . . . . .

7.16 População de estratégias da simulação 1 da bateria 2 de 5000

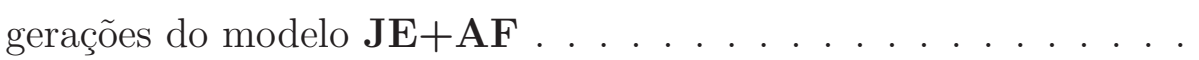

7.17 População de estratégias da simulação 2 da bateria 2 de 5000 gerações do modelo $\mathbf{J E}+\mathbf{A F} \ldots \ldots$. . . . . . . . . . . . 66

7.18 Mapas de jogadas e da localização das mutações para a simulação 1 da bateria 2 de 5000 gerações do modelo $\mathbf{J E}+\mathbf{A F}$. . . . . . .

7.19 Utilidade total dos agentes para a simulação 1 da bateria 1 de 8000

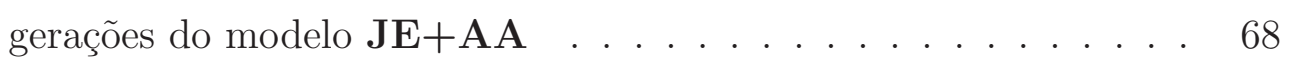

7.20 Utilidade total dos agentes para a simulação 2 da bateria 1 de 8000 gerações do modelo $\mathbf{J E}+\mathbf{A A} \ldots \ldots \ldots$. . . . . . . . .

7.21 Utilidade total dos agentes para a simulação 3 da bateria 1 de 8000 gerações do modelo $\mathbf{J E}+\mathbf{A A} \ldots \ldots \ldots$

7.22 Jogadas feitas pelos agentes para a simulação 1 da bateria 1 de

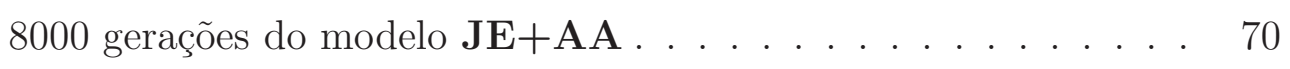

7.23 Jogadas feitas pelos agentes para a simulação 2 da bateria 1 de 8000 gerações do modelo $\mathbf{J E}+\mathbf{A A}$. . . . . . . . . . . . . 70

7.24 Jogadas feitas pelos agentes para a simulação 3 da bateria 1 de 8000 gerações do modelo $\mathbf{J E}+\mathbf{A A} \ldots \ldots \ldots$. . . . . . . . .

7.25 Segunda estratégia predominante na geração 2000 da simulação 1 da bateria 1 do modelo $\mathbf{J E}+\mathbf{A A} \ldots \ldots . \ldots 71$

7.26 Estratégia predominante na geração 8000 da simulação 3 da bateria 1 do modelo $\mathbf{J E}+\mathbf{A A} \ldots \ldots \ldots \ldots$

7.27 Estratégia predominante na geração 8000 da simulação 3 da bateria 1 do modelo $\mathbf{J E}+\mathbf{A A}$ após a execução da função adaptativa da transição $(D 4,4, D 4) \ldots \ldots \ldots \ldots \ldots \ldots$

7.28 Estratégia predominante na geração 7000 da simulação 2 da bateria

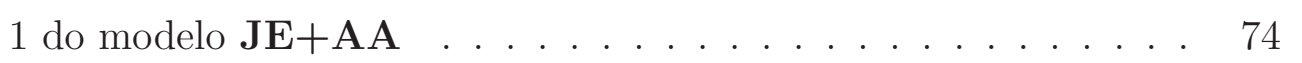

7.29 Estratégia predominante na geração 7000 da simulação 2 da bateria 1 do modelo $\mathbf{J E}+\mathbf{A A}$ após a execução da função adaptativa da transição $(C 5,4, C 5) \ldots \ldots \ldots \ldots \ldots$ 
7.30 Estratégia predominante na geração 7000 da simulação 2 da bateria 1 do modelo $\mathbf{J E}+\mathbf{A A}$ após a execução da função adaptativa da transição $(C 5,0, C 5) \ldots \ldots \ldots \ldots 75$

7.31 Mapas de jogadas e da localização das mutações para a simulação 1 da bateria 1 de 8000 gerações do modelo $\mathbf{J E}+\mathbf{A A} \ldots \ldots$. . . . 76

7.32 Utilidade total dos agentes para a simulação 1 da bateria 2 de 5000

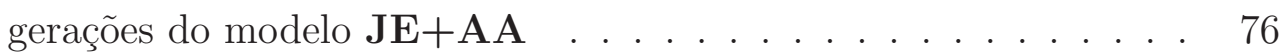

7.33 Utilidade total dos agentes para a simulação 2 da bateria 2 de 5000

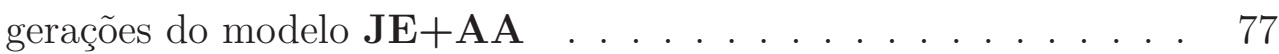

7.34 Jogadas feitas pelos agentes para a simulação 1 da bateria 2 de 5000 gerações do modelo JE+AA . . . . . . . . . . . . . 77

7.35 Jogadas feitas pelos agentes para a simulação 2 da bateria 2 de 5000 gerações do modelo JE+AA . . . . . . . . . . . . . 77

7.36 Mapas de jogadas e da localização das mutações para a simulação 1 da bateria 2 de 5000 gerações do modelo $\mathbf{J E}+\mathbf{A A} \ldots \ldots$. . . . 78 


\section{Lista de Tabelas}

2.1 Exemplos de DPNP com 5 participantes . . . . . . . . . 13

7.1 Tempos de execução das simulações . . . . . . . . . . . . . . . 55

7.2 Sumário dos resultados das simulações do modelo JE+AF - Valores após o equilíbrio . . . . . . . . . . . . . . . 66

7.3 Sumário dos resultados das simulações do modelo JE+AA - Valores após o equilíbrio . . . . . . . . . . . . . . . 79 


\section{Lista de Abreviaturas}

AA Autômato(s) Adaptativo(s)

AF Autômato(s) Finito(s)

C Jogada que representa cooperar

CCD Estratégia implementada por AA que impõe um custo crescente para a não-cooperação quando se está cooperando

CDIND Classe de estratégias que consistem em iniciar jogando $\mathbf{C}$, passando entretanto a jogar $\mathbf{D}$ indefinidamente caso um certo número de outros agentes não cooperarem

CRCDE Classe de estratégias, implementadas por Autômatos Adaptativos, que permitem que o agente volte a jogar $\mathbf{C}$ quando se está jogando $\mathbf{D}$, caso sejam observadas algumas seqüências específicas de jogadas por parte dos outros agentes

D Jogada que representa não cooperar

DP Dilema do Prisioneiro

DPNP Dilema do Prisioneiro para $n$ Participantes

JE+AA Modelo evolutivo desenvolvido onde os agentes implementam suas estratégias através da versão reduzida de Autômatos Adaptativos

JE+AF Modelo evolutivo desenvolvido onde os agentes implementam suas estratégias através de Autômatos Finitos

TT5 Estratégia que consiste em uma adaptação da tit-for-tat para o DPNP

$\mathbf{U}$ Estratégia que consiste em jogar $\mathbf{D}$ indefinidamente 


\section{Introdução}

\subsection{Motivação}

Imaginemos a seguinte situação (GLANCE; HUBERMAN, 1994): um grupo de amigos decide ir a um restaurante, mas antes de chegarem combinam que a conta será igualmente dividida entre eles. O menu do restaurante tem apenas duas opções de prato: um simples e barato e outro sofisticado e caro. Todos preferem comer o prato sofisticado, mas o seu preço é muito alto, de forma que se tivessem que pagar o preço deste prato, não o pediriam. Entretanto, se muitos pedirem o prato barato, quem pedir o prato caro vai saborear o melhor prato, pagando apenas um pouco além do barato. Se você fosse um dos amigos, qual seria a melhor estratégia a seguir?

Individualmente, há um estímulo para a escolha do prato mais caro, pois a satisfação de degustar o prato caro é alta, e se um número suficiente dos outros participantes escolher o prato barato, o custo será suficientemente baixo, de forma a tornar a escolha vantajosa. Ainda, quem optasse pelo prato barato provavelmente pagaria um preço maior do que o custo do mesmo, visto que outros participantes poderiam optar pelo prato caro. Dado que o participante não tem como saber qual será a opção dos outros, a opção pelo prato caro é chamada, portanto, de escolha racional. Se todos pensarem dessa maneira, entretanto, todos optarão pelo prato caro, levando-os a uma situação indesejável.

Vamos agora supor que esse encontro no restaurante ocorra toda semana, sempre com os mesmos participantes. Nesse caso, a dinâmica torna-se essencialmente diferente. Não é de interesse de nenhum dos participantes que o resultado seja sempre aquele em que todos optam pelo prato caro, e como o evento ocorrerá indefinidamente, abre-se a possibilidade de serem estabelecidos acordos implícitos de cooperação. Isso ocorre porque, em cada encontro, cada participante sabe quais foram as suas decisões e a dos outros participantes nos encontros anteriores, podendo basear sua decisão no histórico de decisões anteriores. Em outras palavras, abre-se a possibilidade de, por exemplo, ocorrer uma retaliação sobre o grupo 
quando não ocorre a cooperação, incentivando-se a escolha do prato mais barato, ou outros mecanismos de estabelecimento de cooperação entre os participantes.

Os dois problemas expostos, chamados de Unscrupulous Dinner's Dilemma (em sua versão simples e iterada, respectivamente), são exemplos de um jogo mais conhecido como Dilema do Prisioneiro para $n$ Participantes (DPNP) - uma versão generalizada do Dilema do Prisioneiro (DP) para dois ou mais participantes. O DP é um dos casos mais estudados na teoria dos jogos, pois representa de forma simples e direta uma situação em que dois agentes podem cooperar ou não. Ambos preferem o resultado da cooperação ao da não-cooperação, porém a perda em que um agente incorre ao cooperar quando o outro participante não coopera é alta o suficiente para levá-lo à escolha mais conservadora, que é a de não cooperar. Como diversas situações sociais, econômicas, políticas e biológicas podem ser reduzidas a uma instância do DP (AXELROD, 1984), a melhor compreensão dos mecanismos dinâmicos que podem levar ou não à cooperação nesses casos pode ajudar na formulação de políticas, instituições, mecanismos e intervenções mais eficazes.

Diversos trabalhos estudaram a dinâmica da formação de cooperação em jogos do tipo DPNP (BOYD; RICHERSON, 1988; MATSUSHIMA; IKEGAMI, 1998; ERIKSSON; LINDGREN, 2005; HAUERT; SCHUSTER, 1997; LINDGREN; JOHANSSON, 2003), muitos deles através de simulação computacional. Em geral, parte-se de uma população de agentes que jogam o jogo sendo estudado, onde cada um segue uma estratégia que define qual será sua jogada em cada rodada. As estratégias podem ter qualquer nível de complexidade - desde "sempre cooperar" a outras baseadas no histórico de jogadas. Em ambientes evolutivos, estratégias com melhor desempenho substituem as outras, gerando assim uma dinâmica populacional das diferentes estratégias. Através de experimentos que variam as condições iniciais (como distribuição de estratégias e matrizes de ganho) ou outras características dinâmicas ou evolutivas do sistema (como formas de geração de novas estratégias ou critérios de vizinhança), observa-se o histórico populacional de estratégias, as características das estratégias predominantes, a medição do bem-estar da população, entre outras variáveis. Através da relação observada entre as variações feitas e os resultados das simulações, obtém-se subsídio para formular hipóteses ou efetuar análises mais específicas.

Desde o experimento de competição de estratégias para o Dilema do Prisioneiro Iterado feito por Axelrod (AXELROD, 1984), diversos trabalhos têm sido feitos partindo do mesmo princípio - agentes com estratégias heterogêneas jogando entre si em um ambiente evolutivo - para analisar diferentes configurações 
de jogos, tipos de estratégias e outras variáveis.

Delahaye e Mathieu (DELAHAYE; MATHIEU, 1994) realizaram uma competição análoga à de Axelrod em uma versão modificada do Dilema do Prisioneiro, onde os agentes poderiam recusar-se a jogar com o oponente, e verificou-se que estratégias com alto grau de complexidade apresentaram bons resultados a longo prazo. Killingback et al (IFTI; KILLINGBACK; DOEBELI, 2004) utilizaram uma versão contínua do dilema onde agentes distribuídos espacialmente efetuavam apenas interações locais, e verificaram que essa restrição pode levar à formação de "clusters" cooperativos, aumentando a proporção de agentes cooperando.

Outros trabalhos não partem de um leque pré-estabelecido de estratégias, mas estudam o surgimento e evolução das mesmas através de mecanismos genéticos e evolutivos. Lindgren \& Nordahl (LINDGREN; NORDAHL, 1994) utilizam algoritmos genéticos e estratégias com memória variável em um modelo espacial onde os agentes jogam o Dilema do Prisioneiro dois a dois. Eriksson \& Lindgren (ERIKSSON; LINDGREN, 2005) utilizam autômatos finitos para representar a estratégia de agentes onde as matrizes de ganho podem ser alteradas aleatoriamente. Em ambos, mutações ocorridas ao longo da simulação possibilitam o surgimento de novas estratégias. O presente trabalho utiliza esta abordagem.

\subsection{Objetivos}

Este trabalho tem o objetivo de apresentar uma contribuição ao estudo da formação da cooperação em jogos do tipo DPNP, através do desenvolvimento de um modelo de simulação evolucionário e espacial. Pretende-se com ele comparar a dinâmica observada em uma reprodução do modelo desenvolvido por Lindgren e Johansson (LINDGREN; JOHANSSON, 2003), que utiliza autômatos finitos (AF) para representar estratégias, à de um novo, onde as estratégias dos agentes podem ser representadas pelos chamados autômatos adaptativos (AA) (NETO, 2001). Assim, a idéia é verificar o impacto da utilização de um modelo de representação de estratégias mais robusto na dinâmica da formação da cooperação entre agentes jogando o DPNP. A diferença fundamental entre os AF e os AA é que estes últimos têm a capacidade de gerar comportamentos mais complexos que os proporcionados pelos primeiros (MENEZES; NETO, 2002).

Em síntese, o trabalho buscou responder, entre outras, as seguintes questões:

1. É possível haver uma cooperação no longo-prazo entre diversos agentes, 
onde há um estímulo individual para a não-cooperação? Como se dá, dinamicamente, esse processo?

2. Quais são as condições ambientais e institucionais que catalisam esse processo?

3. Qual o papel da limitação espacial das interações entre os agentes (em outras palavras, o fato de um agente interagir apenas com seus vizinhos) nesse processo?

4. Qual o papel da racionalidade nesse processo? Agentes com processos de decisão mais complexos conseguem melhores resultados individuais e/ou coletivos que aqueles com regras de comportamento mais limitadas?

\subsection{Resultados esperados}

Com a introdução de um modelo de maior poder computacional para representar as estratégias dos agentes, espera-se verificar que comportamentos mais complexos possam surgir neste e que levem os agentes a obter um nível de utilidade maior e/ou mais estável do que aquele obtido por agentes cujas estratégias são mais simples.

A depender dos resultados observados, pode-se inferir melhor o processo evolutivo de formação (ou não) de cooperação entre indivíduos com maior capacidade cognitiva, assim como as principais características das estratégias que propiciam esses resultados.

\subsection{Método}

Em (AXELROD, 1997), o autor sugere que a simulação computacional pode ser utilizada como ferramenta de exploração de fenômenos:

"As a scientific methodology, simulation's value lies principally in prediction, proof, and discovery. Using simulation for prediction can help validate or improve the model upon which the simulation is based. Prediction is the use which most people think of when they consider simulation as a scientific technique. But the use of simulation for the discovery of new relationships and principles is at least as important as proof or prediction. In the social sciences, in particular, 
even highly complicated simulation models can rarely prove completely accurate. Physicists have accurate simulations of the motion of electrons and planets, but social scientists are not as successful in accurately simulating the movement of workers or armies. Nevertheless, social scientists have been quite successful in using simulation to discover important relationships and principles from very simple models.(...)"

Este trabalho utilizou a técnica de simulação computacional com o objetivo proposto pelo autor: como forma de descobrir novas relações e princípios de interação entre os agentes, tentando responder às questões apresentadas no fim da seção 1.2. Para isso, primeiramente foi feito um levantamento bibliográfico de trabalhos que tratam dos temas relacionados: teoria dos jogos, jogos evolutivos, dilema do prisioneiro, simulação computacional, sistemas complexos e autômatos adaptativos. Ao analisar esses trabalhos, encontrou-se um em particular com as características desejadas (simulação de jogos evolutivos com distribuição espacial) e que foi, portanto, escolhido para servir de base para este: Coevolution of strategies in n-person Prisoner's Dilemma(LINDGREN; JOHANSSON, 2003).

Como (LINDGREN; JOHANSSON, 2003) e a maioria dos trabalhos analisados não fornecem nem indicam as ferramentas utilizadas para executar as simulações, e devido a problemas de flexibilidade ou documentação de sistemas disponíveis (LUKE et al., 2005; TISUE; WILENSKY, 2004), optou-se por desenvolver um sistema, denominado $\boldsymbol{S}_{\mathbf{2}} \boldsymbol{E}_{\mathbf{2}}$, que executasse as simulações desejadas e fornecesse os dados necessários para as análises a serem feitas.

De posse desse sistema, foram efetuadas diversas simulações, utilizando tanto uma reprodução do modelo de (LINDGREN; JOHANSSON, 2003) quanto o proposto neste trabalho. O primeiro modelo é denominado no restante deste trabalho como $\mathbf{J E}+\mathbf{A F}$, enquanto o segundo é chamado de $\mathbf{J E}+\mathbf{A A}$. Como resultado dessas simulações, obtiveram-se, entre outros, os seguintes dados:

- Distribuição das estratégias ao longo das gerações, mostrando quantos agentes utilizam cada estratégia ao longo do tempo;

- Utilidade obtida pelos agentes em cada geração;

- Seqüência de jogadas feitas pelos agentes em cada geração;

- Estratégias geradas ao longo da simulação, assim como a quantidade de agentes que as utilizam; 
- Visualização espacial das jogadas cooperativas e não-cooperativas dos agentes, assim como os locais onde ocorrem mutações ao longo do tempo.

Devido à presença de fatores estocásticos no modelo, cada simulação foi feita mais de uma vez, de forma a verificar a robustez dos resultados observados. De forma a obter dados para as análises a serem feitas, foram ainda realizadas simulações com diferentes condições iniciais.

Após as simulações, os dados por elas gerados foram analisados. Para tanto, dados históricos numéricos, como utilidade global por rodada e proporção de estratégias, foram traçados em gráficos com o auxílio de ferramentas matemáticas. Além disto, foram também gerados mapas com a distribuição de jogadas, cooperativas ou não, ao longo do tempo.

Como esses dados são obtidos para diferentes configurações iniciais e tipos de representação de estratégias, obtiveram-se os dados necessários à análise das diferenças quantitativas e qualitativas observadas entre os dois modelos analisados neste trabalho. Os objetos destas análises incluíram:

- Comparação estatística das utilidades obtidas pelos agentes ao longo do tempo em simulações de cada modelo, assim como a velocidade com que esses valores se estabilizam;

- Comparação da estabilidade da população de estratégias, indicando o quanto oscilam ao longo do tempo;

- Análise das estratégias predominantes em ambos os casos, verificando características comuns, peculiaridades e as eventuais mudanças em suas características através do tempo.

\subsection{Descrição do documento}

Além deste capítulo de introdução, este documento está dividido em mais sete capítulos e dois apêndices. No capítulo 2 faz-se uma breve introdução à teoria dos jogos, ao problema do DPNP e aos jogos evolutivos. No capítulo 3 são apresentados a definição, o funcionamento e as características computacionais de autômatos finitos e autômatos adaptativos. O modelo que serve de base para este trabalho, desenvolvido em (LINDGREN; JOHANSSON, 2003), assim como seus resultados são detalhados no capítulo 4. A extensão proposta para esse modelo é apresentada no capítulo 5, onde também é detalhado o modelo simplificado de 
autômatos adaptativos desenvolvido neste trabalho. O capítulo 6 detalha e justifica a estrutura do sistema $\boldsymbol{S}_{\mathbf{2}} \boldsymbol{E}_{\mathbf{2}}$ desenvolvido para a realização das simulações. O capítulo 7 descreve os experimentos realizados, apresentando os seus resultados e uma análise dos mesmos. As conclusões e trabalhos futuros são apresentados no capítulo 8.

No apêndice A apresentam-se as estratégias predominantes obtidas na primeira e segunda baterias de testes do modelo $\mathbf{J E}+\mathbf{A A}$. Uma descrição mais aprofundada da análise estatística realizada da correlação das séries obtidas nas simulações dos modelos $\mathbf{J E}+\mathbf{A F}$ e $\mathbf{J E}+\mathbf{A A}$ é mostrada no apêndice B. 


\section{Teoria dos jogos}

\subsection{Introdução}

A teoria dos jogos estuda situações de interação entre dois ou mais agentes, onde o resultado obtido por cada um depende não apenas de sua decisão, mas também da dos outros agentes. Muitas situações sociais e econômicas são caracterizadas por esse tipo de interação, portanto o seu estudo muitas vezes tem como resultado sugestões de novas políticas organizacionais (GLANCE; HUBERMAN, 1994) e uma melhor compreensão de fenômenos sociais e econômicos.

Duas das áreas do conhecimento que mais utilizam a teoria dos jogos são a economia e as ciências políticas. Devido ao fato de ambas tratarem de interações entre pessoas e organizações, a teoria dos jogos oferece métodos precisos e matemáticos que auxiliam na análise de diversas situações presentes nessas áreas.

Em ciências políticas, a análise da representação de situações de conflito entre nações é utilizada como forma de melhorar sua compreensão, podendo também revelar ações que não se mostram evidentes a partir de uma análise estratégica comum (SNIDAL, 1985). As dificuldades apresentadas na formação da cooperação em negociações multilaterais, por exemplo, são evidenciadas na análise do Dilema do Prisioneiro para N participantes.

Em economia, o desenvolvimento da teoria dos jogos possibilitou o surgimento, entre outros, de modelos analíticos sobre o comportamento de empresas pertencentes a um oligopólio, assim como o funcionamento de leilões (MASCOLELL; WHINSTON; GREEN, 1995).

\subsection{Dilema do prisioneiro}

Um exemplo clássico de jogo é o chamado Dilema do Prisioneiro (AXELROD, 1984). A situação proposta por esse jogo é a seguinte:

Dois indivíduos A e B, suspeitos de um crime, são presos pela polícia. Os 
policiais os interrogam, individualmente, cada um em uma sala separada. Com isso, um suspeito não tem como saber o que o outro disse nem pode comunicar-se com ele. Cada suspeito tem duas opções: permanecer em silêncio ou testemunhar contra o outro. Caso um suspeito testemunhe contra o outro, e este permanecer em silêncio, o que permaneceu em silêncio pega 10 anos de prisão, enquanto o que testemunhou é libertado. Caso ambos permaneçam em silêncio, ficam os dois presos por apenas 6 meses. Por fim, caso ambos testemunhem um contra o outro, ambos pegam 2 anos de prisão. Os dois são informados dessas possibilidades e suas conseqüências.

Individualmente, cada suspeito tem apenas uma decisão: permanecer em silêncio ou testemunhar contra o outro. No entanto, existem quatro possibilidades de resultado, pois o mesmo depende da união das duas decisões.

\subsubsection{Matriz de ganho}

A forma mais utilizada para a representação dos retornos de um jogo com dois participantes é uma matriz de ganho. Um exemplo desta matriz é mostrado na figura 2.1, que representa o cenário do dilema do prisioneiro.

\begin{tabular}{c|c|c|}
\multirow{2}{*}{ Defeat } & \multicolumn{1}{c}{ Defeat } & \multicolumn{1}{c}{ Cooperate } \\
\cline { 2 - 3 } Cooperate & $-2,-2$ & $0,-10$ \\
\cline { 2 - 3 } & $-10,0$ & $-1 / 2,-1 / 2$ \\
\cline { 2 - 3 } & &
\end{tabular}

Figura 2.1: Matriz de ganho DP

As linhas representam as decisões de um jogador e as colunas a do outro jogador. No exemplo, as linhas mostram as duas opções do jogador A: defeat (testemunhar) ou cooperate (silenciar). Da mesma forma, nas colunas observamse as jogadas possíveis do jogador $\mathbf{B}$, que neste caso são as mesmas. As quatro células do interior da matriz mostram os resultados para cada jogador em cada possível combinação de decisões, com o resultado do jogador da linha antes do da coluna. Por exemplo, caso o jogador A permaneça em silêncio e o $\mathbf{B}$ testemunhar, o resultado do jogo será $(-10,0)$, portanto, o jogador A pega 10 anos de prisão e B nenhum.

A partir deste ponto do trabalho, a jogada silenciar será chamada de cooperativa (C), e testemunhar de não-cooperativa (D). Isso será feito pois o Dilema do Prisioneiro representa diversas situações em que dois agentes podem optar por cooperar ou não (AXELROD, 1984), com retornos análogos aos da matriz em questão. 
Existem diversos fatores que podem influenciar as decisões dos jogadores, além da matriz de ganho, dentre os quais pode-se destacar o número de iterações.

\subsubsection{Versão iterada}

O número de iterações em um jogo é um fator fundamental de decisão para um agente. No caso do dilema do prisioneiro, por exemplo, caso ocorra mais de uma iteração do jogo, existe a possibilidade de retaliação. Assim, caso um agente A opte por cooperar e $\mathbf{B}$ não o faça, na jogada seguinte o jogador $\mathbf{A}$ pode não mais cooperar, em retaliação.

No caso de apenas uma iteração, portanto, os jogadores devem optar pela jogada com maior valor de retorno esperado. Para entender o que ocorre, tomase o ponto de vista de cada jogador para verificar qual seria a jogada racional para cada um.

O jogador A tem duas opções: cooperate ou defeat. Como A não tem como saber o que B irá escolher, pois não jogou com ele anteriormente nem tem como comunicar-se, sua escolha deve ser a melhor independentemente da jogada de $\mathbf{B}$. Nesse caso, temos:

- Caso A opte por defeat, seu retorno poderá ser -2 ou 0;

- Caso A opte por cooperate, seu retorno poderá ser -10 ou $-1 / 2$.

Como A não tem nenhum motivo para supor que B irá cooperar, sua opção racional seria, portanto, não cooperar. Como B pensa da mesma forma, o resultado do jogo será $(-2,-2)$. Essa situação é chamada de "equilíbrio sub-ótimo", pois as características do jogo levam a essa situação, embora exista uma outra possibilidade, que seria melhor para os dois: ambos cooperarem, chegando ao resultado $(-1 / 2,-1 / 2)$.

O que leva o sistema a essa situação é o risco envolvido na cooperação. Como o agente não tem nenhuma informação sobre o outro jogador, não tem por que acreditar que ele irá cooperar. Com isso, o risco de cooperar é grande o suficiente para que tal ação não ocorra.

Entretanto, caso o jogo seja repetido diversas vezes, as características do jogo são diferentes, e dependem do conhecimento dos participantes do número de vezes em que irão interagir (PRADO, 1999). 
Se os jogadores forem jogar o DP um número finito $n_{r}$ de vezes, e este valor for conhecido pelos jogadores, estes podem utilizar a técnica de indução reversa para definir quais jogadas farão. A indução reversa é iniciada na última rodada. Como não haverá outra rodada posterior, ela pode ser vista como um jogo simples de uma só rodada. Como visto, o resultado será que ambos jogarão defeat. A partir de então, os agentes examinam as rodadas $n_{r}-1, n_{r}-2 \ldots 1$, chegando ao mesmo resultado para todas elas, pois em cada uma delas o futuro é conhecido, só importando o presente. Assim, para a situação em que o jogo será repetido um número de vezes conhecido pelos jogadores, estes optam por jogar defeat em todas as rodadas.

Por outro lado, se o jogo for repetido infinitas vezes, ou ainda se o número de rodadas for finito porém desconhecido pelos jogadores, não é possível utilizarse a indução reversa e, com isso, inúmeras soluções tornam-se possíveis. Isso decorre do fato de que os jogadores podem utilizar suas jogadas no presente como forma de alterar aquelas feitas pelo outro participante no futuro, utilizando, por exemplo, mecanismos de punição à não-cooperação. Assim, as jogadas que um jogador efetua e suas respostas àquelas feitas pelo outro participante são representadas através de uma estratégia. Um exemplo clássico de estratégia em jogos de cooperação é a tit-for-tat, que consiste em, na primeira jogada, cooperar. A partir de então, repetir a jogada anterior do outro participante.

Embora simples, essa estratégia possui diversas características importantes na criação e manutenção da cooperação entre os agentes:

1. Inicia cooperando: trata-se de uma característica importante, pois tenta criar, desde o início, um ambiente cooperativo, evitando iniciar um ciclo vicioso de não-cooperação;

2. Retalia a não-cooperação: caso o outro agente não tenha cooperado na última jogada, não coopera na próxima. Isso evita que agentes não-cooperativos prosperem à custa dos cooperativos;

3. Retorna à cooperação: caso o outro agente volte a cooperar, o agente com a estratégia tit-for-tat volta a cooperar, permitindo o retorno à cooperação mútua.

Embora seja uma estratégia extremamente simples, a tit-for-tat obteve os melhores resultados (soma da utilidade obtida) em diversas competições computacionais promovidas para avaliar estratégias com diferentes graus de complexidade 
(AXELROD, 1984), caso os jogadores não saibam de antemão quantas vezes irão interagir.

Em suma, jogos simples e jogos iterados possuem diferentes resultados, técnicas de análise e estratégias.

\subsection{Dilema do prisioneiro para $\mathbf{n}$ participantes}

O DPNP é uma generalização do Dilema do Prisioneiro para mais de dois participantes. Consideremos então um jogo com $n$ participantes, onde em cada rodada um jogador pode optar entre jogar $\mathbf{C}$ ou $\mathbf{D}$.

No fim da rodada, a utilidade obtida pelo jogador que optou por $\mathbf{C}$ é dada por $V\left(C \mid n_{C}\right)$, onde $n_{C}$ é o número de agentes que cooperaram. Ainda, a utilidade obtida pelo agente que não coopera $(\mathbf{D})$ é $V\left(D \mid n_{C}\right)$, dependendo também, portanto de quantos jogadores cooperaram. A função $V$ deve ter as seguintes características (LINDGREN; JOHANSSON, 2003):

$$
\begin{gathered}
V\left(D \mid n_{C}\right)>V\left(D \mid n_{C}-1\right) \\
V\left(C \mid n_{C}\right)>V\left(C \mid n_{C}-1\right) \\
V\left(D \mid n_{C}\right)>V\left(C \mid n_{C}\right)
\end{gathered}
$$

$\left(n_{C}+1\right) V\left(C \mid n_{C}+1\right)+\left(n-n_{C}-1\right) V\left(D \mid n_{C}+1\right)>n_{C} V\left(C \mid n_{C}\right)+\left(n-n_{C}\right) V\left(D \mid n_{C}\right)$

As inequações 2.1 e 2.2 refletem o fato de que, independentemente da jogada feita pelo agente, sua utilidade será maior quanto maior for o número de agentes que cooperarem. A inequação 2.3 diz que, para um mesmo número de cooperadores, jogar $\mathbf{D}$ produz individualmente um resultado maior que $\mathbf{C}$. Por fim, a inequação 2.4 exige que, em um grupo com $n$ participantes, caso um jogador passe de $\mathbf{D}$ para $\mathbf{C}$ e portanto passe a cooperar, a utilidade total do grupo aumenta.

Em (LINDGREN; JOHANSSON, 2003) são adotadas as seguintes equações para 


\begin{tabular}{|c||c|c||c|c||c|c||c|c|}
\hline \hline \multicolumn{1}{|c||}{} & \multicolumn{2}{c||}{ Rodada 1 } & \multicolumn{2}{c||}{ Rodada 2 } & \multicolumn{2}{c||}{ Rodada 3 } & \multicolumn{2}{c|}{ Rodada 4 } \\
\hline & Jogada & Utilidade & Jogada & Utilidade & Jogada & Utilidade & Jogada & Utilidade \\
\hline Jogador 1 & $\mathrm{C}$ & 1.25 & $\mathrm{D}$ & 1.5 & $\mathrm{C}$ & 0.75 & $\mathrm{D}$ & -0.5 \\
\hline Jogador 2 & $\mathrm{C}$ & 1.25 & $\mathrm{C}$ & 1 & $\mathrm{D}$ & 1 & $\mathrm{D}$ & -0.5 \\
\hline Jogador 3 & $\mathrm{C}$ & 1.25 & $\mathrm{C}$ & 1 & $\mathrm{C}$ & 0.75 & $\mathrm{D}$ & -0.5 \\
\hline Jogador 4 & $\mathrm{C}$ & 1.25 & $\mathrm{C}$ & 1 & $\mathrm{D}$ & 1 & $\mathrm{D}$ & -0.5 \\
\hline Jogador 5 & $\mathrm{C}$ & 1.25 & $\mathrm{C}$ & 1 & $\mathrm{C}$ & 0.75 & $\mathrm{D}$ & -0.5 \\
\hline \hline Total $^{a}$ & & 6.25 & \multicolumn{1}{|c|}{} & 5.5 & & 4.25 & & -2.5 \\
\hline \hline
\end{tabular}

${ }^{a}$ Soma da utilidade dos participantes

Tabela 2.1: Exemplos de DPNP com 5 participantes

$V$, que obedecem às restrições da definição do DPNP:

$$
\begin{gathered}
V\left(C \mid n_{C}\right)=\frac{n_{C}}{n-1} \\
V\left(D \mid n_{C}\right)=\frac{T \cdot n_{C}}{n-1}-\frac{P\left(n-n_{C}-1\right)}{n-1}
\end{gathered}
$$

As constantes $T$ e $P$ refletem, respectivamente, a vantagem por não-cooperar (temptation score) e a punição pela não-cooperação mútua (punishment). Assumese, portanto, $1<T<2$ e $0<P<1$.

A tabela 2.1 mostra as jogadas e os resultados obtidos por cada participante, para os valores $T=1.5$ e $P=0.5$. Nela podemos ver, na prática, todas as características do DPNP:

- A maior utilidade total foi obtida na rodada 1 , onde todos os agentes joga$\operatorname{ram} \mathbf{C}$;

- Quanto maior o número de jogadas D, menor a utilidade total;

- Em um ambiente onde a maioria coopera, não cooperar é uma opção extremamente vantajosa, como mostra a utilidade do jogador 1 na rodada 2 ;

- O resultado individual de cada agente quando ninguém coopera é significativamente pior do que se ele e todos os outros cooperassem (comparando as rodadas 1 e 4 ).

Assim como no DP, a estratégia racional para um jogador em uma única rodada do jogo é não cooperar, dado que a incerteza em relação às jogadas dos outros participantes faz com que o custo esperado de uma jogada cooperativa 
seja mais alto que a não-cooperativa, levando o resultado do jogo mais uma vez a um equilíbrio sub-ótimo.

Ao considerarmos a versão iterada do DPNP, entretanto, existe uma diferença essencial em relação ao DP: enquanto no DP é possível para um agente punir a não-cooperação em uma rodada anterior (não cooperando na rodada seguinte, como na estratégia tit-for-tat), no DPNP a punição é estendida a todos os agentes participantes, inclusive aqueles que cooperaram em suas últimas jogadas. Por esse motivo, o DPNP apresenta um desafio distinto daquele do DP (GLANCE; HUBERMAN, 1994): dado não ser possível punir individualmente o agente que não coopera, como a cooperação entre eles pode ser atingida e, principalmente, mantida?

\subsection{Jogos evolutivos}

Ao avaliar-se um jogo não-cooperativo ${ }^{1}$ com apenas um iteração, presume-se normalmente a racionalidade perfeita ${ }^{2}$ dos agentes, que possuem ainda informação completa $^{3}$, inclusive das preferências sobre os resultados por parte dos outros jogadores (WEIBULL, 1995).

Em jogos evolutivos, entretanto, supõe-se que o jogo é jogado repetidamente por participantes sociais ou biológicos, aleatoriamente amostrados de uma população (WEIBULL, 1995). Diferentemente da suposição de racionalidade perfeita, cada agente é "pré-programado" a apresentar um certo comportamento, que pode ou não considerar conhecimento das matrizes de ganho, e considera-se que algum processo de seleção opere ao longo do tempo na distribuição desses comportamentos. Assim, obtém-se um processo dinâmico, em que o comportamento dos agentes se altera ao longo do tempo, podendo ou não chegar a uma situação estável. Procura-se com isso verificar como uma população de agentes evolui suas estratégias na busca da melhora de seus resultados individuais, assim como a evolução dos resultados agregados nesse mesmo cenário. Jogos evolutivos são, portanto, uma espécie de "laboratório virtual" da teoria dos jogos em contextos biológicos e sociais.

Em geral, existem três elementos fundamentais em um jogo evolutivo: um me-

\footnotetext{
${ }^{1}$ Jogos não-cooperativos são aqueles onde as estratégias não são propositadamente correlacionadas nem há pagamentos paralelos (OWEN, 1995).

${ }^{2}$ Agentes racionais são aqueles cujas decisões são consistentes com seus objetivos (MYERSON, 1991). Ainda, a racionalidade perfeita presume a capacidade de se prever com exatidão os ganhos obtidos com qualquer decisão ou seqüência de decisões, assim como a capacidade computacional de avaliá-las por completo.

${ }^{3}$ Conhecem portanto a matriz de ganho completa do jogo.
} 
canismo de mutação, um mecanismo de seleção e um mecanismo de reprodução. O mecanismo de seleção é aquele que define a variável utilizada para avaliar o desempenho de um comportamento. Nos seres vivos, por exemplo, o mecanismo de seleção é a combinação da capacidade reprodutiva com a longevidade. Um indivíduo com maior capacidade reprodutiva e que sobreviver por mais tempo terá um maior número de descendentes. Em uma simulação de jogos evolutivos, escolhe-se uma variável, como por exemplo a soma das utilidades obtidas ao jogar-se com os outros participantes, e define-se que o número de descendentes produzidos numa geração será proporcional a essa utilidade.

O mecanismo de mutação é responsável pelo surgimento de novos comportamentos dos agentes, e ocorre em geral durante a reprodução desse comportamento, isto é, a passagem do comportamento de um agente a outro no fim de uma geração. Define-se uma probabilidade $P_{m}$ de que ocorra uma mutação durante a reprodução, assim como os diferentes tipos de mutação. Geralmente opta-se por pequenas mutações, de forma que as características principais do comportamento sendo reproduzido não se alterem de forma radical na maioria das vezes.

Por fim, o mecanismo de reprodução permite que comportamentos que proporcionam um melhor resultado na variável escolhida para seleção se propaguem pela população na mesma proporção de seu desempenho na obtenção de bons resultados. Com isso, estratégias que surgem através de mutações e apresentam melhores resultados são replicadas em novos agentes, que substituem aqueles cujas estratégias apresentavam resultados inferiores.

\subsection{Considerações finais}

Como já mencionado anteriormente na seção 1.2, neste trabalho são realizadas e analisadas simulações de jogos evolutivos do DPNP.

Ao longo do restante deste trabalho, as seguintes definições são utilizadas:

- Jogo: regras que definem as ações que cada participante pode efetuar, assim como as utilidades obtidas por cada agente em cada situação. Exemplos de jogos: Dilema do Prisioneiro e Dilema do Prisioneiro para $n$ participantes;

- Rodada: uma iteração de um jogo particular, onde os participantes ${ }^{4}$ definem qual é sua ação e recebem suas utilidades;

\footnotetext{
${ }^{4}$ Dois para o DP, $n$ para o DPNP
} 
- Jogada: ação tomada por um agente em uma rodada. Exemplo: cooperar ou não-cooperar;

- Rodada múltipla: seqüência de rodadas sucessivas jogadas pelos mesmos participantes;

- Fase de Reprodução: etapa em que, ao final da rodada múltipla, as estratégias dos agentes com melhores resultados são copiadas para alguns que tiveram resultado inferior. Nessa etapa podem ocorrer mutações;

- Mutação: pequena alteração na estratégia que pode ocorrer durante a fase de reprodução, sendo que a estratégia resultante da mutação é alocada no agente que recebe a nova estratégia;

- Geração: unidade ampla da simulação, onde todos os grupos de agentes que podem jogar entre si efetuam rodadas múltiplas. Após isso, segue-se ainda uma fase de reprodução.

No contexto deste trabalho, são utilizados dois modelos de representação de estratégias para os agentes: AF e AA. Na seqüência, apresentam-se as principais características desses modelos. 


\section{Autômatos finitos e autômatos adaptativos}

\subsection{Autômatos finitos}

Um autômato finito (AF) é uma estrutura que representa um modelo de computação simples. É descrito fundamentalmente por três elementos: um conjunto de estados, um conjunto de transições, e um estado inicial.

Durante seu processamento, entradas são recebidas, que ativam transições, alterando então o estado corrente do autômato ao longo de sua execução. Em geral, existe um conjunto de estados definidos como estados de aceitação, que indicam que a seqüência de entradas recebida até então é tida como válida.

Um exemplo de AF, representado como um grafo, pode ser visto na figura 3.1. No grafo, os vértices (círculos) representam os estados, e as arestas (setas) representam as transições. Os rótulos colocados sobre as arestas representam o símbolo de entrada que dispara a respectiva transição. Para efeito de notação, a representação adotada no restante do texto para uma transição do estado $A$ para o estado $B$ com a entrada $x$ será $(A, x, B)$.

O AF do exemplo possui dois estados: $\mathbf{C 1}$ e $\mathbf{D} 1$, sendo $\mathbf{C 1}$ um estado de aceitação (representado por um círculo duplo). Seu estado inicial, indicado por uma seta sem origem, é C1. O alfabeto de entrada deste autômato é $\Sigma=$ $\{0,1,2,3,4\}$, de forma que qualquer entrada não pertencente a esse conjunto é considerada inválida.

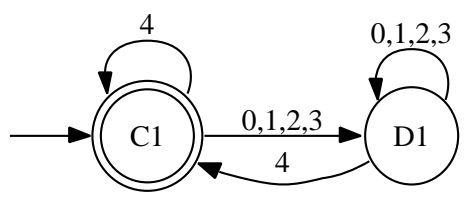

Figura 3.1: Exemplo de AF

Partindo de sua inicialização, onde o estado corrente é definido como o estado 
inicial, o autômato segue as transições correspondentes às entradas que recebe. Por exemplo, se após a sua inicialização ele receber a entrada $\mathbf{0}$, seu estado corrente será alterado para D1, seguindo a transição $(C 1,0, D 1)$. Se a segunda entrada que o autômato receber for 3, o autômato permanecerá no estado D1, pois a transição $(D 1,3, D 1)$ leva a ele mesmo. Se a terceira entrada for $\mathbf{4}$, o estado corrente muda para $\mathbf{C 1}$, e assim por diante.

AFs podem ser determinísticos ou não-determinísticos. Em um AF nãodeterminístico, o estado corrente e a entrada não são necessariamente suficientes para se determinar o próximo estado corrente. Isso ocorre porque pode haver mais de uma transição partindo de um estado com a mesma entrada. Prova-se que AFs determinísticos têm o mesmo poder de expressão de AFs não-determinísticos (LEWIS; PAPADIMITRIOU, 2004). Neste trabalho são utilizados, portanto, AFs determinísticos.

Formalmente, um AF determinístico é uma quíntupla $M=\left(K, \Sigma, \delta, s_{0}, F\right)$, onde (LEWIS; PAPADIMITRIOU, 2004):

- $K$ é o conjunto finito de estados;

- $\Sigma$ é o alfabeto de entrada;

- $s_{0} \in K$ é o estado inicial;

- $F \subseteq K$ é o conjunto de estados de aceitação;

- $\delta$ é a função de transição, $\delta: K \times \Sigma \rightarrow K$.

Ao fornecer como entrada para um autômato uma seqüência $\sigma_{0} \sigma_{1} \ldots \sigma_{n}$, com $\sigma_{k} \in \Sigma$, o estado corrente do autômato é alterado a cada passo, obtendo-se portanto uma seqüência de estados $s_{0} s_{1} \ldots s_{n+1}$, com $s_{k} \in K$ correspondente. Assim, dado um instante $t$, pode-se definir $M(t)=\left(K, \Sigma, \delta, s_{0}, F, s_{t}\right)$, onde $s_{t}$ representa o estado corrente do autômato $M$ no instante $t$.

Finalmente, prova-se também que um dado AF possui infinitos AFs equivalentes, sendo que o termo equivalente significa que os autômatos aceitam as mesmas cadeias de entrada. Assim, AFs que aceitam as mesmas cadeias de entrada formam uma classe de equivalência. Pode-se então denotar uma classe por meio de um AF mínimo que a representa. Isso é feito através de um processo chamado de minimização de autômatos (CHROBAK, 2005). Neste processo, um autômato é reduzido à menor representação de sua classe de equivalência.

A minimização de um AF consiste, basicamente, de duas etapas: 
1. Eliminação dos estados inalcançáveis: estados inalcançáveis são aqueles que nunca chegam a serem o estado corrente, independentemente da seqüência de entradas. Na figura 3.2(a), por exemplo, os estados D2 e C2 são inalcançáveis, pois partindo do estado inicial C1 é impossível chegar a eles. Com isso, o autômato resultante da remoção dos mesmos, mostrado na figura 3.2(b), é equivalente ao da figura 3.2(a).

2. Combinação de estados equivalentes: se existirem dois ou mais estados que se combinados em apenas um o autômato reconheça a mesma linguagem, essa combinação é feita. No autômato da figura 3.3(a), por exemplo, a combinação dos estados C1 e C2 no estado C3 (figura 3.3(b)), resulta no mesmo comportamento. Vale ressaltar que os dois estados devem ser ambos de aceitação ou não.

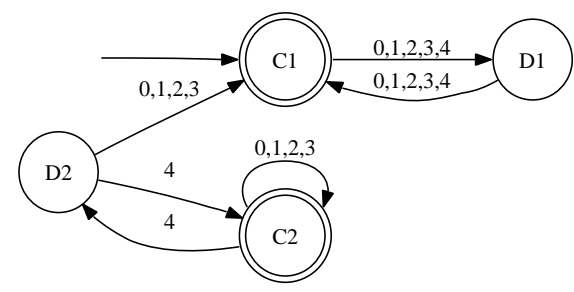

(a) AF com estados inalcançáveis

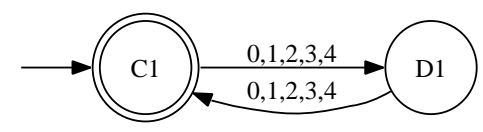

(b) AF após remoção dos estados inalcançáveis

Figura 3.2: Exemplo de remoção de estados inalcançáveis

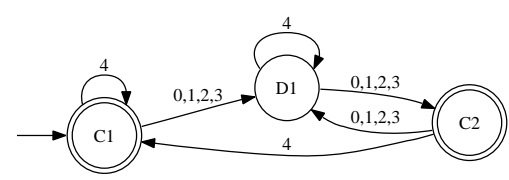

(a) AF com estados equivalentes

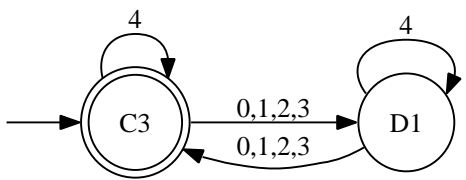

(b) AF após combinação dos estados C1 e C2 em C3

Figura 3.3: Exemplo de combinação de estados equivalentes

\subsection{Autômatos adaptativos}

Autômatos adaptativos (AAs) são um tipo de dispositivo adaptivo baseado em regras (NETO, 2001), que consistem em uma generalização do modelo de AF. Neles estão presentes, além dos elementos pertencentes a um AF já citados, um conjunto de funções adaptativas, e regras que definem quando elas devem ser executadas.

Formalmente, um AA determinístico pode ser definido, no instante $t$, por uma tupla $M A(t)=\left(K_{t}, \Sigma, \delta_{t}, s_{0}, F_{t}, s_{t}, \Pi, \Omega, \Psi_{t}\right)$, onde: 
- $K_{t}$ é o conjunto finito de estados no instante $t$;

- $\Sigma$ é o alfabeto de entrada;

- $\delta_{t}$ é a função de transição no instante $t, \delta: K_{t} \times \Sigma \rightarrow K_{t}$;

- $s_{0} \in K_{0}$ é o estado inicial;

- $F_{t} \subseteq K_{t}$ é o conjunto de estados de aceitação no instante $t$;

- $s_{t}$ é o estado corrente;

- II é um conjunto de ações adaptativas;

- $\Omega$ é o conjunto de funções adaptativas $\omega_{k} \in \Omega$, onde $\omega_{k} \in\left(\pi_{1} \pi_{2} \ldots \pi_{n}\right) \times R T$, onde $\pi_{k} \in \Pi$ e $R T=\{a, b\}$. Assim, uma função adaptativa $\omega_{k}$ é composta por uma seqüência de ações adaptativas $\pi_{1} \pi_{2} \ldots \pi_{n}$ e um valor $r t \in R T$ que define em que momento a função é executada: antes $(r t=b)$ ou após $(r t=a)$ a mudança de estado;

- $\Psi_{t}: \psi_{t, k} \rightarrow \omega_{k}$ é uma função que associa regras $\psi_{t, 1} . . \psi_{t, n_{r}}$ que definem determinadas características de transições nas quais as funções adaptativas serão executadas.

É importante notar que, diferentemente do AF, a cada instante os conjuntos $K, F$, e $\delta$ podem ser diferentes. Assim, a estrutura do autômato pode ser alterada ao longo de sua execução, através da adição ou remoção de estados e transições, assim como a alteração do conjunto de estados de aceitação.

As regras $\psi_{t, k}$ definem as características das transições que resultam na execução da função adaptativa a elas associadas pela função $\Psi_{t}$. Um exemplo simples de regra é aquela que se refere a uma transição específica. Por exemplo, a regra $\psi_{0,1}: \forall\left(K_{t, i}, K_{t, j}\right) \in \delta_{t}$ se refere a qualquer transição que parte do estado $K_{t, i}$ e vai para $K_{t, j}$. Assim, se a função $\Psi_{t}$ associa essa regra a uma função adaptativa $\omega_{k}$, tal função será executada quando o autômato passa do estado $K_{t, i}$ para $K_{t, j}$.

As ações adaptativas podem ser de três tipos elementares (NETO, 2001):

- Ação de busca - AB: ação que não modifica a estrutura do autômato, mas que possibilita a busca no autômato por alguma característica;

- Ação de remoção - AR: ação que remove elementos do autômato que seguem um padrão definido na ação; 
- Ação de inserção - AI: ação que insere elementos ao autômato, como estados e transições.

Dessa forma podemos definir, por exemplo, uma função adaptativa $\omega_{0}$ com a seguinte especificação (os tipos das ações adaptativas são informados ao final de cada ação):

1. Pegue uma referência para o estado atual e guarde em $v_{1}-\mathrm{AB}$;

2. Crie um novo estado $s_{n}$, chamado $D 1$ - AI;

3. Crie uma transição de $v_{1}$ para $s_{n}$ para a entrada 1 - AI;

4. Remova todas as transições de $v_{1}$ para $v_{1}$ - AR;

5. Insira uma transição de entradas $0,2,3,4$ de $v_{1}$ para $v_{1}$ - AI;

6. Insira uma transição de entradas $0,1,2,3,4$ de $s_{n}$ para $s_{n}$ - AI.

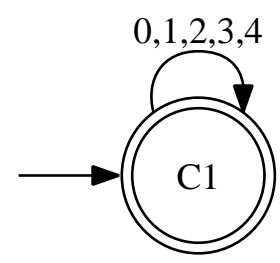

Figura 3.4: Autômato antes da execução da função adaptativa $\omega_{0}$

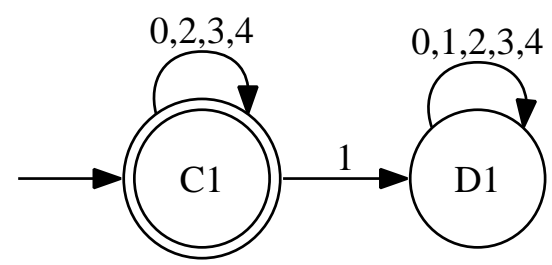

Figura 3.5: Autômato após a execução da função adaptativa $\omega_{0}$

A figura 3.4 mostra um AA no instante $t=0$. Definimos, para este autômato, a seguinte regra $\psi_{0,1}$ :

$$
\psi_{0,1}: \forall\left(K_{0, i}, K_{0, j}\right) \in \delta_{t} \mid K_{0, i}=C 1 \wedge K_{0, j}=C 1
$$

Seja $\Psi_{0}\left(\psi_{0,1}\right)=\omega_{0}$. Dessa forma, se o autômato seguir uma transição que passa do estado C1 para ele mesmo, a função adaptativa $\omega_{0}$ é executada.

Assim, após uma entrada qualquer entre 0 e 4, a função adaptativa $\omega_{0}$ é executada, resultando no autômato da figura 3.5. Vamos supor que a entrada 
tenha sido 1. Qual será o estado corrente ao fim dessa entrada? Isso depende da definição de quando a função deve ser executada.

Caso a função $\omega_{0}$ tenha $r t=a$, observa-se a seguinte seqüência:

1. Como há uma transição $0,1,2,3,4$ de $\mathbf{C} 1$ para $\mathbf{C 1}$, o estado corrente permanece $\mathbf{C} 1$;

2. Após a mudança de estado corrente, aplica-se $\omega_{0}$, resultando no autômato da figura 3.5, e C1 como estado corrente.

Por outro lado, caso $\omega_{0}$ tenha $r t=b$, o resultado será diferente:

1. A entrada 1 indica que a função $\omega_{0}$ será executada. Desta forma, antes de ocorrer a mudança de estado, o autômato passa do da figura 3.4 para o da 3.5 ;

2. Após a execução de $\omega_{0}$, efetua-se a mudança de estado. Como há uma transição de $\mathbf{C} 1$ para D1 com entrada 1, o estado corrente muda para D1.

Este exemplo mostra que o instante de execução da função adaptativa (antes ou depois da mudança de estado) pode refletir em mudanças significativas no comportamento do autômato. Dessa forma, em um AA, é importante saber as conseqüências das duas possibilidades de tempo de execução das funções adaptativas.

Uma característica essencial dos AAs é que eles incluem os AFs, isto é, todo AF é também um AA. Entretanto, a recíproca não é verdadeira: nem todo AA é um AF. Reconsiderando a definição aqui dada para um AA como sendo uma tupla $M A(t)=\left(K_{t}, \Sigma, \delta_{t}, s_{0}, F_{t}, s_{t}, \Pi, \Omega, \Psi_{t}\right)$, se considerarmos $\forall t, \Psi_{t}=\emptyset$ (não há nenhuma transição com função adaptativa associada), teremos que $K_{0}=K_{1}=$ $\cdots=K_{n}$, pois os estados não são alterados, assim como $\delta_{0}=\delta_{1}=\cdots=\delta_{n}$ e $F_{0}=F_{1}=\cdots=F_{n}$. Dessa forma, a estrutura do autômato permanece a mesma ao longo do tempo, e a definição se reduz à do AF. Assim, pode-se dizer que os AFs são um caso particular dos AAs.

\subsection{Considerações finais}

Como já dito anteriormente na seção 1.2, neste trabalho são utilizados AF e AA como modelos de representação de estratégias para jogos evolutivos do DPNP. Algumas considerações particulares desta utilização são as seguintes. 
O conceito de seqüência de entrada válida em um AF ou AA é utilizado quando o autômato se comporta como um reconhecedor de linguagem formal. No escopo deste trabalho, esta idéia não é utilizada, e portanto todos os estados poderiam ser considerados como estados de aceitação. Entretanto, como será necessário minimizar os AFs resultantes, optou-se por representar apenas os estados onde se joga $\mathbf{C}$ como sendo estados de aceitação.

Além disto, ao longo deste trabalho são exibidas diversas representações gráficas de AAs e AFs. Como as mesmas foram geradas automaticamente a partir da representação interna do sistema desenvolvido, em alguns autômatos exibidos daqui em diante serão omitidas algumas transições cujo efeito não acarrete mudança de estado. O autômato da figura 3.6 mostra um exemplo. Nele, é mostrada apenas a transição $(D 2,1, D 2)$ saindo do estado D2. A ausência das transições para as entradas 0,2,3 e 4 significam simplesmente que elas levam ao próprio estado D2.

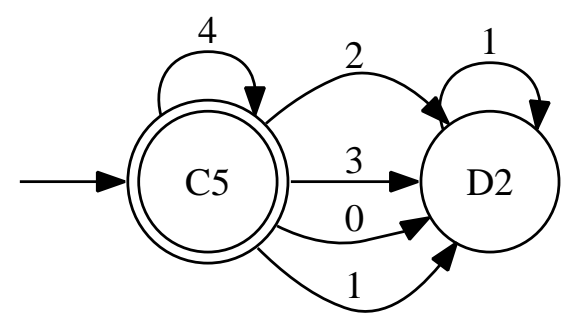

Figura 3.6: Exemplo de representação de autômato sem todas as transições

Embora os AFs sejam um caso especial dos AAs, os dois possuem uma diferença fundamental: suas capacidades de processamento de linguagens. Enquanto os AFs são capazes de reconhecer apenas linguagens regulares, os AAs têm poder de processamento equivalente a uma Máquina de Turing (ROCHA; NETO, 2001). Uma das hipóteses deste trabalho é que a utilização de AAs para representar as estratégias dos jogadores do DPNP pode acarretar em diferentes dinâmicas de evolução em um modelo evolutivo, em relação ao uso de AFs, que foram utilizados no trabalho de Lindgren \& Johansson. Tal trabalho é mostrado a seguir. 


\section{Modelo de Lindgren \& Johansson}

\subsection{Ambiente evolutivo e espacial}

A característica mais importante do ambiente utilizado em (LINDGREN; NORDAHL, 1994) é o fato de tratar-se de um ambiente evolutivo. Isso significa que os agentes que compõem a simulação nascem, se reproduzem e morrem ao longo do tempo. Se adicionarmos a isso o fato de a probabilidade de reprodução ser resultante de alguma característica desejada, como por exemplo o desempenho em alguma tarefa e a possibilidade de ocorrência de mutação nas características do agente em sua reprodução, temos como resultado um sistema que reproduz, em essência, o mecanismo de seleção natural.

Esse ambiente possui ainda distribuição geográfica, limitando as interações entre os agentes por suas vizinhanças. Isso significa que cada agente pode interagir apenas com os outros agentes considerados "vizinhos". Quando o ambiente de simulação não possui essa restrição, em geral um agente pode interagir com todos os agentes disponíveis, o que em geral altera a dinâmica do sistema e também seus resultados de equilíbrio (LINDGREN; NORDAHL, 1994).

O espaço geográfico desse ambiente é representado por um reticulado de tamanho arbitrário, cuja projeção bidimensional pode ser vista na figura 4.1. Nele, cada quadrado é ocupado por um agente. Como critério de vizinhança, utilizou-se a vizinhança de Von Neumann, que considera vizinhas as quatro células imediatamente ligadas aos lados da célula em questão (assim como na figura 4.1). As células nos limites do reticulado possuem vizinhança com as do lado oposto. A figura 4.2 mostra dois exemplos deste caso. Considerando-se essa vizinhança nos limites do reticulado, o espaço de simulação pode ser mais bem entendido como um toro (figura 4.2), que devido à sua superfície contínua, possui vizinhança completa para qualquer célula.

Temos, portanto, que cada agente interage em cada rodada com quatro vizi- 


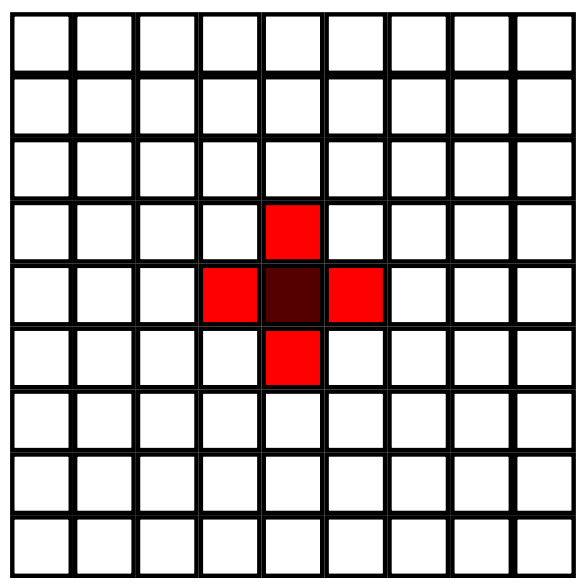

Figura 4.1: Exemplo de reticulado e vizinhança
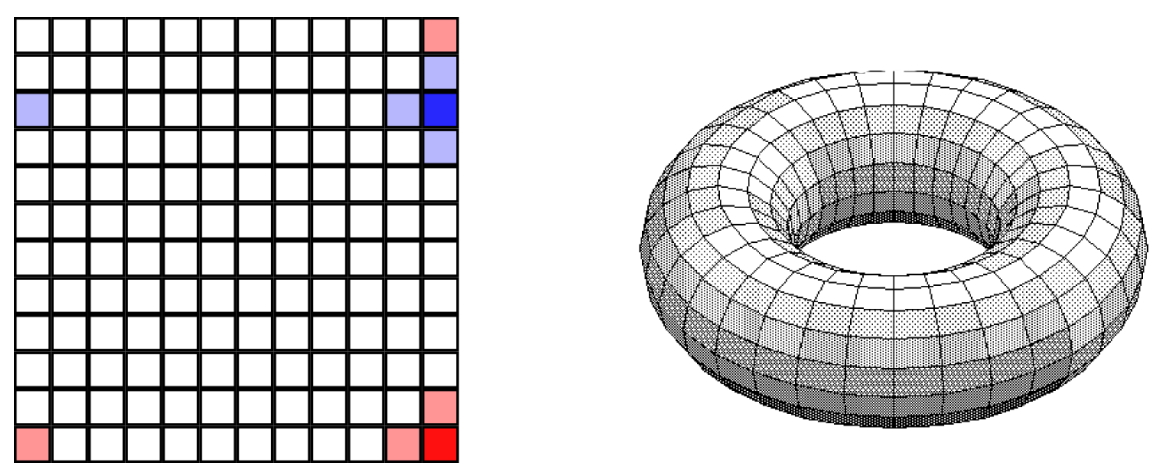

Figura 4.2: Vizinhança no limite e toro

nhos, o que significa que os jogos serão DPNPs com 5 participantes. Se definirmos o reticulado como sendo de tamanho $m \times n$, por exemplo, serão m.n agentes no total. Cada rodada múltipla é composta por $n_{\text {rep }}$ rodadas. Em uma geração, portanto, são executadas m.n.n $n_{\text {rep }}$ rodadas $^{1}$. Como as estratégias não são alteradas dentro de uma mesma geração, a ordem de escolha dos agentes que irão efetuar as jogadas é irrelevante. Em outras palavras, a escolha do próximo agente a interagir com seus vizinhos durante a simulação pode ser seqüencial ou aleatória.

Após todos os agentes terem jogado com seus vizinhos em uma geração, cada um terá participado de $5 n_{\text {rep }}$ rodadas, pois participa tanto das rodadas em que ele está no centro da vizinhança quanto nas em que seus quatro vizinhos estão no centro da vizinhança. Isso significa que, embora possua apenas quatro vizinhos, a cada geração um agente participa de jogos com 12 outros agentes, sempre, porém, em grupos de 5. A figura 4.3 mostra o jogador em questão em cinza escuro, os seus quatro vizinhos com hachuras horizontais, e os oito jogadores com os quais participa indiretamente através dos jogos de seus vizinhos com hachuras verticais.

\footnotetext{
${ }^{1}$ Tanto o tamanho do reticulado quanto o número de rodadas que compõem uma rodada múltipla são valores arbitrários, que podem ser ajustados de forma a obter uma boa relação entre significância dos resultados e viabilidade computacional.
} 


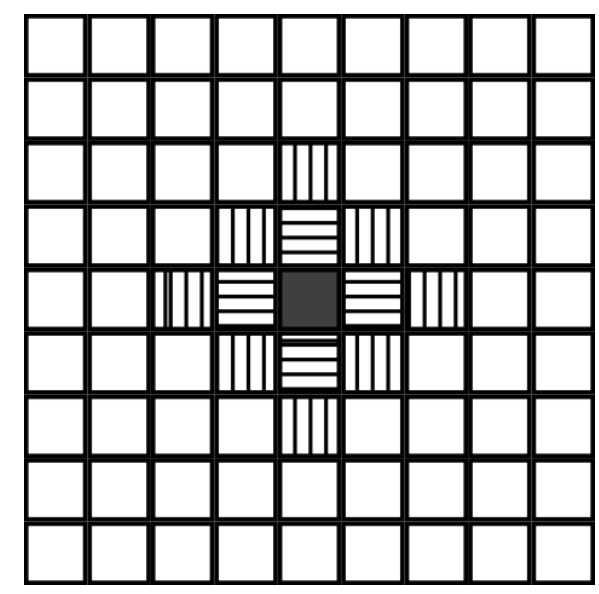

Figura 4.3: Vizinhança extendida

Ao fim de cada geração, cada agente acumulou uma utilidade, resultante da soma de todos os resultados individuais de suas $5 n_{\text {rep }}$ rodadas. Essa utilidade reflete o desempenho que o agente obteve jogando com sua estratégia. Em outras palavras, ela indica a adequação da estratégia em lhe proporcionar bons resultados, e será o critério utilizado para decidir a reprodução de estratégias. Dessa forma, no fim de uma geração será comparada a utilidade obtida por cada agente com a de seus quatro vizinhos. Caso a utilidade do agente analisado tenha sido maior ou igual a todas as obtidas por seus vizinhos, o agente que ocupará a célula na próxima geração terá a mesma estratégia. Caso contrário, essa estratégia é substituída pela estratégia do agente da mesma vizinhança que obteve a maior utilidade. Caso haja mais de um com a mesma utilidade, a escolha é aleatória entre eles. Essa operação deve ser feita em paralelo², para todos os agentes ao fim de cada geração, de forma que uma reprodução ocorrida em uma célula não seja propagada na mesma geração.

Durante a fase de reprodução pode ocorrer uma mutação na estratégia, com probabilidade $P_{m}{ }^{3}$. Se a reprodução ocorresse sem mutação, teríamos que uma célula com um agente $\mathbf{A}$, que possuía a estratégia $E_{a}$ passaria a ser ocupada por um com a estratégia $E_{b}$ de um agente $\mathbf{B}$. Ao fim desse processo, o agente que ocupa a célula de $\mathbf{A}$ passaria a ter a estratégia $E_{b}$ e aquele que ocupa a de $\mathbf{B}$ permaneceria com a estratégia $E_{b}$. Entretanto, caso ocorra uma mutação neste processo, o agente na célula de $\mathbf{B}$ possuirá a estratégia $E_{b}$ mas aquele que ocupar a célula de $\mathbf{A}$ receberá uma estratégia $E_{b}^{\prime} \neq E_{b}$. As mutações são pequenas alterações na estrutura que representa a estratégia, como a adição ou remoção de uma transição ou estado.

\footnotetext{
${ }^{2}$ Não necessariamente em múltiplos processadores, mas de forma que o resultado final seja o mesmo que se assim fosse.

${ }^{3}$ Adota-se a mesma probabilidade $P_{m}$ para todos os agentes.
} 
Em suma, o ambiente que será utilizado tenta recriar o tipo de situação onde se desenvolvem repetidas interações sociais ao longo de diversas gerações: existe restrição geográfica (os agentes podem interagir diretamente apenas com agentes próximos), os agentes são heterogêneos e ocorrem reprodução e mutação.

\subsection{Representação de estratégias}

No modelo de Lindgren \& Johansson, as estratégias de cada agente são representadas por uma estrutura baseada em AFs, como a mostrado na figura 4.4, onde está representada uma estratégia para um jogo com cinco participantes. D significa "não cooperar" (defeat) e C "cooperar" (cooperate). Para que diferentes estados não tenham o mesmo nome, é adicionado ao tipo (C ou D) um número que o diferencie (por exemplo, D1, C1, D2, etc). Os rótulos das transições indicam o número de outros agentes que cooperaram. Assim, vamos supor que um agente A seja portador da estratégia da figura 4.4. Na primeira rodada ele não coopera, pois seu estado inicial é D1 (do tipo D). Dependendo do comportamento dos outros jogadores nessa primeira rodada, o estado de $\mathbf{A}$ pode mudar:

- Se até 3 outros agentes jogarem C, A permanece no mesmo estado (pois as transições de entradas " $0,1,2,3$ ” saindo de D1 levam ao próprio estado D1), e na próxima rodada continuará jogando $\mathbf{D}$;

- Se todos os outros agentes jogarem $\mathbf{C}$, a transição $(D 1,4, C 1)$ será disparada e A passa para o estado $\mathbf{C} 1$, sendo que na próxima rodada passará a jogar C.

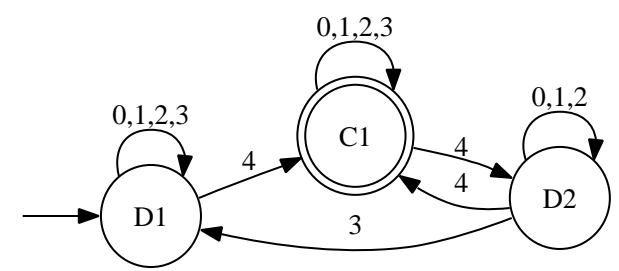

Figura 4.4: Representação de estratégias por Lindgren \& Johansson

No caso do Unscrupulous Dinner's Dilemma com cinco participantes, descrito na seção 1.1, a estratégia de um agente $\mathbf{A}$ da figura 4.4 poderia gerar a seguinte seqüência de eventos:

1. Na primeira noite, A escolhe o prato caro, pois D1 é seu estado inicial; 
2. Nessa noite, os outros quatro colegas escolhem o prato barato e A passa de D1 para C1;

3. Na segunda noite, $\mathbf{A}$ escolhe o prato barato, pois agora seu estado é $\mathbf{C 1}$;

4. Nessa noite, mais uma vez os outros quatro colegas escolheram o prato barato e $\mathbf{A}$ passa de $\mathbf{C} 1$ para $\mathbf{D} 2$;

5. Na terceira noite, $\mathbf{A}$ escolhe o prato caro, pois seu estado é D2;

6. Nessa noite, dois outros colegas escolheram o prato caro e A continua no estado D2;

7. Na quarta noite, A escolhe o prato caro, pois seu estado ainda é D2;

8. Nessa noite, um dos colegas escolheu o prato caro e os outros três o prato barato e A passa de $\mathbf{D} 2$ para $\mathbf{D} \mathbf{1}$;

9. Na quinta noite, $\mathbf{A}$ escolhe o prato caro, pois seu estado é D1.

Essa representação de estratégias permite, portanto, definir a jogada que o agente deve fazer para um número infinito de rodadas.

\subsection{Mutação de estratégias}

Como explicado na seção 4.1, na fase de reprodução pode ocorrer uma mutação. No modelo de Lindgren \& Johansson, as mutações podem ser dos seguintes tipos:

- Alterar o tipo de um estado, por exemplo, do tipo $\mathbf{C}$ para o tipo D;

- Alterar uma transição;

- Alterar o estado inicial;

- Adicionar um novo estado.

A ocorrência de mutações possibilita que novas estratégias surjam ao longo da simulação, e a seleção natural proporcionada pelos mecanismos de reprodução e mutação faz com que estratégias com melhores resultados se reproduzam e se espalhem entre os agentes da simulação. Esse tipo de simulação, portanto, mostra o surgimento de estratégias e sua evolução no tempo, assim como a interação entre elas. 


\subsection{Resultados obtidos}

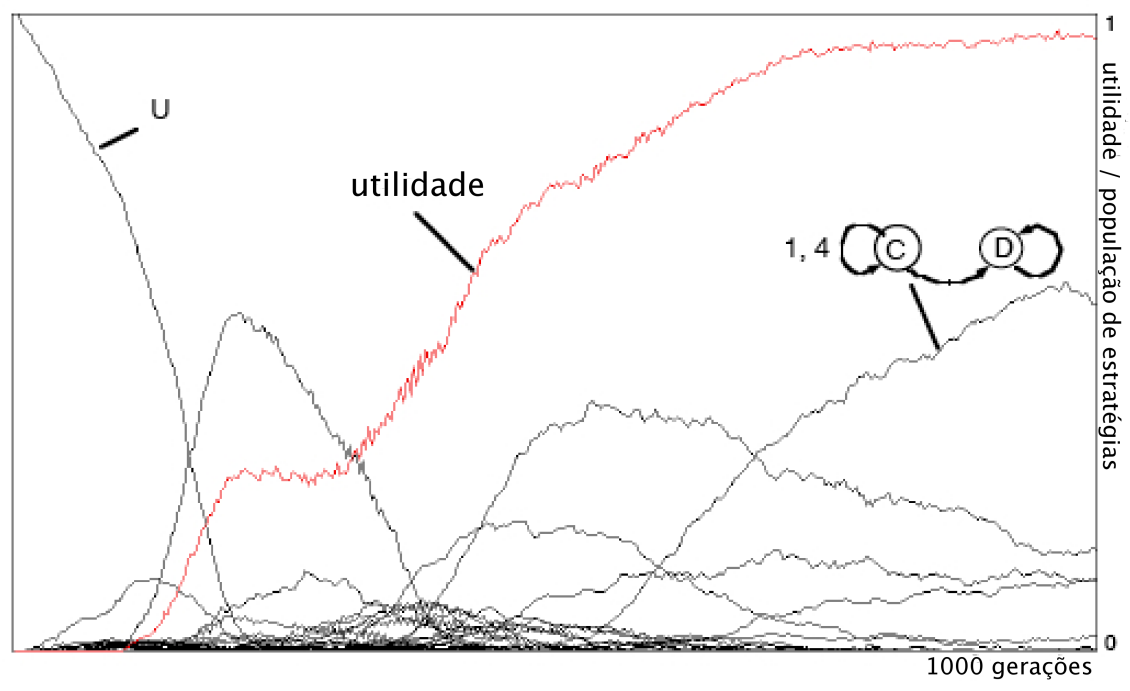

Figura 4.5: Resultado da simulação feita por Lindgren \& Johansson (LINDGREN; JOHANSSON, 2003)

A simulação exibida em (LINDGREN; JOHANSSON, 2003) para o modelo apresentado neste capítulo foi executada com os seguintes parâmetros:

- Reticulado de tamanho 128x128, totalizando 16384 agentes;

- Todos os agentes iniciam com a estratégia mostrada na figura 4.6: sempre jogar D. Assim como em (LINDGREN; JOHANSSON, 2003), esta estratégia será chamada neste trabalho de $\mathbf{U}$;

- Valores dos parâmetros T e $\mathbf{P}$ (na fórmula do DPNP) iguais a 1.5 e 0.25, respectivamente

- Probabilidade de mutação $\left(P_{m}\right)$ igual a 0.002

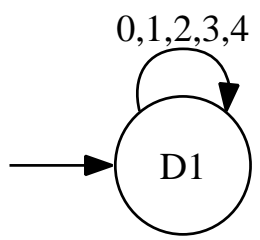

Figura 4.6: Estratégia U

A figura 4.5 mostra os resultados obtidos pelos autores para uma simulação de 1000 gerações do modelo exposto neste capítulo. O gráfico mostra dois dados: a população de cada estratégia (linhas pretas) e a utilidade global dos agentes (linha vermelha), para cada geração da simulação. 
Nele observamos que há um aumento progressivo da utilidade global dos agentes, causada pela diminuição do número de agentes que utilizam a estratégia U, e o surgimento de outras estratégias com comportamento cooperativo.

Ao final das 1000 gerações, observa-se uma estabilidade do valor da utilidade global dos agentes em um patamar significativamente mais alto que o inicial. Nota-se também a predominância, ao término da simulação, de uma estratégia com o seguinte comportamento, representada na figura 4.7:

- Inicia cooperando;

- Enquanto um ou todos os agentes cooperarem, continua cooperando;

- Se nenhum, 2 ou 3 outros agentes cooperarem, passa a não cooperar, assim permanecendo até o fim.

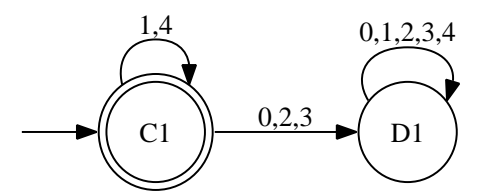

Figura 4.7: Estratégia predominante após 1000 gerações na simulação feita por Lindgren \& Johansson

No próximo capítulo, descreve-se a extensão do modelo de representação de estratégias proposto neste trabalho, que utiliza AAs, assim como outras alterações realizadas. 


\section{Extensão do modelo de Lindgren e Johansson}

\subsection{Introdução}

De forma a analisar as diferenças observadas no modelo desenvolvido por Lindgren \& Johansson quando os agentes possuem um modelo de representação de estratégias com um maior poder computacional, foi primeiramente replicado e implementado o modelo descrito em (LINDGREN; JOHANSSON, 2003). Essa implementação, designada de $\mathbf{J E}+\mathbf{A F}$, tem o objetivo de obter dados suficientes para a comparação de seus resultados com os do modelo desenvolvido neste trabalho, onde as estratégias dos agentes são implementadas através de uma versão simplificada de AAs, denominado JE+AA.

Devido ao fato de os AAs serem uma generalização dos AFs, a estrutura e o funcionamento geral dos modelos permanecem os mesmos, sendo a alteração principal do modelo $\mathbf{J E}+\mathbf{A} \mathbf{A}$ a adição de uma quinta mutação à lista de mutações possíveis durante a fase de reprodução: a associação de uma função adaptativa a uma transição existente.

Além disso, foram adicionados ao modelo original, em ambos os modelos, dois elementos: a ocorrência de erros de entendimento ou enganos (misunderstandings ou mistakes), como proposto como trabalhos futuros em (LINDGREN; JOHANSSON, 2003), e a minimização dos AFs na avaliação das populações de estratégias no modelo $\mathbf{J E}+\mathbf{A F}$, de forma a obter uma caracterização mais precisa das populações de estratégias.

As próximas seções detalham o modelo simplificado de AAs desenvolvido para este trabalho, assim como a sua forma de execução. 


\subsection{Modelo simplificado de autômatos adapta- tivos}

Para este trabalho, foi desenvolvido um modelo simplificado de AA, de forma a facilitar sua implementação, porém mantendo a capacidade de representação de estratégias mais complexas.

O modelo simplificado de AA é composto, em cada instante $t$, por uma sêxtupla $M A A S_{t}=\left(K_{t}, \Sigma, \delta_{t}, s_{0}, F_{t}, A F_{t}\right)$, onde:

- $K_{t}$ é um conjunto finito de estados no instante $t$, que podem ser do tipo $t p \in\{C, D\}$

- $\Sigma$ é o alfabeto de entrada $\{0,1,2,3,4\}$;

- $\delta_{t}$ é a função de transição, $\delta: K_{t} \times \Sigma \rightarrow K_{t}$;

- $s_{0} \in K$ é o estado inicial;

- Ft: $K \times \Sigma \rightarrow A F_{t}$ é a função que associa funções adaptativas a transições do autômato;

- $A F_{t}$ é o conjunto de funções adaptativas $F A_{t, i}$ presentes no autômato no instante $t$.

Neste modelo simplificado, a mudança de estado ocorre sempre após a execução da função adaptativa, ou seja, caso a transição que está sendo seguida seja alterada durante sua execução, a mudança de estado se dará de acordo com a nova estrutura do autômato. Tal situação equivale a $r t=b$ na definição dos AAs apresentada na seção 3.2 .

Cada função adaptativa $F A_{t, i}$ é composta por uma seqüência de 1 até $n_{A}$ ações adaptativas $A A_{t, i, j=1 \ldots n_{A}}$. Uma ação adaptativa $A A_{t, i, j}$ possui os seguintes componentes:

- Tipo: I (ação de inserção) ou $\mathbf{R}$ (ação de remoção)

- Estado de origem: pode ser um estado $s_{k} \in K_{t}$ ou uma referência, que pode ser do tipo $\mathbf{C}$ ou $\mathbf{D}$ (representados como C_REF e D_REF)

- Entrada: uma entrada $I \in \Sigma$

- Estado de destino: pode ser um estado $s_{k} \in K_{t}$ ou uma referência, que também pode ser do tipo $\mathbf{C}$ ou $\mathbf{D}$ 
Um exemplo simples de ação adaptativa é:

$\mathrm{I}(\mathrm{C} 1,3, \mathrm{D} 1)$

O tipo da ação em questão é de inserção (I) e possui como estado de origem C1, entrada 3 e estado de destino D1. Isso significa que, quando essa ação for executada, será inserida uma transição $(C 1,3, D 1)$ ao autômato. Caso essa transição já exista, nenhuma alteração será efetuada. Caso exista no autômato uma transição com entrada $\mathbf{3}$ partindo de $\mathbf{C} \mathbf{1}$ para um outro estado, esta será substituída pela transição com destino D1.

Uma ação de remoção funciona de forma semelhante. Por exemplo, seja a seguinte ação:

$R(D 1,3, C 1)$

Esta ação removerá a transição $(D 1,3, C 1)$, assim como qualquer função adaptativa associada à mesma. Como a função de transição $\delta_{t}$ é completa, existem transições partindo de todos os estados para qualquer entrada $\{0,1,2,3,4\}$. Assim, após a execução desta ação de remoção, a transição $(D 1,3, C 1)$ será substituída pela $(D 1,3, D 1)$. Caso a transição $(D 1,3, C 1)$ não exista no momento em que a ação for executada, a execução da ação será abortada, passando-se para a próxima ação.

Uma função adaptativa pode ser composta por diversas ações adaptativas seqüenciais. Dessa maneira, um exemplo de função adaptativa tem a seguinte forma:

$\mathrm{R}(\mathrm{D} 2,4, \mathrm{C} 1)$

$\mathrm{I}(\mathrm{D} 2,4, \mathrm{D} 1)$

$R(D 1,3, D 2)$

A função, quando executada, efetua as ações na ordem em que estão definidas. Como já foi dito anteriormente, tanto o estado de origem quanto o estado de destino de uma ação adaptativa podem ser uma referência. Uma referência é uma variável que se refere a um estado não previamente conhecido do autômato no momento em que a ação adaptativa foi criada. Isso torna possível para a função adaptativa criar novos estados e manipulá-los em diferentes momentos. Um exemplo de ação adaptativa com referência pode ser visto a seguir: 
I (C1, 3, D_REF1)

Os parâmetros por referência podem ser de dois tipos: para obtenção de valor e para utilização de valor. O formato de um parâmetro por referência para obtenção de valor é t_REFn, onde n é um número seqüencial que identifica a variável e t o tipo do estado (C ou D). Parâmetros por referência para utilização de valor possuem simplesmente o formato REFn, sem a indicação de um tipo. Essa diferenciação é importante, pois permite que o valor de um parâmetro seja obtido em uma ação e posteriormente utilizado em uma ação seguinte. Exemplos de utilização a seguir explicam melhor o funcionamento de ambos os parâmetros.

A ação adaptativa mostrada anteriormente possui um estado de destino D_REF1, que é um parâmetro por referência do tipo D para obtenção de valor. Isso significa que quando a ação for executada, será criado um novo estado do tipo D, e a transição de origem $\mathbf{C} 1$ e entrada 3 terá como destino esse novo estado criado. Ainda, o nome desse novo estado é alocado na variável REF1, podendo ser utilizado em uma outra ação. Parâmetros para obtenção de valor em ações de inserção, portanto, sempre resultam na criação de novos estados.

A utilização de parâmetros por referência em ações de remoção operam de forma diferente. O exemplo a seguir mostra uma ação de remoção que os utiliza:

$R\left(D 2,2, D \_R E F 1\right)$

Como uma ação de remoção se refere a transições existentes, neste caso a variável REF1 será substituída pelo estado do tipo $\mathbf{D}$ que recebe a transição com entrada 2 a partir de D2. Dessa forma, a execução desta ação irá remover esta transição, assim como qualquer função adaptativa que esteja associada a ela, substituindo-a pela transição $(D 2,2, D 2)$. Caso essa transição já seja de D2 para D2, qualquer função adaptativa que esteja associada a essa transição será também removida. Após a execução desta ação, a variável REF1 terá o valor do estado $x$ da transição $(D 2,2, x)$ existente.

Combinando mais de uma ação que utilizam parâmetros por referência, podemse criar funções com um maior nível de complexidade e adaptabilidade, como no exemplo a seguir:

$\mathrm{R}\left(\mathrm{C} 1,2, \mathrm{C} \_\mathrm{REF} 1\right)$

$\mathrm{I}(\mathrm{C} 2,2, \mathrm{REF} 1)$

Esta função efetua as seguintes modificações no autômato: 
1. Remove a transição de entrada $\mathbf{2}$ que sai de $\mathbf{C} \mathbf{1}$ para um outro estado de tipo $\mathbf{C}$;

2. Altera a transição de entrada $\mathbf{2}$ que sai de $\mathbf{C} \mathbf{2}$ para o estado referenciado na ação anterior.

Do ponto de vista da representação gráfica, as funções adaptativas são representadas junto ao símbolo do alfabeto de entrada como rótulo de uma transição. Na seção a seguir, será mostrado um exemplo completo de utilização e execução com o modelo simplificado de AA.

\subsection{Complexidade de estratégias possíveis}

De forma a mostrar que o modelo simplificado de AAs tem capacidade de representação de estratégias mais complexas que um AF, apresenta-se nesta seção um exemplo simples de um autômato que utiliza este modelo e que não poderia ser reproduzido através de $\mathrm{AFs}^{1}$.

A figura 5.1 mostra um exemplo de AA simplificado. Ele possui inicialmente dois estados (C1 e D1), e a transição $(C 1,4, C 1)$ tem associada a seguinte função adaptativa:

$\mathrm{R}$ (D_REF1, 4,C1)

I (REF1, 4,D_REF2)

$\mathrm{I}(\mathrm{REF} 2,4, \mathrm{C} 1)$

Essa função, quando executada, efetua as seguintes alterações:

1. Remove a transição de entrada 4 que parte de um estado do tipo $\mathbf{D}$ e chega a C1, guardando esse estado na variável REF1

2. Insere uma transição do estado armazenado em REF1 de entrada 4 para um novo estado de tipo $\mathbf{D}$, e armazena esse novo estado na variável REF2

3. Insere uma transição de entrada $\mathbf{4}$ do estado em REF2 para $\mathbf{C} 1$

Dessa forma, o autômato implementa a seguinte estratégia:

\footnotetext{
${ }^{1}$ É possível representar, através de AFa, o mesmo comportamento para um número determinado de rodadas, embora sua representação envolva um número extremamente alto de estados e transições. Para um número indeterminado de rodadas, entretanto, essa estratégia não pode ser representada por AFs.
} 


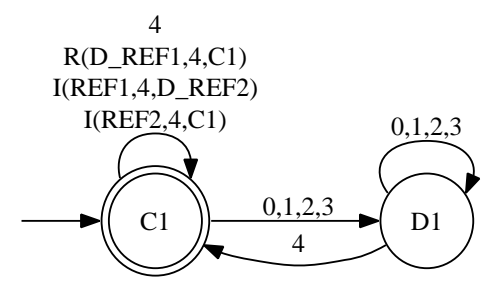

Figura 5.1: Estrutura inicial do autômato

- Inicia jogando $\mathbf{C}$;

- Caso algum outro agente não jogue $\mathbf{C}$, passa a jogar $\mathbf{D}$, só voltando a jogar $\mathbf{C}$ depois que todos os outros agentes também voltem a jogar $\mathbf{C}$;

- Se todos os outros agentes jogarem $\mathbf{C}$, incrementa o número de jogadas necessárias para que volte a jogar $\mathbf{C}$ quando jogou $\mathbf{D}$ na rodada anterior.

O último item da estratégia é implementado através da função adaptativa presente na transição $(C 1,4, C 1)$, que adiciona novos estados do tipo $\mathbf{D}$ que se colocam no caminho antes da volta de D1 para C1. Como essa estratégia impõe um custo crescente para a ocorrência de uma jogada $\mathbf{D}$ quando se está jogando C, ela será designada de CCD (Custo Crescente para a jogada D) no restante deste trabalho. A execução a seguir ilustra o seu comportamento:

\section{Rodada 1}

Na primeira rodada, a estrutura do autômato é a mostrada na figura 5.1. Seu estado corrente é o inicial $\mathbf{C 1}$, e portanto sua jogada é $\mathbf{C}$. Suponha-se que nesta rodada todos os outros agentes jogaram C. A transição $(C 1,4, C 1)$ mantém o estado corrente $\mathbf{C 1}$, porém a função adaptativa associada a ela é executada. O autômato, portanto, altera sua estrutura ao fim desta rodada, permanecendo porém no estado $\mathbf{C} 1$.

\section{Rodada 2}

A estrutura do autômato no início da segunda rodada é mostrada na figura 5.2. Nela vê-se que um novo estado D2 foi adicionado. O estado corrente, entretanto, ainda é $\mathbf{C 1}$, portanto a jogada do agente nesta rodada será novamente C. Suponha-se que mais uma vez todos os agentes jogaram C. O autômato então dispara a transição $(C 1,4, C 1)$, executando novamente a função adaptativa e alterando novamente a estrutura do autômato. Ao fim da rodada, entretanto, o estado corrente permanece $\mathbf{C} 1$.

\section{Rodada 3}




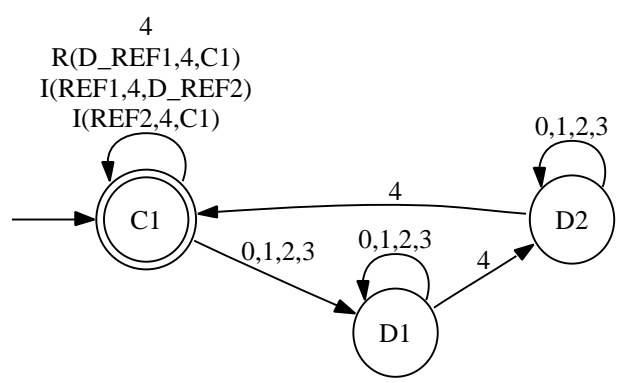

Figura 5.2: Estrutura do autômato no início da rodada 2

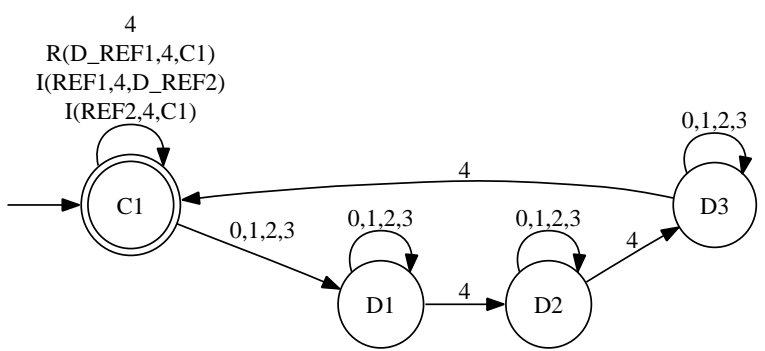

Figura 5.3: Estrutura do autômato no início da rodada 3

A figura 5.3 mostra o autômato no início da terceira rodada, resultante da nova aplicação da função adaptativa da transição $(C 1,4, C 1)$. Nela, mais um estado D3 foi adicionado. O estado corrente permanece C1, e mais uma vez a jogada a ser efetuada é $\mathbf{C}$. Suponha-se mais uma vez que todos os agentes jogaram C na terceira rodada. Novamente, executa-se a função adaptativa e altera-se a estrutura do autômato.

\section{Rodada 4}

O autômato passa a ter a estrutura mostrada na figura 5.4, com mais um novo estado D4. Nesta rodada, entretanto, um outro participante jogou D. Com isso, 3 participantes jogaram $\mathbf{C}$, e a transição de $\mathbf{C} 1$ para a entrada 3 leva a D1, sem nenhuma função adaptativa associada. O estado corrente muda, portanto, para D1.

\section{Rodada 5}

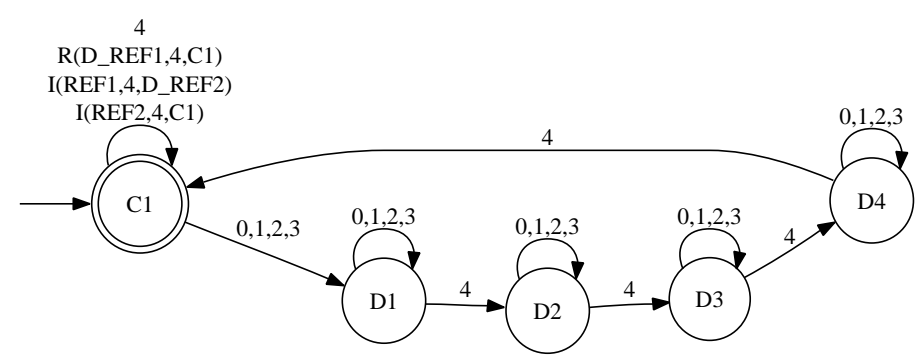

Figura 5.4: Estrutura do autômato no início das rodadas 4,5,6,7,8 e 9 
A estrutura do autômato permanece a mostrada na figura 5.4, porém como o estado corrente é do tipo $\mathbf{D}$, sua jogada nesta rodada será $\mathbf{D}$. Caso qualquer dos outros agentes também jogue D, o estado corrente permanecerá D1. Suponha-se, entretanto, que todos os outros agentes cooperaram. Com isso, o autômato segue a transição para entrada 4 e o estado corrente muda para D2.

\section{Rodadas 6,7 e 8}

Supondo que nas três rodadas seguintes todos os outros participantes jogaram C, o estado corrente do autômato muda respectivamente para D3, D4 e C1. Como o tipo de estado corrente para todas essas rodadas é $\mathbf{D}$, o agente possuidor desta estratégia joga $\mathbf{D}$ nas três rodadas.

\section{Rodada 9}

Na nona rodada, após 4 rodadas em que todos os outros agentes jogaram $\mathbf{C}$, o agente possuidor desta estratégia volta a jogar $\mathbf{C}$.

Observa-se, portanto, que com apenas três ações adaptativas, já é possível obter-se um AA que apresenta um comportamento mais complexo daqueles possíveis através de AFs, onde o histórico de jogadas é utilizado para moldar a resposta do autômato às suas entradas. Assim, de forma a evitar o surgimento de funções adaptativas desnecessariamente complexas, neste trabalho o número máximo de ações adaptativas em uma função adaptativa é fixado em três $\left(n_{A}=3\right)$.

\subsection{Funcionamento dos modelos}

Os algoritmos 1 a 7 detalham o funcionamento da simulação para os modelos $\mathbf{J E}+\mathbf{A F}$ e JE+AA. O funcionamento do procedimento Simulação, presente no algoritmo 1, implica na execução de três etapas para cada uma das NumGeracoes gerações. Na primeira etapa, são executadas as rodadas múltiplas, linhas 9 a 22, para todos os agentes. Para cada agente do reticulado, o DPNP é jogado $n_{r e p}$ vezes entre o agente e seus vizinhos, para que se possa utilizar suas estratégias. Esta rodada múltipla é executada n.m vezes ${ }^{2}$, tendo como agente central cada um dos agentes do reticulado.

Na segunda etapa, linhas 23 a 25, as estratégias dos agentes são armazenadas para posterior análise. Por fim na terceira etapa, linhas 26 a 39, é executada a etapa de reprodução, onde podem ocorrer as mutações, gerando os elementos da população da próxima geração.

\footnotetext{
${ }^{2}$ Para um reticulado de dimensões $m \times n$
} 
As possíveis mutações, como descritas nas seções 4.3 e 5.1, consistem em alterar o tipo de um estado, alterar uma transição, alterar o estado inicial, criar um novo estado e associar uma nova função adaptativa a uma transição. A implementação dessas mutações são mostradas nos algoritmos 3,4,5,6 e 7, respectivamente, apresentados ao final desta seção.

No caso de mutações que associam uma nova função adaptativa a uma trasição, mostrada no algoritmo 7, os elementos constituintes de cada uma das $n_{\text {acts }}$ ações da função sendo criada são o tipo da ação, definido na linha 5, assim como os três parâmetros (estado de origem, símbolo de entrada e estado de destino), definidos respectivamente nas linhas 6 a 18, 19 e 20 a 32 .

De forma a evitar que o tamanho das estratégias cresça desnecessariamente, criou-se o conceito de custo de complexidade. Este tem o objetivo de dar vantagem a um agente que utiliza uma estratégia com o mesmo desempenho, porém com um menor número de estados. Isso é obtido fazendo com que a utilidade dos agentes seja descontada por um valor proporcional ao número de estados de sua estratégia. O parâmetro complexityPrice, definido na especificação dos parâmetros de simulação, é multiplicado pelo número de estados da estratégia do agente e descontado do valor da utilidade obtida pelo mesmo na rodada múltipla. O valor desse parâmetro é escolhido de forma a resultar em um baixo impacto na utilidade final, porém fornecendo uma vantagem suficiente para estratégias implementadas de maneira mais simples.

A minimização dos autômatos (CHROBAK, 2005), ocorrida na etapa em que a população de estratégias é analisada no modelo $\mathbf{J E}+\mathbf{A F}$, consiste em reduzir o autômato à menor representação que implementa a sua estratégia. Com isso, dois autômatos estruturalmente distintos mas que aplicam a mesma estratégia são reduzidos a um mesmo autômato. Assim, a análise da população de estratégias torna-se mais precisa, não considerando como distintas estratégias que são equivalentes. No modelo JE+AA a minimização não é implementada, pois não existe método conhecido para minimização de AAs.

Por fim, assim como sugerido porém não implementado em (LINDGREN; JOHANSSON, 2003), existe em cada rodada uma pequena probabilidade $P_{e}$ de o agente efetuar a jogada oposta àquela definida em sua estratégia. Isso representa eventuais falhas no entendimento por parte do grupo ou erro do agente ao submeter sua decisão.

A seguir, descreve-se o sistema $\boldsymbol{S}_{\mathbf{2}} \boldsymbol{E}_{\mathbf{2}}$, desenvolvido para efetuar os experimentos de simulação dos modelos $\mathbf{J E}+\mathbf{A F}$ e $\mathbf{J E}+\mathbf{A A}$. 


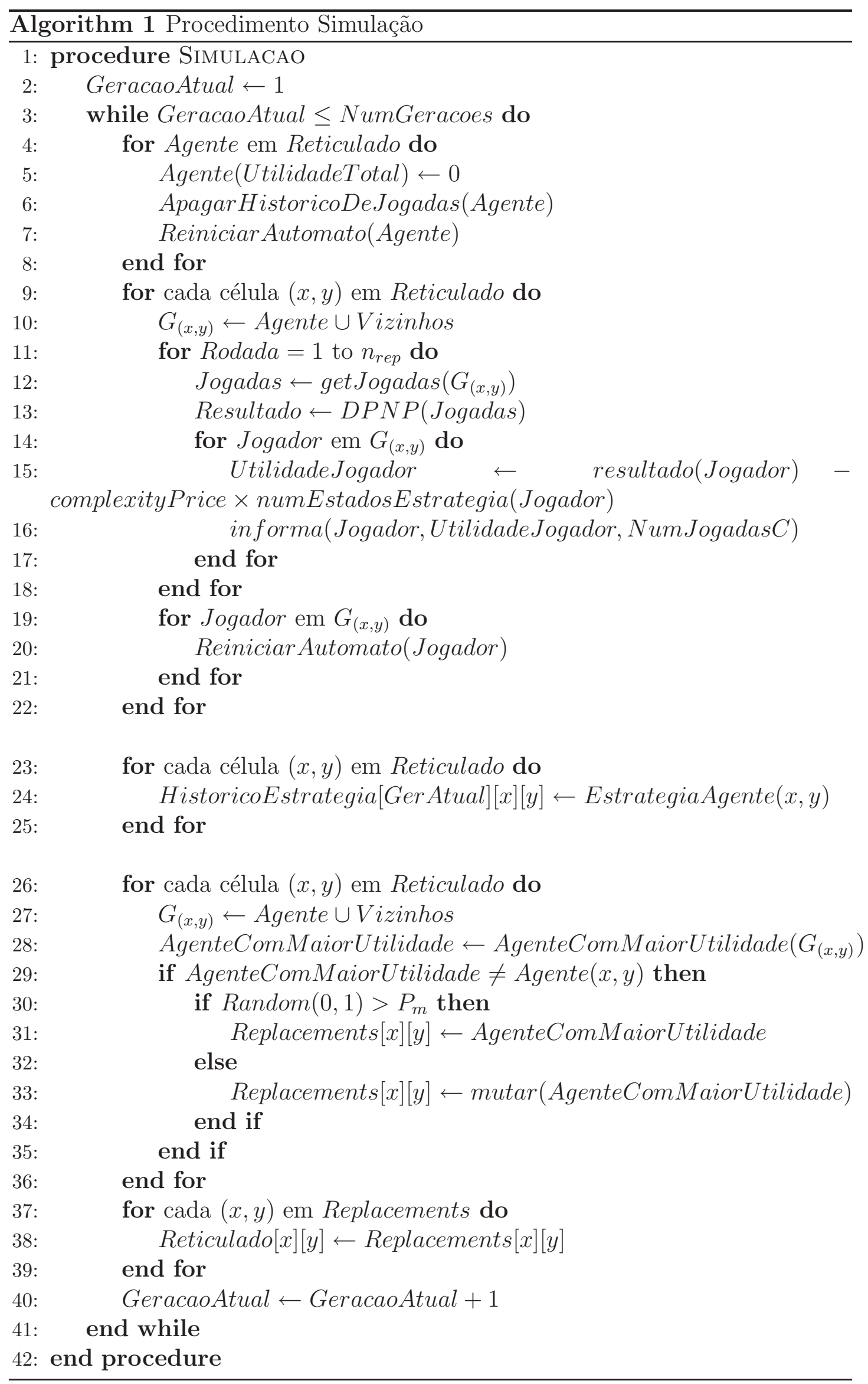



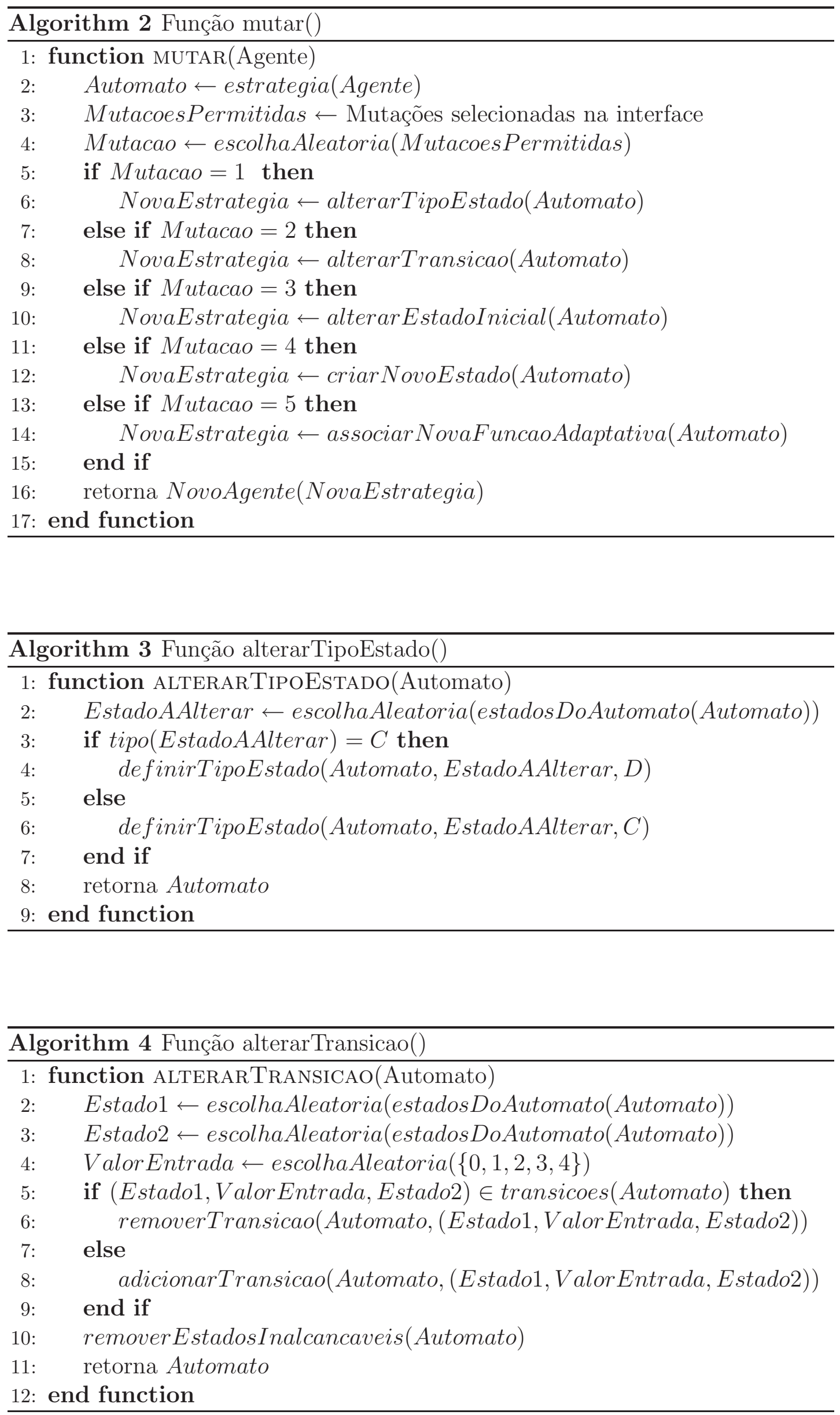

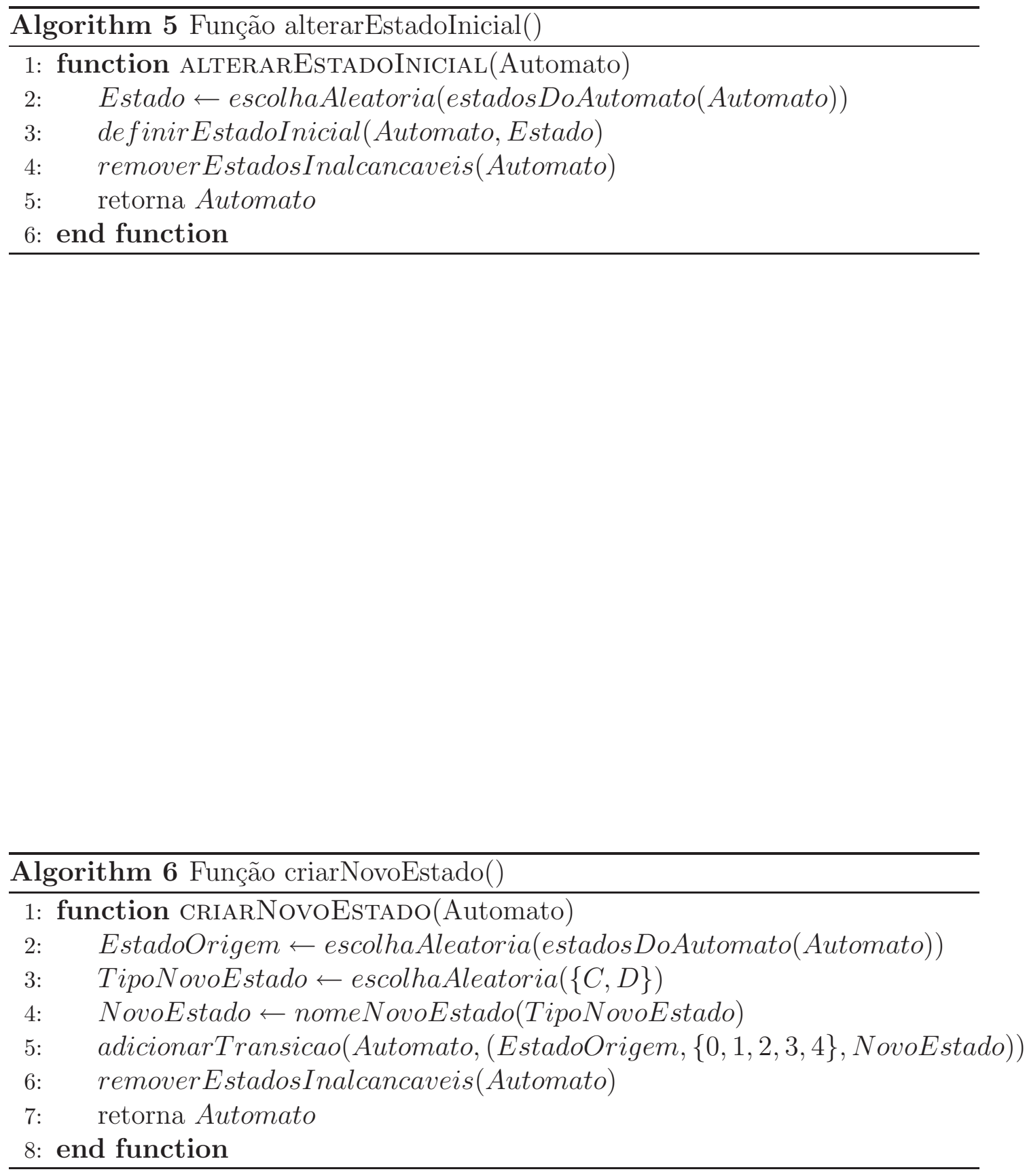


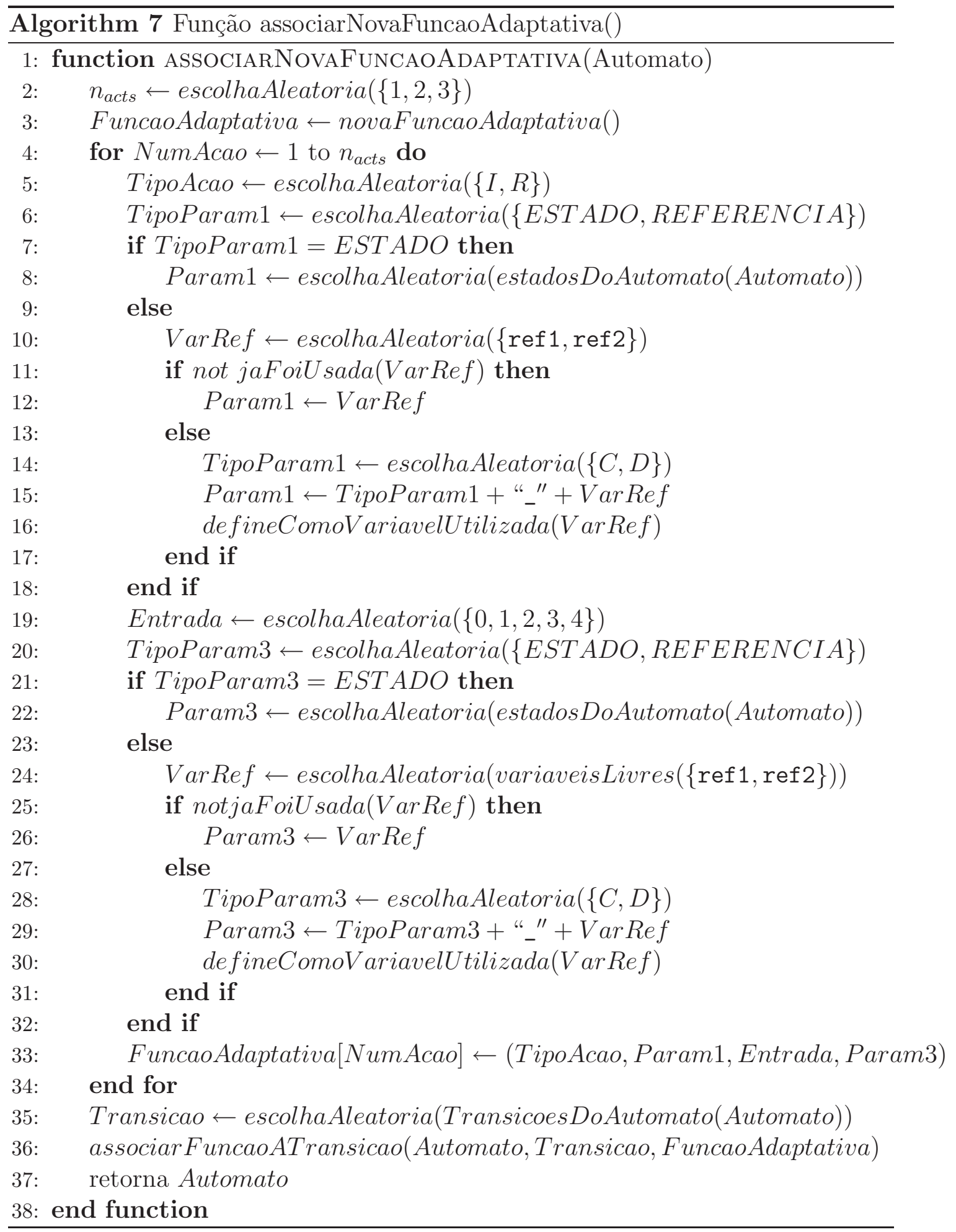




\section{$6 \quad$ Sistema $S_{2} E_{2}$}

\subsection{Escolha do ambiente de desenvolvimento}

Para escolher o ambiente de desenvolvimento a ser utilizado para realizar este trabalho, foram inicialmente avaliadas duas ferramentas de simulação de sistemas multiagentes: MASON (Multi-Agent Simulator Of Neighborhoods) (LUKE et al., 2005) e NetLogo (TISUE; WILENSKY, 2004).

O MASON é uma biblioteca de simulação de eventos discretos para sistemas multiagentes. Desenvolvido em código 100\% em Java, possui portanto alta portabilidade. Sua principal característica é permitir alteração dos modelos e das suas visualizações de forma independente, gerando também visualizações $2 \mathrm{D}$ e 3D dos mesmos. Além disso, produz como saída das visualizações imagens em formato PNG e filmes em formato Quicktime.

Embora o $M A S O N$ possua diversas características interessantes para este trabalho, como por exemplo a visualização em tempo-real da simulação e a possibilidade de alterar parâmetros durante a simulação, a documentação disponível é pequena, gerando uma grande dificuldade para implementar novos modelos não baseados em exemplos pré-existentes.

Já o NetLogo é um sistema de modelagem e simulação derivado da linguagem didática Logo. É amplamente utilizado em diversas áreas de estudo, como biologia, ciências sociais, matemática e computação, devido principalmente à sua facilidade de uso, disponibilidade de uma ampla biblioteca de modelos pré-definidos, linguagem de programação própria simples e boa documentação.

As estruturas de dados disponíveis, entretanto, são pouco flexíveis, e embora possua interface para extensões através da linguagem Java, não há disponibilidade suficiente de exemplos de sua utilização. Por fim, o desempenho computacional observado poderia implicar em limitações às simulações a serem feitas no trabalho. 
Avaliou-se então a possibilidade de desenvolver um ambiente específico para as simulações, através de uma linguagem de programação que possuísse flexibilidade, estruturas de dados e desempenho computacional adequados. Optou-se por essa escolha, mais especificamente pelo desenvolvimento de um sistema na linguagem Python (MARTELLI, 2003), pelos seguintes motivos:

- As funcionalidades proporcionadas tanto pelo NetLogo quanto pelo MA$S O N$ e que poderiam ser utilizadas neste trabalho são a visualização gráfica durante a simulação e o gerenciamento da ordem em que as interações ocorreriam. A visualização gráfica não teria grande valia neste trabalho, pois a característica que identifica um agente - sua estratégia - não pode ser codificada de forma satisfatória através de uma cor. Além disso, devido à necessidade de simular a execução paralela das ações, é importante ter um controle de como é implementada a ordem das iterações;

- A linguagem Python possui diversas características desejáveis para a elaboração das simulações: é multi-plataforma, possui estruturas de dados extremamente flexíveis e é orientada a objetos;

- Existem bibliotecas que integram Python a boa parte das ferramentas necessárias para este trabalho, como a pygraphviz para a geração de representação gráfica de autômatos, ou a Gnuplot.py para geração de gráficos;

- Embora seja interpretada, possui uma extensão para aceleração de processamento, chamada Psyco, que melhora significativamente o desempenho da execução de sistemas com forte utilização de memória e cálculos matemáticos.

Decidiu-se, portanto, desenvolver um sistema com uma estrutura básica em Python para as simulações, de forma que eventuais alterações na programação dos agentes não tenham grande impacto nas outras partes do sistema. A arquitetura e a interface do sistema, chamado de $\boldsymbol{S}_{\mathbf{2}} \boldsymbol{E}_{\mathbf{2}}$ (Sistema de Simulação Evolutiva Espacial), são descritas na seqüência.

\subsection{Arquitetura do software}

O sistema $\boldsymbol{S}_{\mathbf{2}} \boldsymbol{E}_{\mathbf{2}}$ foi projetado de forma a permitir que alterações que porventura se fizessem necessárias ao longo do trabalho não tivessem grande impacto em outras partes do sistema. Para tanto, optou-se pela programação orientada a 


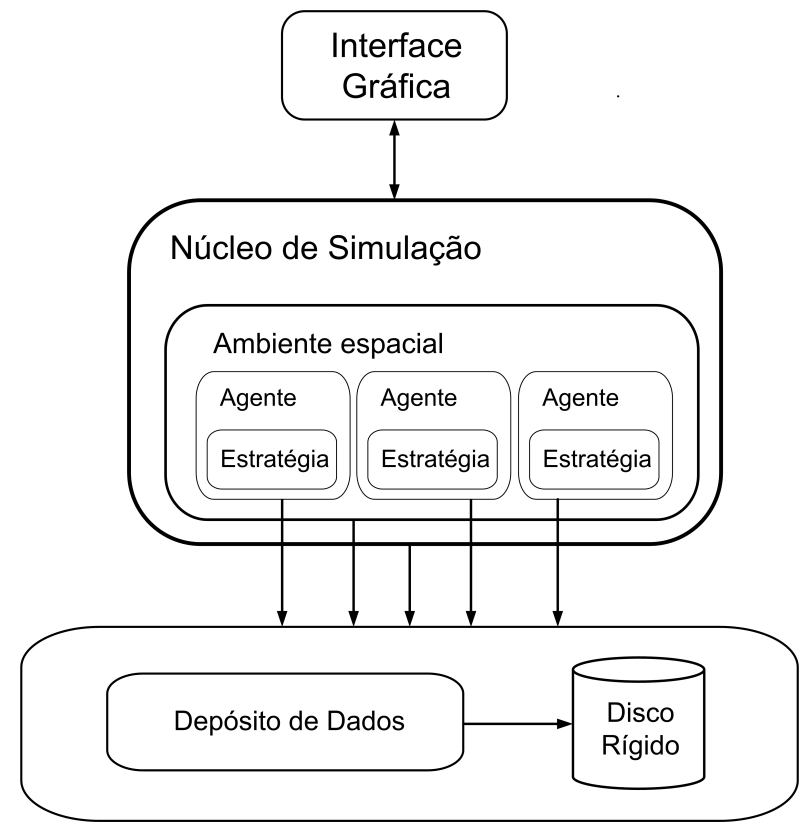

Figura 6.1: Estrutura do sistema $\boldsymbol{S}_{2} \boldsymbol{E}_{2}$

objetos. A figura 6.1 mostra a estrutura básica do sistema, que é composto por uma interface gráfica, um núcleo de simulação e um módulo responsável pelo armazenamento dos dados em disco. A seguir são detalhados, para cada elemento do sistema, as classes que o compõem e seu funcionamento.

\subsubsection{Núcleo de simulação}

A figura 6.2 mostra o diagrama das classes pertencentes ao núcleo de simulação. Nele, a classe Simulation é responsável pela simulação propriamente dita. Ela é iniciada com todos os parâmetros de simulação - a matriz que representa o reticulado onde estão localizados os agentes (matrix), o jogo a ser utilizado (game), as mutações permitidas (mutations), o número de iterações em cada rodada múltipla (numlnteractionsPerRound), a probabilidade de ocorrerem mutações (mutationProb) e a probabilidade de erros dos agentes (mistakeProb). O parâmetro game é uma instância de alguma subclasse de Game. Para este trabalho somente foi criada uma única instância, denominada NPPD. Após cada ativação do método oneGeneration(), uma geração é executada, tendo como retorno a matriz correspondente ao final da geração.

A execução das rodadas múltiplas entre um mesmo grupo de agentes é implementada na classe AgentsInteraction. Essa etapa foi separada da classe Simulation de forma a facilitar uma futura implementação distribuída do sistema, por tratar-se da etapa de maior custo computacional. Já MutationAA e MutationAF são sub-classes de Mutation, e executam as mutações nas es- 


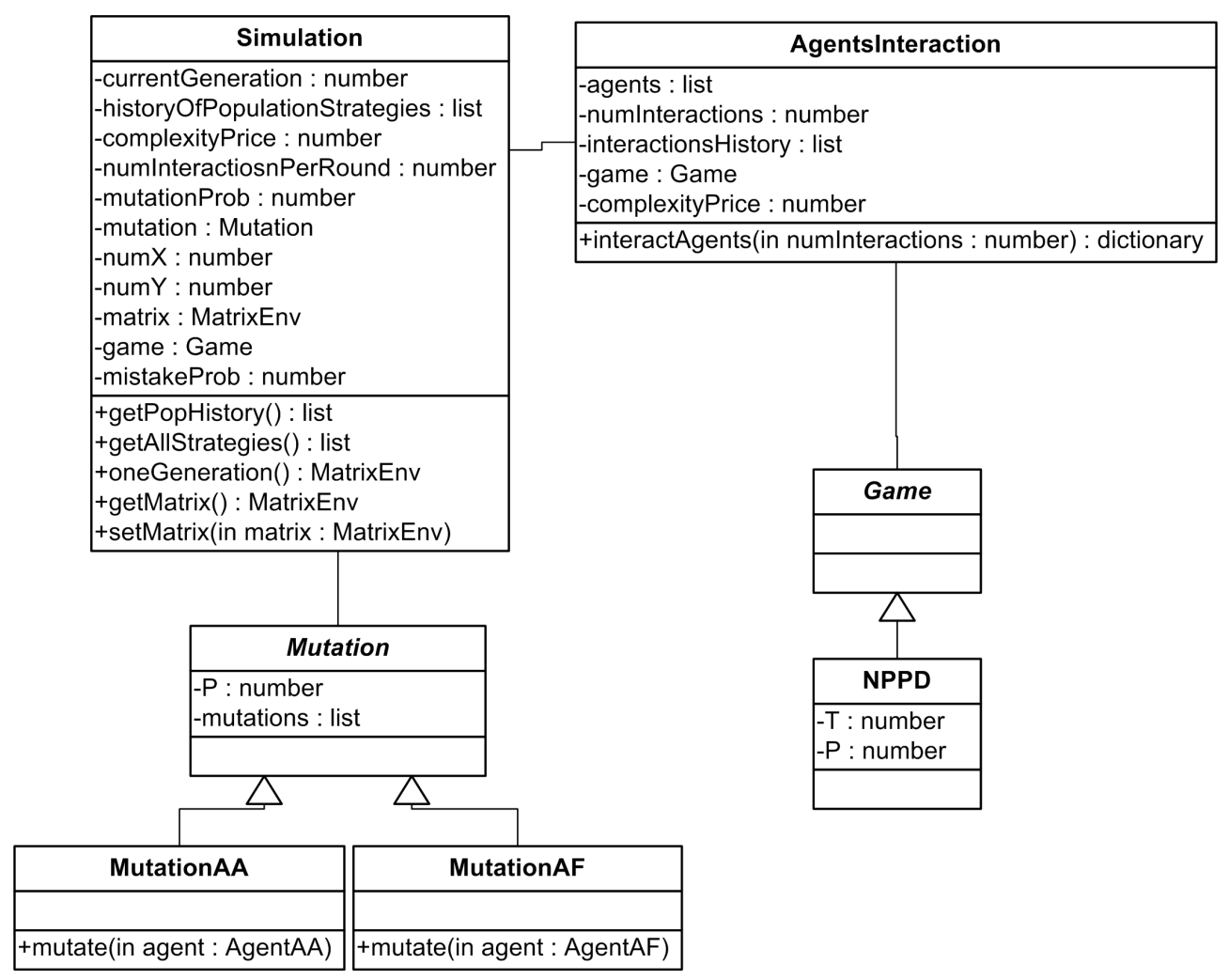

Figura 6.2: Diagrama de classes - núcleo de simulação

tratégias representadas respectivamente nos modelos AA e AF.

\subsubsection{Ambiente espacial}

\begin{tabular}{|l|}
\multicolumn{1}{c|}{ MatrixEnv } \\
\hline -matrix : list \\
-xTotal : number \\
-yTotal : number \\
\hline +numCells() : number \\
+ +addAgent(in $\mathrm{x}:$ number, in $\mathrm{y}:$ number, in agent : Agent, in makeDeepCopy : boolean) \\
+ +fillAgents(in agent : Agent) \\
+ +getAgent(in $\mathrm{x}:$ number, in $\mathrm{y}:$ number) : Agent \\
+getNeighborhood(in $\mathrm{x}:$ number, in $\mathrm{y}:$ number, in returnSelf : boolean) : list \\
+ +neighborWithMostPoints(in $\mathrm{x}:$ number, in $\mathrm{y}:$ number) : Agent \\
+ +tolmage(in infoUsed : number, in imgSize : list, in highlightMutations : boolean) : object \\
+ +toString(in infoPrinted : number, in format : number) : string
\end{tabular}

Figura 6.3: Diagrama de classes - ambiente espacial

O módulo Ambiente espacial, implementado através da classe MatrixEnv mostrada na figura 6.3, armazena todos os agentes da simulação. Ela possui internamente uma matriz de tamanho definido na sua instanciação, onde os agentes são armazenados. Além de possuir métodos que retornam representações gráficas e textuais dos agentes e suas jogadas, ela é também responsável pela seleção dos agentes que irão interagir em cada rodada múltipla. 


\begin{tabular}{|l|l|}
\hline \multicolumn{1}{|c|}{ Agent } \\
\hline -numPlays : number \\
-points : number \\
-playsHistory : list \\
-mistakeProb : number \\
-justMutated : boolean \\
-strategy : FSA
\end{tabular}

Figura 6.4: Diagrama de classes - agentes

\begin{tabular}{l}
\hline \multicolumn{1}{|c|}{ FSA } \\
\hline -startNode : string \\
-currentNode : string \\
\hline +getStartNode() : string \\
+restart() \\
+getNodes() : list \\
+setStartNode(in node : string) \\
+changeNodeType(in node : string, in newType : char) \\
+getNumNodes() : number \\
+getTransitions() : list \\
+getCurrentNode() : string \\
+existsTransitions(in fromNode : string, in toNode : string, in inputList : list) \\
+addTransition(in fromNode : string, in toNode : string, in inputList : list) \\
+removeTransition(in fromNode : string, in toNode : string, in inputList : list) \\
+getTransitionsFromNode(in node : string) \\
+removeOrphanNodes() \\
+getComplexity() : number \\
+start() \\
+walk(in inputChar : char) : string \\
+getNextNode(in inputChar : char) : string \\
+getNextNodelndex() : number \\
+removeSelfTransitions() \\
+minimize() \\
+getldentifier() : string \\
+toDot() : string
\end{tabular}

\begin{tabular}{|c|c|}
\hline & AdaptFunction \\
\hline -actions : list & \\
\hline $\begin{array}{l}\text { +appendAction(in actionType : char, in arg1: AdaptFunction } \\
\text { +execute(in adapFSA : AdapFSA) } \\
\text { +toString() : string }\end{array}$ & Argument, in arg2 : AdaptFunctionArgument, in arg3 : AdaptFunctionArgument) \\
\hline & \\
\hline AdaptFunctionArgument & \\
\hline $\begin{array}{l}\text {-argname : string } \\
\text {-type : char } \\
\text {-ref : boolean }\end{array}$ & \\
\hline $\begin{array}{l}\text { +isReference }() \text { : boolean } \\
+ \text { getName }(): \text { string } \\
\text { +getType }(): \text { char }\end{array}$ & \\
\hline
\end{tabular}

Figura 6.5: Diagrama de classes - estratégias 


\begin{tabular}{|l|}
\hline \multicolumn{1}{|c|}{ DataStorage } \\
\hline -dicConfigurations : dictionary \\
-dicData : dictionary \\
-dicFSObjects : dictionary \\
\hline +initDeposit(in rootDir : string, in osSystem : string) \\
+addKey(in key : string, in folder : string, in file : string) \\
+feedData(in key : string, in data : string) \\
+closeStorage(in key : string) \\
+closeAllStorages() \\
+getRootDir() : string \\
\hline
\end{tabular}

Figura 6.6: Diagrama de classes - depósito de dados

\subsubsection{Agentes e estratégias}

As figuras 6.4 e 6.5 mostram as classes que compõem respectivamente os agentes e suas estratégias.

Os agentes são implementados por duas classes: AgentAF e AgentAA. Ambas são sub-classes de Agent, com a diferença de que as estratégias dos agentes do tipo AgentAA são implementadas através da classe AdaptFSA. Embora simplesmente suprimir a mutação que associa novas funções adaptativas a uma transição seja suficiente para que um AdaptFSA comporte-se como um FSA, simulações feitas somente com agentes do tipo AgentAF têm um desempenho melhor, pois os métodos de FSA não levam em consideração a existência de funções adaptativas.

A classe FSA implementa todas as funções necessárias para definir e executar um AF, como adição e remoção de transições, métodos para percorrer o autômato, assim como de minimização. AdaptFSA é uma sub-classe de FSA, onde além das transições são também armazenadas as funções adaptativas (da classe AdaptFunction). Nela, o método walk() executa as funções adaptativas quando estas devem ser executadas, e o método minimize() não efetua nenhuma alteração no autômato. As classes AdaptFunction e AdaptFunctionArgument codificam e executam as funções adaptativas.

\subsubsection{Depósito de dados}

A classe DataStorage, mostrada na figura 6.6, centraliza a obtenção e o armazenamento dos dados da simulação a serem analisados posteriormente. Trata-se de uma classe do tipo singleton ${ }^{1}$, que quando instanciada em qualquer ponto do sistema, refere-se ao mesmo objeto em memória.

Para cada simulação, são definidas chaves ("utilidade", por exemplo), que são

\footnotetext{
${ }^{1}$ Uma classe que segue o padrão de desenvolvimento singleton é instanciada apenas uma vez durante a execução do sistema. Dessa forma, sempre que um objeto da classe é instanciado, o mesmo refere-se a um objeto já existente na memória.
} 
associadas a arquivos em disco, onde são armazenados os dados que são enviados à classe através do método feedData(). Como resultado, todos os dados enviados para uma mesma chave são armazenados seqüencialmente no mesmo arquivo dentro da estrutura de diretórios criada para a simulação sendo executada. Os dados que efetivamente serão armazenados em disco, entretanto, são definidos pelo método addKey(), que é executado antes do início da simulação. Desta forma, os dados associados a chaves que não foram iniciadas por este método são simplesmente ignorados. Esse comportamento tem o objetivo de acelerar a execução do sistema, que somente irá armazenar em disco os dados que forem escolhidos pelo usuário na sua inicialização.

\subsubsection{Interface}

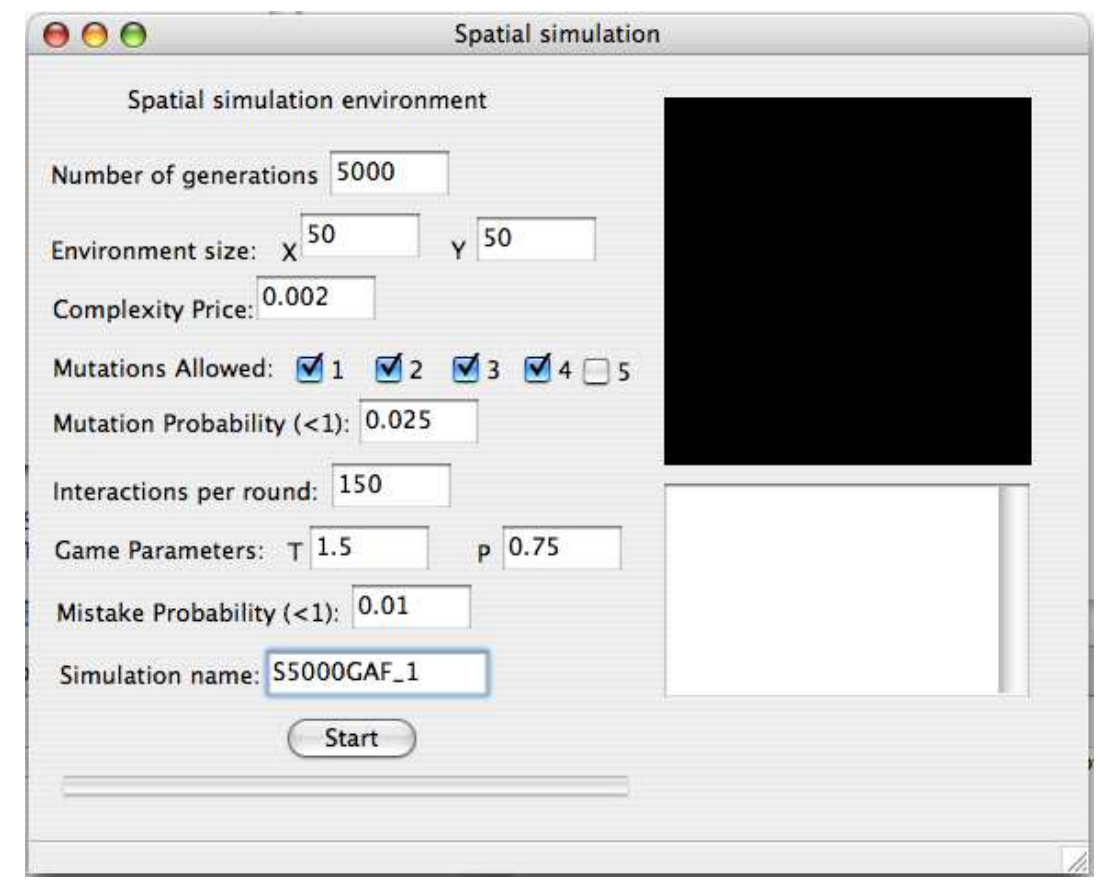

Figura 6.7: Interface para realização dos experimentos

Para a execução de experimentos, foi criada uma interface simples do sistema com o usuário, mostrada na figura 6.7. Essa interface foi implementada através da biblioteca PythonCard, e consiste em dois arquivos: um com a diagramação da tela e outro com as funções a serem executadas para eventos como a inicialização do sistema ou o clicar de um botão. Na versão atual do sistema $\boldsymbol{S}_{\mathbf{2}} \boldsymbol{E}_{\mathbf{2}}$, este segundo arquivo deve ser editado, programando-se as estratégias iniciais dos agentes através das classes FSA ou AdapFSA.

O usuário pode definir através da interface os seguintes parâmetros das simulações: 
- Number of generations: define quantas gerações serão executadas;

- Environment size: define o tamanho do reticulado;

- Mutations allowed: define os tipos de mutação que podem ocorrer durante a fase de reprodução:

1. Alterar o tipo de um estado;

2. Alterar uma transição;

3. Alterar o estado inicial;

4. Adicionar um novo estado;

5. Criar uma nova função adaptativa e associá-la a uma transição existente

- Interactions per round: define o número de rodadas em uma rodada múltipla;

- Os valores dos parâmetros complexityPrice, $P_{m}, T, P$ e $P_{e}$ são definidos, respectivamente, nos campos Complexity price, Mutation probability, T, $P$ e Mistake probability;

- O valor do campo Simulation name é utilizado para a criação da estrutura de diretórios onde os resultados da simulação são armazenados.

A integração da interface com o resto do sistema é feita através da instanciação da classe Simulation em seu código. Ao longo da simulação, são gerados mapas visuais que indicam, para cada agente em cada geração, a proporção de jogadas cooperativas e não-cooperativas, assim como os locais onde ocorrem mutações.

Após o término da simulação, é gerada uma estrutura de diretórios da simulação executada, com os seguintes itens:

- Arquivo texto com os valores dos parâmetros utilizados na simulação;

- Arquivo texto indicando data e hora do início e fim da execução da simulação;

- Representação gráfica das estratégias de todos os agentes na última geração (formato PNG);

- Imagens que representam o reticulado de agentes, a proporção de jogadas cooperativas e locais de mutações para cada geração da simulação; 
- Arquivo texto com um mapa que indica o número de estados de cada estratégia, assim como o tipo de estado inicial, para cada geração;

- Arquivo $\mathrm{CSV}^{2}$ com o número de jogadas $\mathbf{C}$ e $\mathbf{D}$ para cada geração;

- Arquivo CSV com a utilidade total obtida pelos agentes para cada geração;

- Arquivo texto com o número de agentes com cada estratégia para cada geração;

No próximo capítulo, os diversos experimentos realizados com o sistema $\boldsymbol{S}_{\mathbf{2}} \boldsymbol{E}_{\mathbf{2}}$ são detalhados e analisados.

${ }^{2}$ Comma-separated values, padrão de arquivo texto com valores separados por vírgulas e linhas. 


\section{Experimentos realizados}

\subsection{Descrição dos experimentos}

Com o objetivo de analisar o impacto do modelo de representação de estratégias na dinâmica da cooperação, foram realizadas diversas simulações, tanto do modelo $\mathbf{J E}+\mathbf{A F}$ quanto do $\mathbf{J E}+\mathbf{A A}$.

Inicialmente, foram feitas duas baterias de simulações com o modelo $\mathbf{J E}+\mathbf{A F}$, com o objetivo de obter uma base de comparação e também de verificar se os resultados obtidos seriam aqueles publicados em (LINDGREN; JOHANSSON, 2003). O tamanho do reticulado utilizado foi de 50x50 (totalizando 2500 agentes), em oposição ao tamanho utilizado por Lindgren \& Johansson, de 120x120. Tal escolha foi feita para se poder viabilizar simulações com um número maior de gerações, verificando o comportamento dos agentes por um horizonte temporal maior, podendo-se analisar melhor a estabilidade dos resultados.

Foram feitas duas baterias de simulações do modelo $\mathbf{J E}+\mathbf{A F}$ :

- Bateria 1, composta por 3 simulações de 8000 gerações, onde todos os agentes iniciam com a estratégia $\mathbf{U}$, mostrada na figura 4.6;

- Bateria 2, composta por 2 simulações de 5000 gerações, onde todos os agentes iniciam com a estratégia TT5, mostrada na figura 7.1.

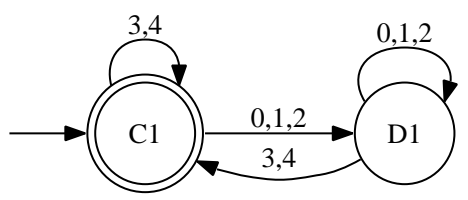

Figura 7.1: Estratégia inicial TT5 para a bateria 2 de simulações de 5000 gerações do modelo $\mathbf{J E}+\mathbf{A F}$

A estratégia TT5, utilizada como inicial na segunda bateria de testes, é uma aproximação da estratégia tit-for-tat para o DPNP com 5 participantes, e pode ser sumarizada com a seguinte descrição: 
- Iniciar jogando C;

- Enquanto a maioria dos outros agentes jogar $\mathbf{C}$, segue jogando $\mathbf{C}$;

- Caso a maioria ou a metade dos outros agentes jogar $\mathbf{D}$, passa a jogar $\mathbf{D}$, e assim permanece enquanto a maioria não jogar $\mathbf{C}$;

- Caso a maioria volte a jogar $\mathbf{C}$, volta a jogar $\mathbf{C}$.

O objetivo da segunda bateria de testes foi verificar o comportamento dos agentes dadas condições iniciais diferentes daquelas descritas em (LINDGREN; JOHANSSON, 2003), assim como a estabilidade evolutiva de uma estratégia semelhante ao tit-for-tat em um modelo evolutivo do DPNP.

O número de gerações a serem simuladas foi escolhido de forma que fosse maior do que o utilizado em (LINDGREN; JOHANSSON, 2003), onde a simulação foi efetuada por 1000 gerações, e que fossem viáveis dadas as restrições computacionais e de tempo disponíveis.

Da mesma forma, foram feitas duas baterias de simulações do modelo $\mathbf{J E}+\mathbf{A A}$ :

- Bateria 1, composta por 3 simulações de 8000 gerações, onde todos os agentes iniciam com a estratégia $\mathbf{U}$;

- Bateria 2, composta por 2 simulações de 5000 gerações, onde todos os agentes iniciam com a estratégia CCD, apresentada na seção 5.3.

A segunda bateria de simulações tem objetivos semelhantes àqueles da do modelo $\mathbf{J E}+\mathbf{A F}$ : verificar o comportamento dos agentes dadas diferentes condições iniciais mas, adicionalmente, ao iniciar com uma estratégia com comportamento mais complexo, facilitar o surgimento de outras que possam apresentar níveis maiores de complexidade.

A tabela 7.1 apresenta o tempo dispendido nas simulações, realizadas em uma única máquina com um processador AMD Athlon 64X2 3800+ e 1 GB de memória RAM. Nota-se que o tempo dispendido é extremamente alto, sugerindo que experimentos deste gênero devem ser muito bem planejados para que não se percam dados devido a problemas contingenciais, como por exemplo queda de energia.

Excetuando-se as estratégias iniciais, todos os outros parâmetros foram mantidos para todas as simulações: 


\begin{tabular}{|c|c|}
\hline Simulação & Tempo de execução \\
\hline "JE+AF Bateria 1 Simulação 1 & $\begin{array}{l}72 \mathrm{~h} 27 \mathrm{~m} \\
\end{array}$ \\
\hline JE+AF Bateria 1 Simulação 2 & $73 \mathrm{~h} 31 \mathrm{~m}$ \\
\hline JE+AF Bateria 1 Simulação 3 & $70 \mathrm{~h} 23 \mathrm{~m}$ \\
\hline JE+AF Bateria 2 Simulação 1 & $47 \mathrm{~h} 24 \mathrm{~m}$ \\
\hline JE+AF Bateria 2 Simulação 2 & $46 \mathrm{~h} 1 \mathrm{~m}$ \\
\hline JE+AA Bateria 1 Simulação 1 & 146h 46m \\
\hline JE+AA Bateria 1 Simulação 2 & $132 \mathrm{~h} 32 \mathrm{~m}$ \\
\hline JE+AA Bateria 1 Simulação 3 & $177 \mathrm{~h} 10 \mathrm{~m}$ \\
\hline JE+AA Bateria 2 Simulação 1 & $104 \mathrm{~h} 18 \mathrm{~m}$ \\
\hline JE+AA Bateria 2 Simulação 2 & $92 \mathrm{~h} 42 \mathrm{~m}$ \\
\hline
\end{tabular}

Tabela 7.1: Tempos de execução das simulações

- $P_{m}$ (probabilidade de ocorrer mutação durante a reprodução): 0.01

- $n_{r e p}$ (número de rodadas em uma rodada múltipla): 150

- $T: 1.5$

- $P: 0.25$

- $P_{e}$ (probabilidade de erro de entendimento): 0.01

- complexityPrice (valor que é multiplicado pelo número de estados e descontado da utilidade obtida): 0.002

Os valores de $T$ e $P$ foram reproduzidos de (LINDGREN; JOHANSSON, 2003), e o valor de $P_{m}$ foi escolhido de forma a obter na média o mesmo número de mutações resultantes do $P_{m}$ utilizado em (LINDGREN; JOHANSSON, 2003) em cada geração. Os valores de complexityPrice e $P_{e}$ foram calibrados de forma que o primeiro não interfira significativamente no resultado dos jogos, e o segundo ocorra de forma esporádica. Por fim, o valor de $n_{r e p}$, não disponível no artigo original, foi obtido de (MILLER, 1989), que desenvolve um modelo semelhante ao de (LINDGREN; JOHANSSON, 2003).

\subsection{Experimentos com o modelo JE+AF}

Como dito anteriormente, foram realizadas duas baterias de testes para o modelo JE+AF, cujos resultados são descritos a seguir. 


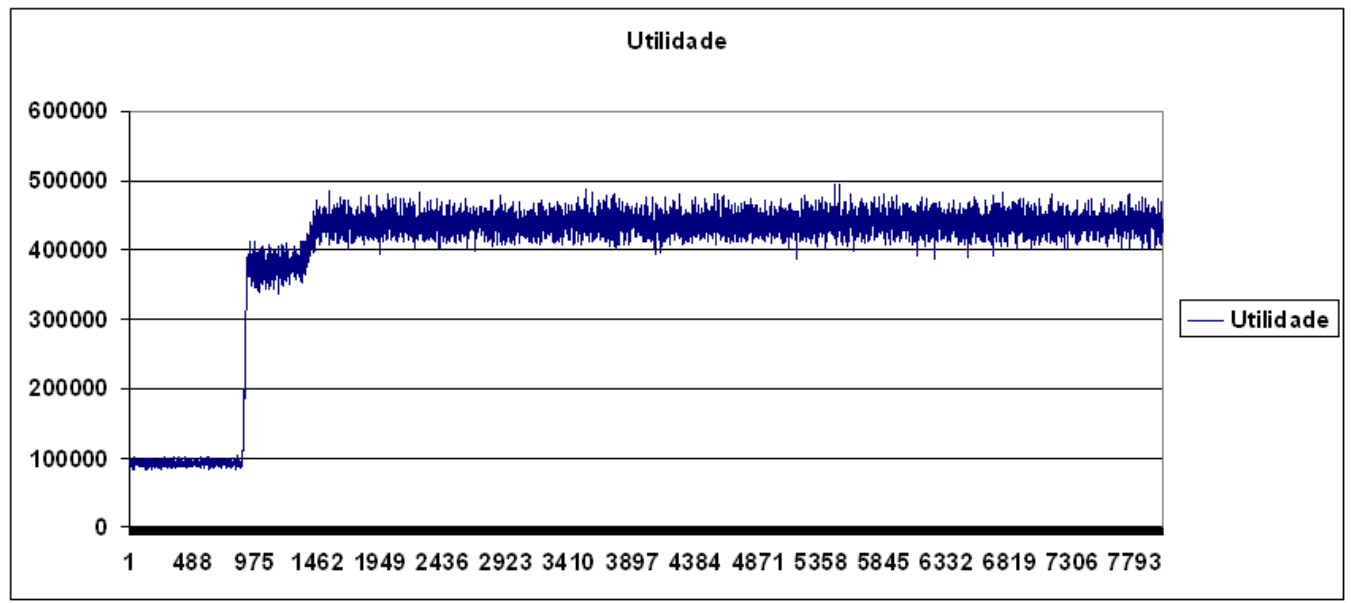

Figura 7.2: Utilidade total dos agentes para a simulação 1 da bateria 1 de 8000 gerações do modelo $\mathbf{J E}+\mathbf{A F}$

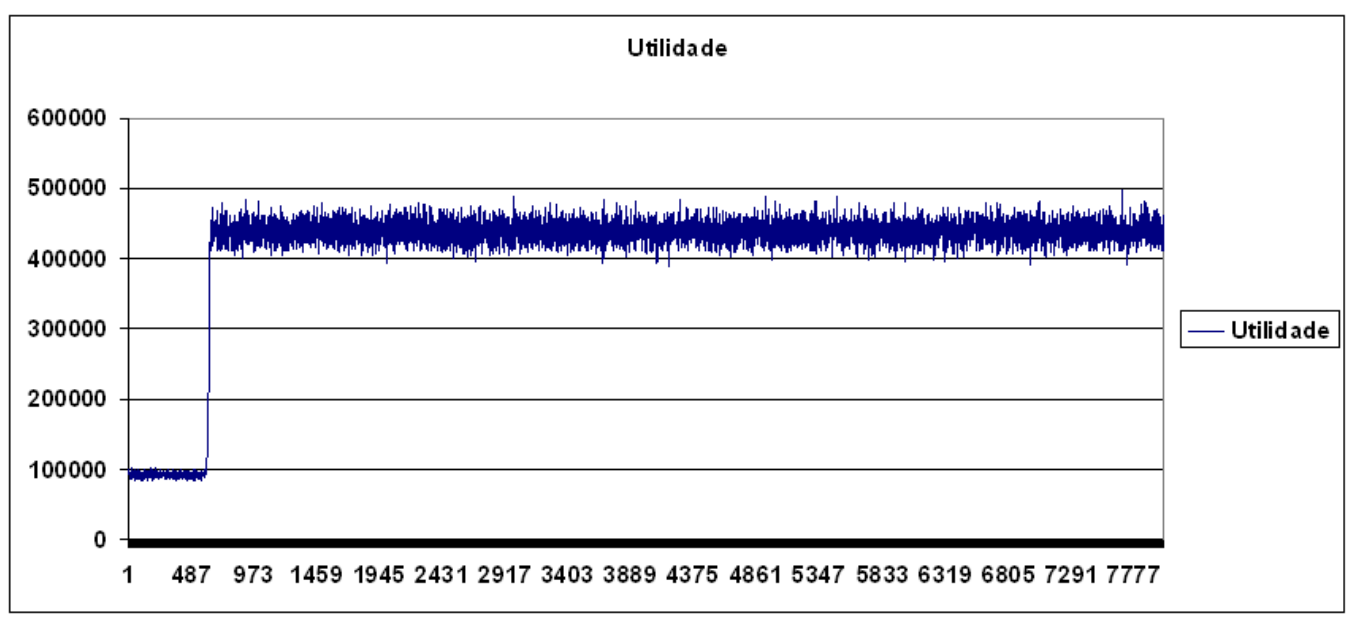

Figura 7.3: Utilidade total dos agentes para a simulação 2 da bateria 1 de 8000 gerações do modelo $\mathbf{J E}+\mathbf{A F}$

\subsubsection{Primeira bateria de testes}

As figuras 7.2, 7.3 e 7.4 mostram os gráficos da utilidade total de todos os agentes por geração para as três simulações efetuadas na primeira bateria do modelo $\mathbf{J E}+\mathbf{A F}$, de 8000 gerações cada. No eixo horizontal estão representadas as gerações da simulação, e no vertical o valor somado de todas as utilidades obtidas pelos agentes em cada geração. Pode-se observar que, após um início onde a utilidade dos agentes é baixa, ocorre um rápido incremento, que persiste, embora com oscilações locais, num mesmo nível até a última geração. Na primeira simulação (figura 7.2), verifica-se que, antes de se alcançar o nível de equilíbrio, há um período intermediário com um nível menor de utilidade que aquele alcançado em seguida. A análise das estratégias e da distribuição espacial das jogadas dos agentes explicará o fenômeno em seguida.

As quantidades de jogadas $\mathbf{C}$ e $\mathbf{D}$ feitas por todos os agentes nessas simulações 


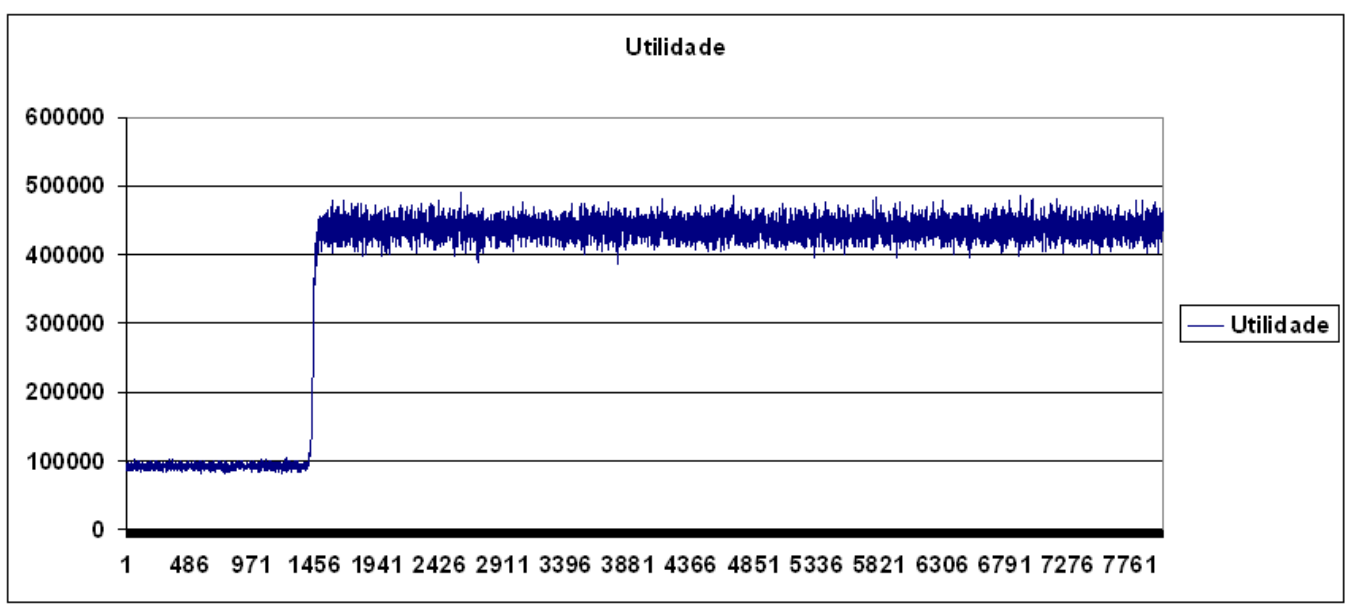

Figura 7.4: Utilidade total dos agentes para a simulação 3 da bateria 1 de 8000 gerações do modelo $\mathbf{J E}+\mathbf{A F}$

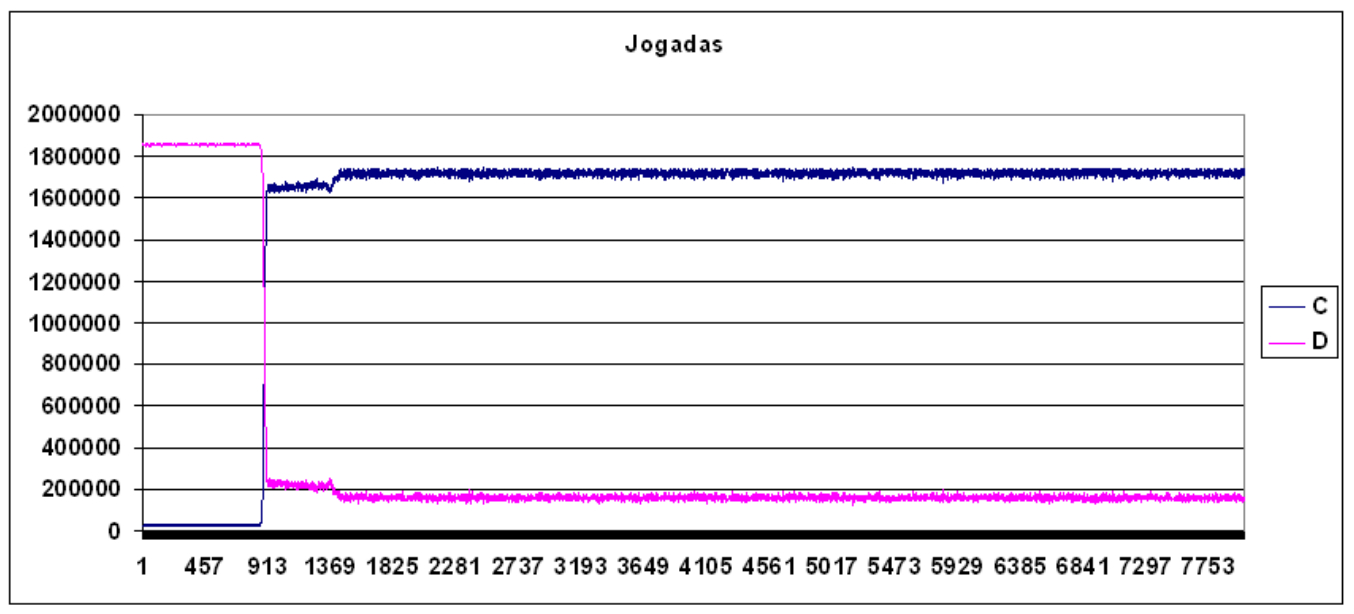

Figura 7.5: Jogadas feitas pelos agentes para a simulação 1 da bateria 1 de 8000 gerações do modelo $\mathbf{J E}+\mathbf{A F}$

podem ser vistas nas figuras 7.5, 7.6 e 7.7. No eixo horizontal estão as gerações da simulação, e as linhas azul escuro e rosa indicam o número de jogadas $\mathbf{C}$ e $\mathbf{D}$ respectivamente efetuadas por todos os agentes em cada geração. A causa dos aumentos nos níveis de utilidade é evidenciada neste gráfico: a partir de certo momento há uma forte mudança nas jogadas efetuadas pelos agentes.

De forma a entender melhor o processo que levou às mudanças observadas, deve-se analisar as estratégias adotadas pelos agentes ao longo do tempo. A figura 7.8 mostra a população de estratégias da simulação 1 da primeira bateria. Nela, o eixo horizontal mostra as gerações da simulação, e as linhas coloridas representam, cada uma, uma estratégia diferente. Os valores correspondentes no eixo vertical indicam a quantidade de agentes que possuem a estratégia em cada geração. No gráfico estão indicadas também, através de letras, as representações gráficas de algumas das estratégias. Devido ao fato de ocorrerem ao longo da simulação 


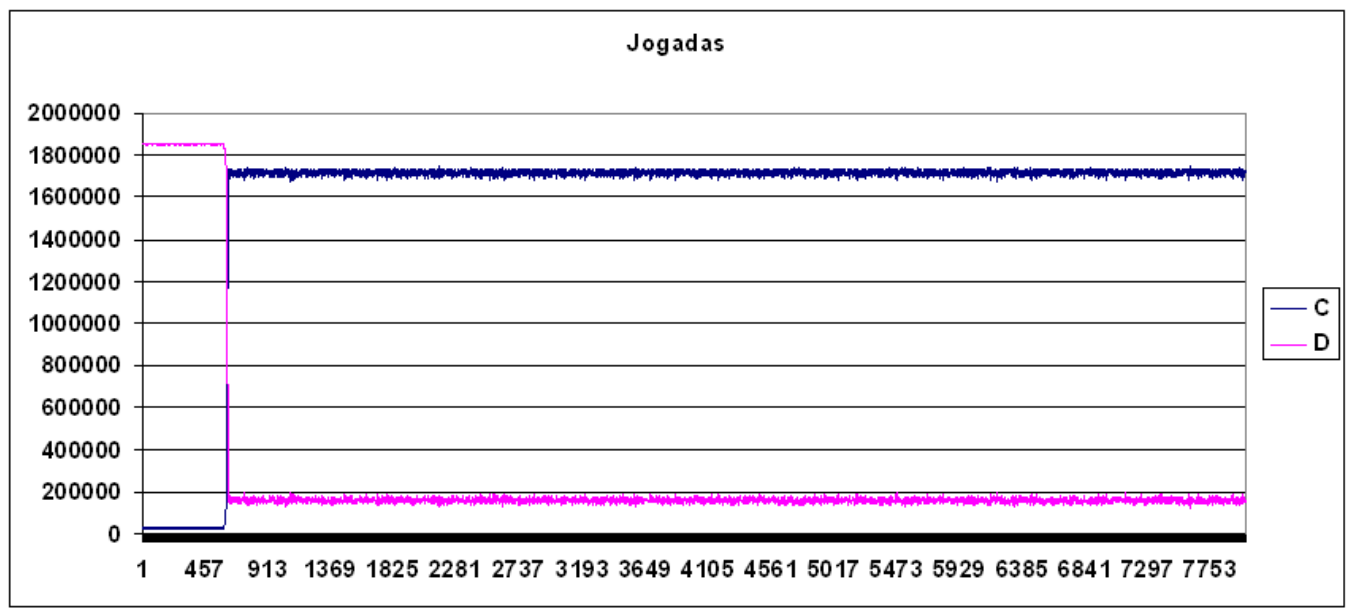

Figura 7.6: Jogadas feitas pelos agentes para a simulação 2 da bateria 1 de 8000 gerações do modelo $\mathbf{J E}+\mathbf{A F}$

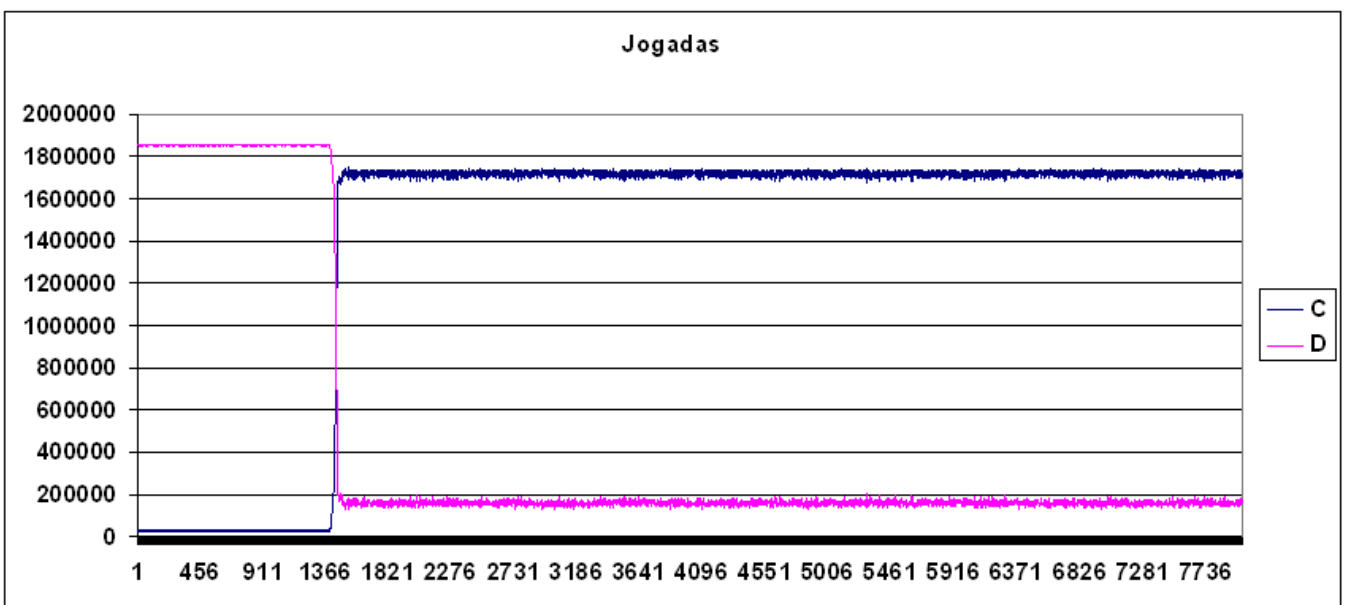

Figura 7.7: Jogadas feitas pelos agentes para a simulação 3 da bateria 1 de 8000 gerações do modelo $\mathbf{J E}+\mathbf{A F}$

centenas de estratégias distintas, algumas cores do gráfico são utilizadas mais de uma vez. As indicações das estratégias no gráfico, entretanto, ajudam na compreensão do mesmo.

A primeira observação a ser feita é que a estratégia inicial U predomina fortemente durante as primeiras 850 gerações. A explicação deste fenômeno é simples: estratégias com comportamento cooperativo surgem através de mutações isoladamente, mas estas terão um desempenho pior do que aquelas que priorizam a não cooperação. Para que um agente com uma estratégia que jogue $\mathbf{C}$ em algum momento tenha um melhor desempenho, ele deve ter como vizinho ao menos um outro agente que também jogue C. Esse é o motivo pelo qual passam-se diversas gerações onde a sociedade tem um baixo desempenho até que a dinâmica da cooperação se altere. 


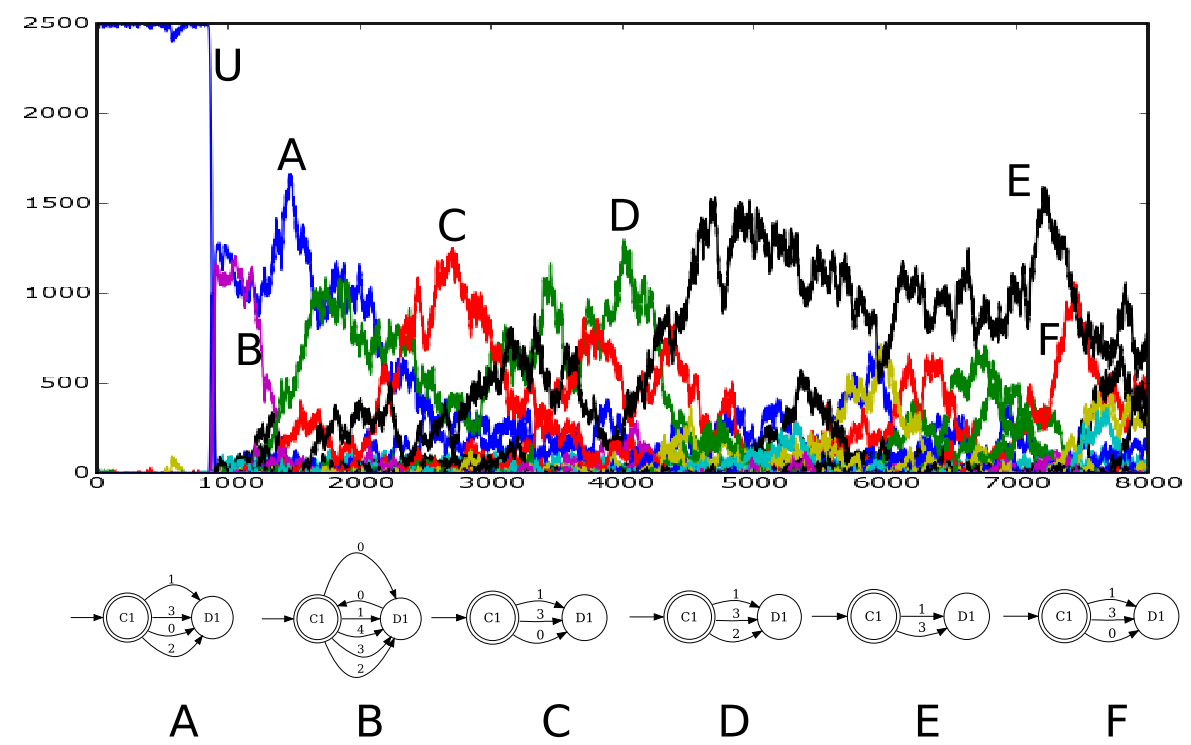

Figura 7.8: População de estratégias da simulação 1 da bateria 1 de 8000 gerações do modelo $\mathbf{J E}+\mathbf{A F}$

A partir da geração 850, entretanto, observa-se uma rápida queda na população da estratégia $\mathbf{U}$, sendo esta substituída por duas outras estratégias: uma que inicia jogando $\mathbf{C}$, assim permanecendo até que um outro vizinho jogue $\mathbf{D}$ e a partir de então passa a jogar $\mathbf{D}$ indefinidamente $(\mathbf{A})$; e uma outra que joga $\mathbf{C}$ na primeira rodada, passando então a jogar $\mathbf{D}$, só voltando a jogar $\mathbf{C}$ quando todos jogarem D (B). A existência de um grande número de agentes com a estratégia B explica o período intermediário com um nível menor do que aquele alcançado a partir da geração 850 mostrado na figura 7.2. Devido ao fato de haver coexistência de agentes com essas duas estratégias, não há um nível suficientemente alto de jogadas cooperativas entre os agentes, dado que parte deles possui a estratégia B, que pára de jogar $\mathbf{C}$ mesmo quando todos assim fizeram.

A partir da geração 1450, entretanto, a sociedade alcança um nível máximo de utilidade, que persiste com oscilações até o fim da simulação. Isso, entretanto, não é causado pela predominância de apenas uma estratégia, como pode ser visto na figura 7.8. O que se observa é uma alternância constante entre diversas estratégias (como as $\mathbf{C , D}, \mathbf{E}$ e $\mathbf{F}$ ), que resulta, entretanto, num mesmo resultado global. Como podem ser observadas na figura, todas essas estratégias possuem um comportamento em comum: iniciam jogando $\mathbf{C}$ e, caso um determinado número de outros agentes joguem $\mathbf{D}$, passam a jogar $\mathbf{D}$ indefinidamente.

De forma a visualizar melhor como ocorre espacialmente essa transição, foram feitos mapas que indicam o nível de cooperação dos agentes, mostrados na figura 7.9. Neles são reproduzidos os reticulados onde os agentes estão distribuídos, sendo cada pequeno quadrado neles uma célula, que contém um agente. A co- 


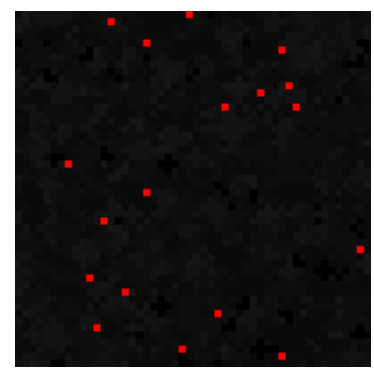

(a) Geração 1

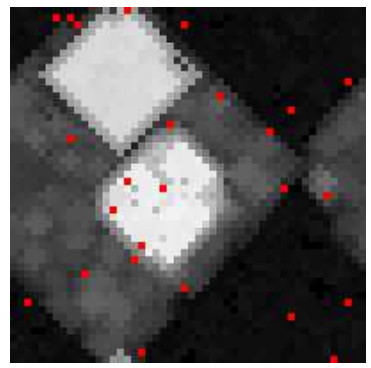

(d) Geração 880

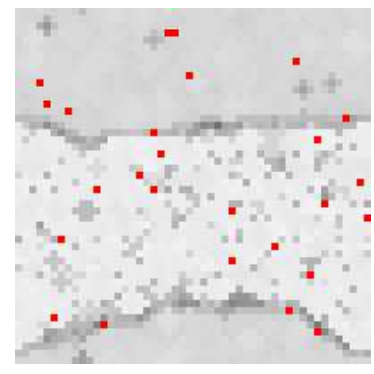

(g) Geração 1216

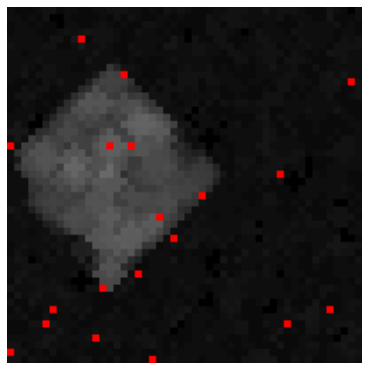

(b) Geração 868

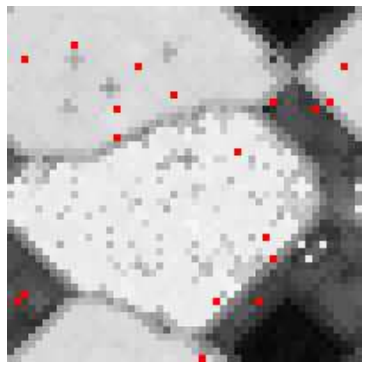

(e) Geração 894

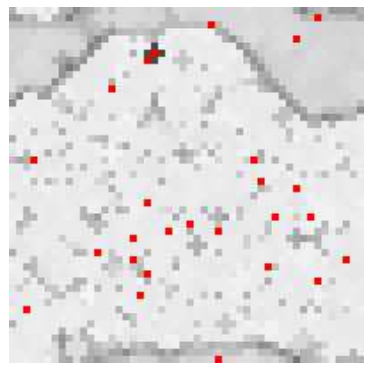

(h) Geração 1351

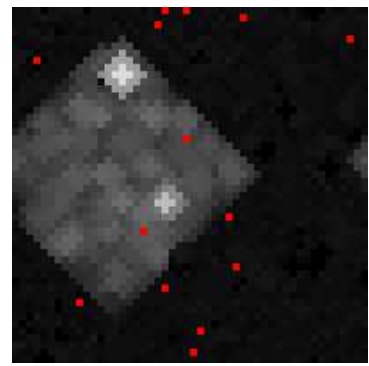

(c) Geração 872

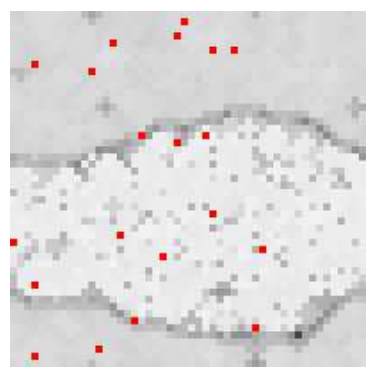

(f) Geração 908

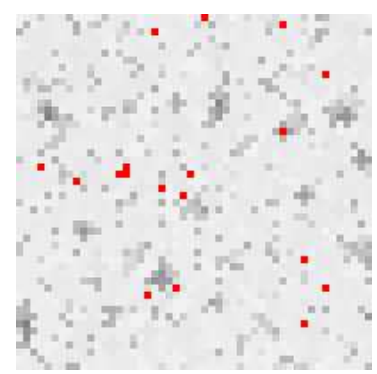

(i) Geração 1451

Figura 7.9: Mapas de jogadas e da localização das mutações para a simulação 1 da bateria 1 de simulações de 8000 gerações do modelo $\mathbf{J E}+\mathbf{A F}$

loração de cada célula indica a proporção de jogadas $\mathbf{C}$ feitas pelo agente na geração indicada: quanto mais clara, maior a proporção. Pontos em vermelho indicam os locais onde ocorreram mutações.

Na primeira geração (figura 7.9(a)), vê-se que as jogadas são quase que em sua totalidade $\mathbf{D}$, assim persistindo por mais de 800 gerações. Na geração 868 (figura 7.9(b)), nota-se a disseminação de estratégias com maior proporção de jogadas C. A partir de então, mutações que ocorrem em dois pontos distintos do reticulado geram as duas estratégias indicadas pelas letras $\mathbf{A}$ e $\mathbf{B}$ da figura 7.8, que rapidamente ocupam quase que a totalidade do mapa (figuras 7.9(c), 7.9(d), $7.9(\mathrm{e})$ e $7.9(\mathrm{f}))$.

Nesse momento, e durante cerca de 500 gerações, observa-se uma coexistência de agentes com as duas estratégias, com uma fronteira nítida entre as duas. 
É de particular interesse notar que a coloração média dos agentes das duas é diferente: há uma parte mais escura e homogênea, e uma mais clara, porém mais heterogênea. A observação das figuras 7.9(f), 7.9(g), 7.9(h) e 7.9(i) juntamente com o gráfico da população de estratégias leva à conclusão de que tratam-se das estratégias B e A da figura 7.8, respectivamente. Através dessa visualização, torna-se possível verificar uma característica que diferencia as duas estratégias: o grupo de agentes que possuem a estratégia B, embora obtenham um nível menor de utilidade, apresentam resultados mais estáveis que o grupo que utiliza a estratégia A. Após algumas gerações, entretanto, a estratégia $\mathbf{A}$ lentamente ocupa o espaço da B (figuras $7.9(\mathrm{~g})$ e $7.9(\mathrm{~h})$ ), passando a ser predominante na sociedade (figura 7.9(i)).

A partir da geração 1451, os mapas de jogadas permanecem com as mesmas características do da figura 7.9(i), mostrando que, embora haja oscilações na população de outras estratégias, a configuração da cooperação observada na sociedade permanece a mesma, o que corrobora a relativa estabilidade observada na utilidade dos agentes a partir desse momento.

As figuras 7.10 e 7.11, que mostram o gráfico de população de estratégias para as duas outras simulações da primeira bateria mostram o mesmo fenômeno: após uma abrupta queda na população da estratégia inicial, há predominância de estratégias que iniciam jogando $\mathbf{C}$ e, após uma dada quantidade de agentes jogarem $\mathbf{D}$, passa a jogar $\mathbf{D}$ indefinidamente.
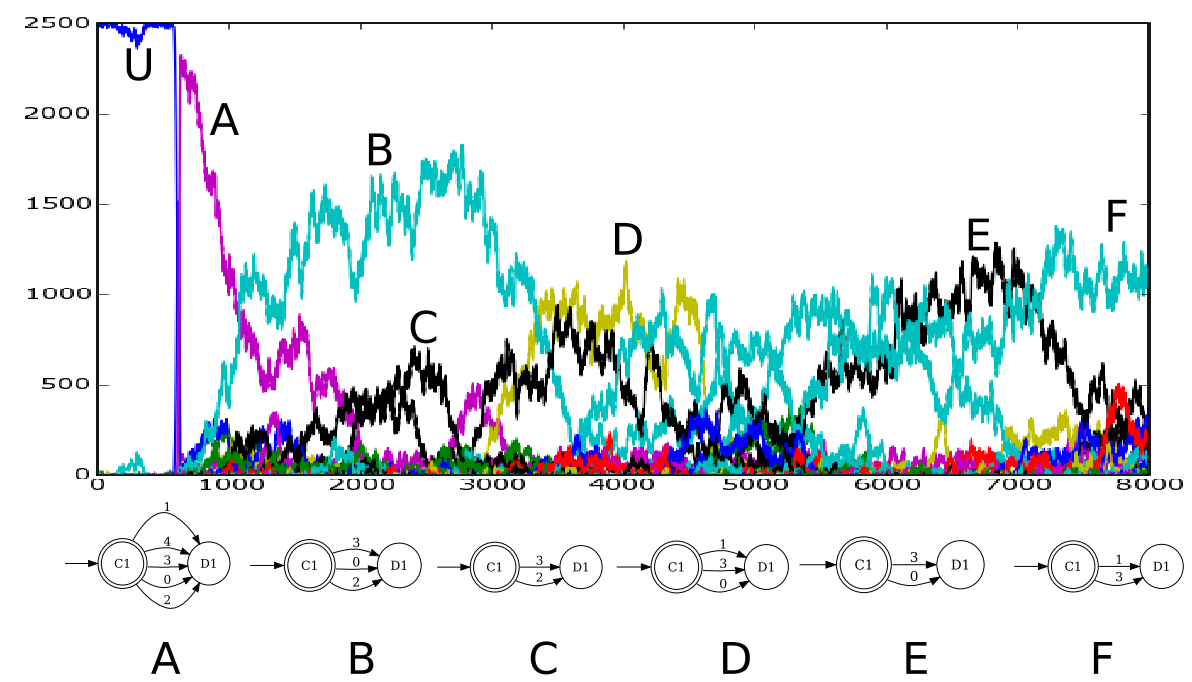

Figura 7.10: População de estratégias da simulação 2 da bateria 1 de 8000 gerações do modelo $\mathbf{J E}+\mathbf{A F}$

Os mapas de jogadas das outras duas simulações efetuadas sob as mesmas condições são semelhantes aos anteriores analisados para a primeira bateria, com 


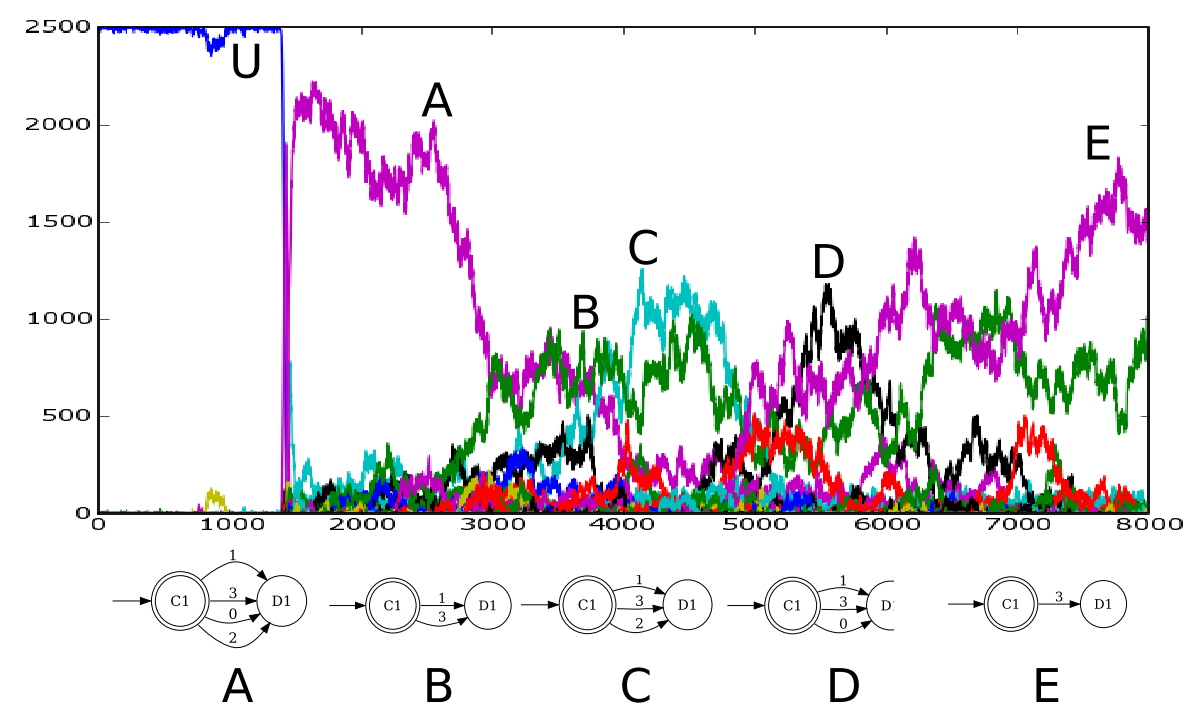

Figura 7.11: População de estratégias da simulação 3 da bateria 1 de 8000 gerações do modelo $\mathbf{J E}+\mathbf{A F}$

a exceção do fato de que não é observada uma coexistência de duas populações diferentes por um longo tempo como na primeira simulação, sendo a estratégia inicial substituída rapidamente por outras semelhantes à estratégia A.

O resultado observado nesta primeira bateria é, portanto, equivalente ao obtido em (LINDGREN; JOHANSSON, 2003). Na simulação apresentada nesse trabalho, após 1000 gerações a estratégia predominante na sociedade inicia cooperando e assim permanece enquanto um ou todos os outros agentes também cooperam. Na simulação 2 (figura 7.10), observa-se que essa mesma estratégia predomina após 1000 gerações, por exemplo. Como as simulações feitas neste trabalho tiveram um horizonte temporal maior, verifica-se que com o passar do tempo estratégias semelhantes, com variação no número de agentes jogando $\mathbf{D}$ necessários para passar a jogar $\mathbf{D}$, oscilam sua população, em um processo não-estacionário da população de estratégias. Essas oscilações entre instâncias dessa família de estratégias, entretanto, não se refletem em mudanças significativas na utilidade global dos agentes.

A primeira bateria de simulações do modelo $\mathbf{J E}+\mathbf{A F}$ conseguiu, portanto, reproduzir com sucesso os resultados obtidos em (LINDGREN; JOHANSSON, 2003): há inicialmente uma queda rápida da população de estratégias inicial, que é substituída por outras estratégias que possuem uma característica em comum: iniciam cooperando e, caso um dentre determinados números de agentes não cooperarem, passa a não cooperar indefinidamente. Essa classe de estratégias será doravante designada por CDIND (jogar C, passando a jogar D indefinidamente caso $\mathbf{N}$ outros agentes jogarem $\mathbf{D})$. Como resultado dessa mudança nas estratégias dos 
agentes, a maioria das jogadas efetuadas por eles passa a ser de cooperação, permanecendo assim até o fim. Esse resultado mostrou, ainda, que a introdução de erros de entendimento e enganos ${ }^{1}$ com o valor adotado para $P_{e}$ não levou a um resultado significativamente diferente daquele apresentado em (LINDGREN; JOHANSSON, 2003).

A classe de estratégias CDIND, entretanto, tem um comportamento contraintuitivo: não seria melhor uma estratégia que tivesse a capacidade de retomar a cooperação, como a tit-for-tat no DP? Teria a dinâmica do modelo impedido o surgimento de uma estratégia equivalente para o DPNP, ou o horizonte de simulação não foi grande o suficiente para permitir que esse tipo de estratégia surja?

\subsubsection{Segunda bateria de testes}

Para responder à pergunta proposta na seção 7.2.1, executou-se uma segunda bateria de testes, na qual os agentes iniciam com a estratégia TT5. As duas simulações dessa segunda bateria foram executadas por 5000 gerações, utilizando os mesmos valores para todos os outros parâmetros.

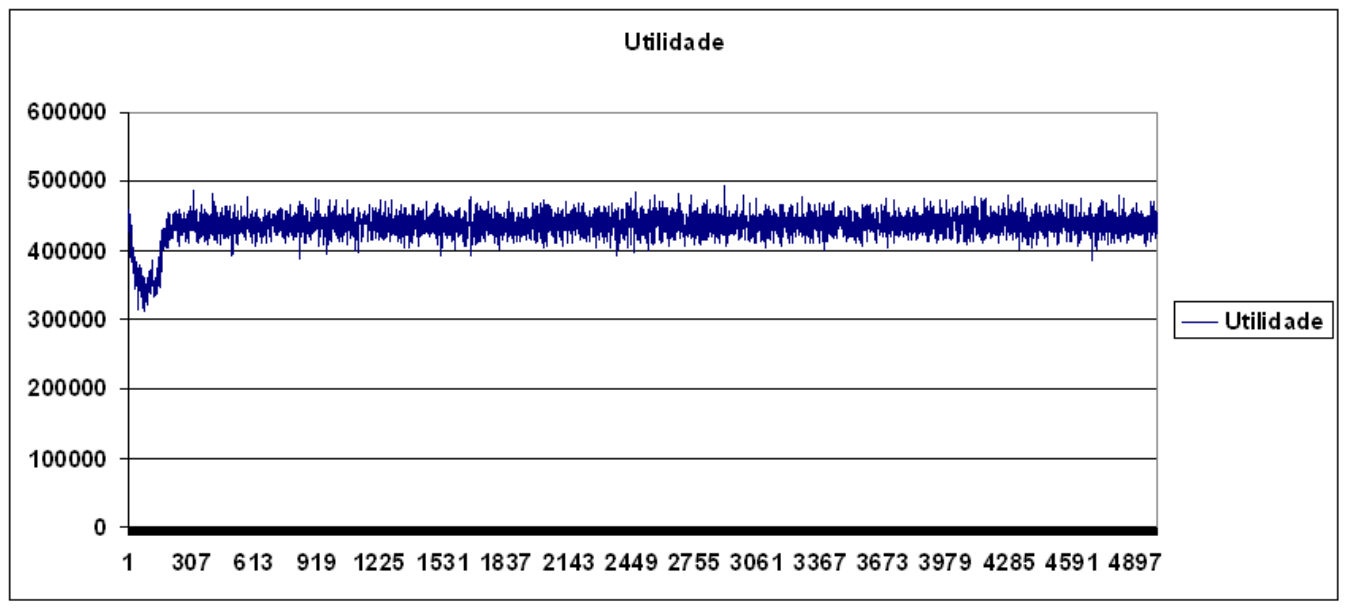

Figura 7.12: Utilidade total dos agentes para a simulação 1 da bateria 2 de 5000 gerações do modelo $\mathbf{J E}+\mathbf{A F}$

As figuras 7.12 e 7.13 mostram o gráfico de utilidade total dos agentes para as duas simulações. Ambas apresentam o mesmo comportamento: logo nas primeiras gerações há uma pequena queda no nível da utilidade, que posteriormente é recuperado, seguindo assim até o fim da simulação. As figuras 7.14 e 7.15, que mostram as jogadas feitas pelos agentes, exibem uma situação equivalente no número de jogadas cooperativas.

\footnotetext{
${ }^{1}$ Descritos na seção 5.1 .
} 


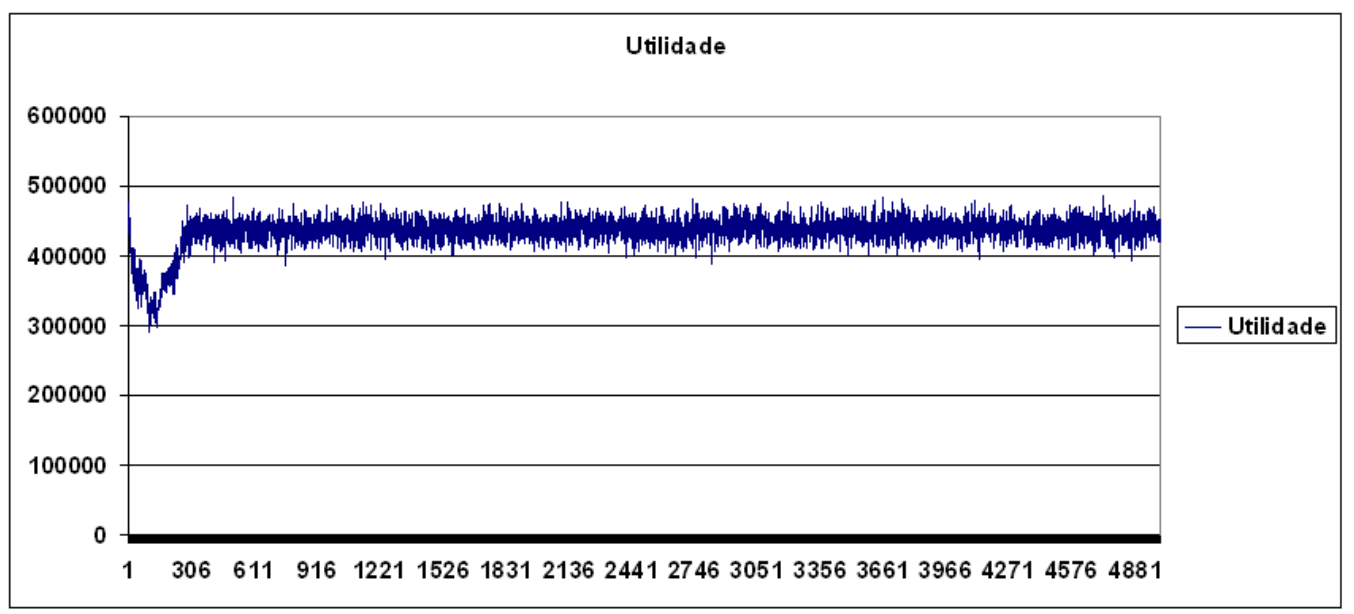

Figura 7.13: Utilidade total dos agentes para a simulação 2 da bateria 2 de 5000 gerações do modelo $\mathbf{J E}+\mathbf{A F}$

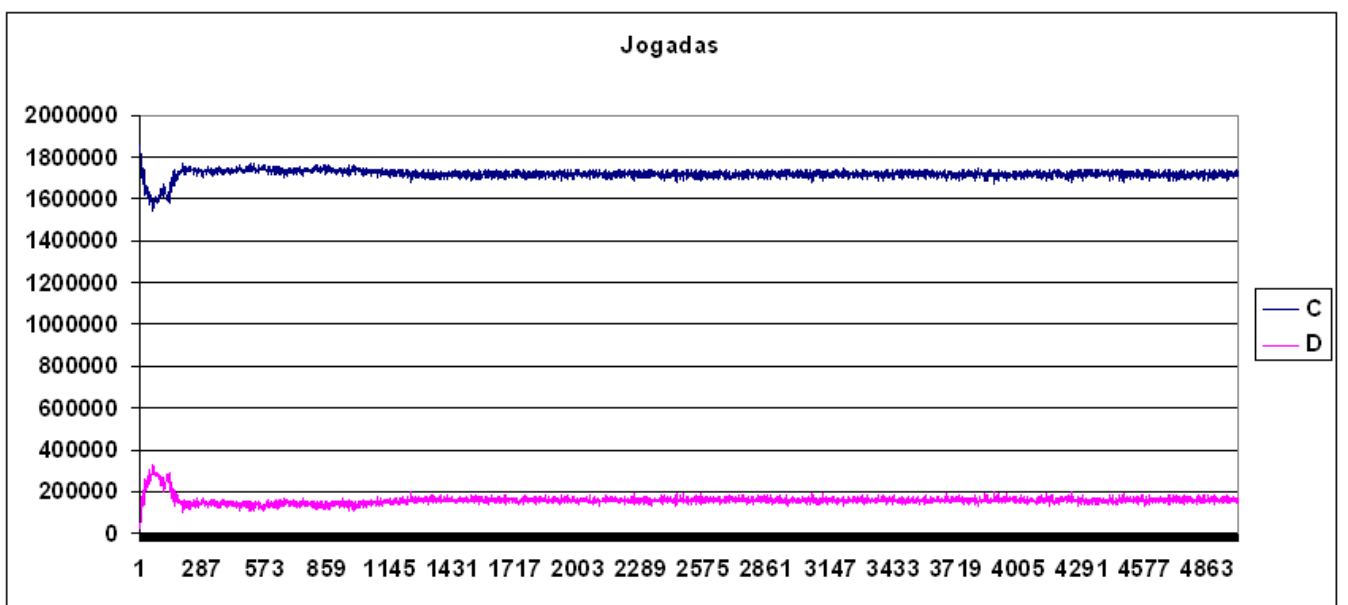

Figura 7.14: Jogadas feitas pelos agentes para a simulação 1 da bateria 2 de 5000 gerações do modelo $\mathbf{J E}+\mathbf{A F}$

Os gráficos da população de estratégias para ambas as simulações (figuras 7.16 e 7.17), mostram que a estratégia inicial TT5 desaparece rapidamente da sociedade, sendo substituída, assim como na primeira bateria de simulações, por estratégias da classe CDIND. Neste caso, entretanto, a queda foi ainda mais rápida, indo de 2500 para 126 agentes com a estratégia inicial em apenas 80 gerações na simulação 1, ocorrendo de forma semelhante na simulação 2. Vemos, portanto, que a estratégia TT5 é fraca neste ambiente evolutivo.

Os mapas de jogadas (figura 7.18) mostram que, embora inicialmente a sociedade tenha uma alta proporção de jogadas cooperativas, ocorrem situações em que vários grupos de agentes não cooperam ao longo de toda a rodada múltipla (figura 7.18(b)). Com isso, outras estratégias mais estáveis passam a ganhar espaço (figuras 7.18(c), 7.18(d) e 7.18(e)), antes de estratégias do tipo CDIND passarem a predominar (figura $7.18(\mathrm{f})$ ). 


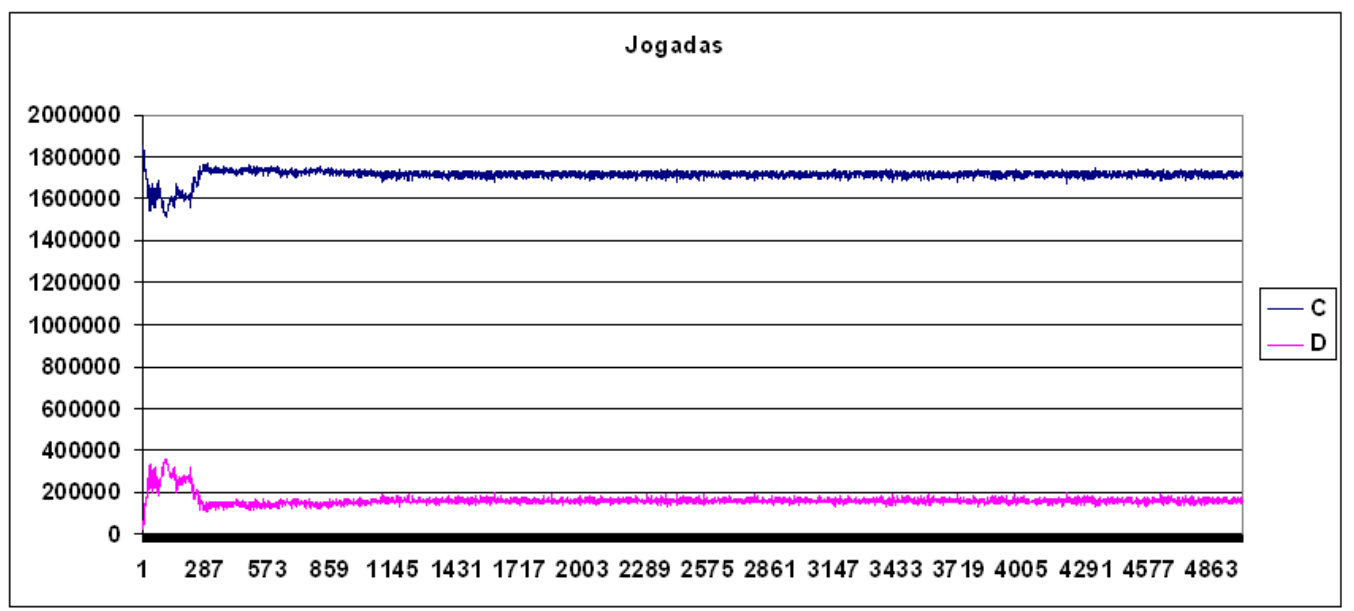

Figura 7.15: Jogadas feitas pelos agentes para a simulação 2 da bateria 2 de 5000 gerações do modelo $\mathbf{J E}+\mathbf{A F}$

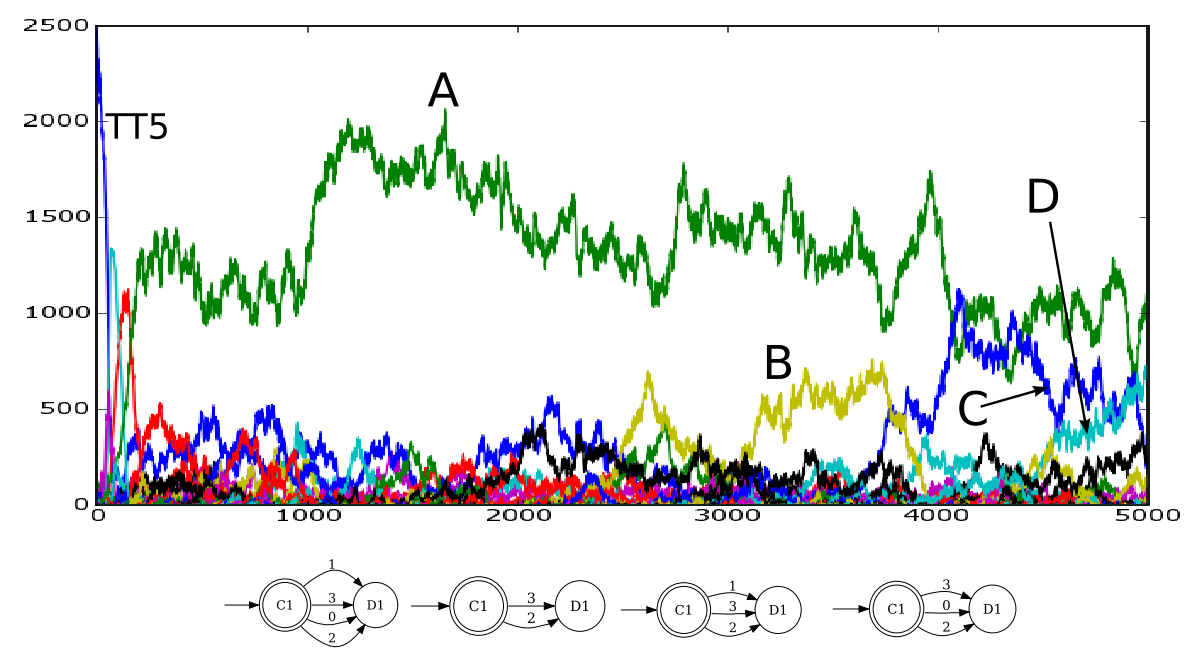

A

B

C

D

Figura 7.16: População de estratégias da simulação 1 da bateria 2 de 5000 gerações do modelo $\mathbf{J E}+\mathbf{A F}$

\subsubsection{Síntese dos resultados}

Os resultados agregados das simulações do modelo $\mathbf{J E}+\mathbf{A F}$ são sumarizados na tabela 7.2. Nesta tabela, apresentam-se para as duas baterias as médias e desviospadrões das utilidades totais obtidas pelos agentes, bem como suas jogadas, após alcançar-se o equilíbrio. Indica-se também a geração em que esse equilíbrio é alcançado.

Nota-se que esses resultados indicam não haver diferença significativa na utilidade total dos agentes, assim como em suas jogadas, tanto ao comparar-se simulações de uma mesma bateria quanto ao comparar-se simulações de duas baterias diferentes. Esses resultados mostram, portanto, que não houve uma influência nos resultados de longo-prazo ao se utilizar estratégias iniciais distintas 


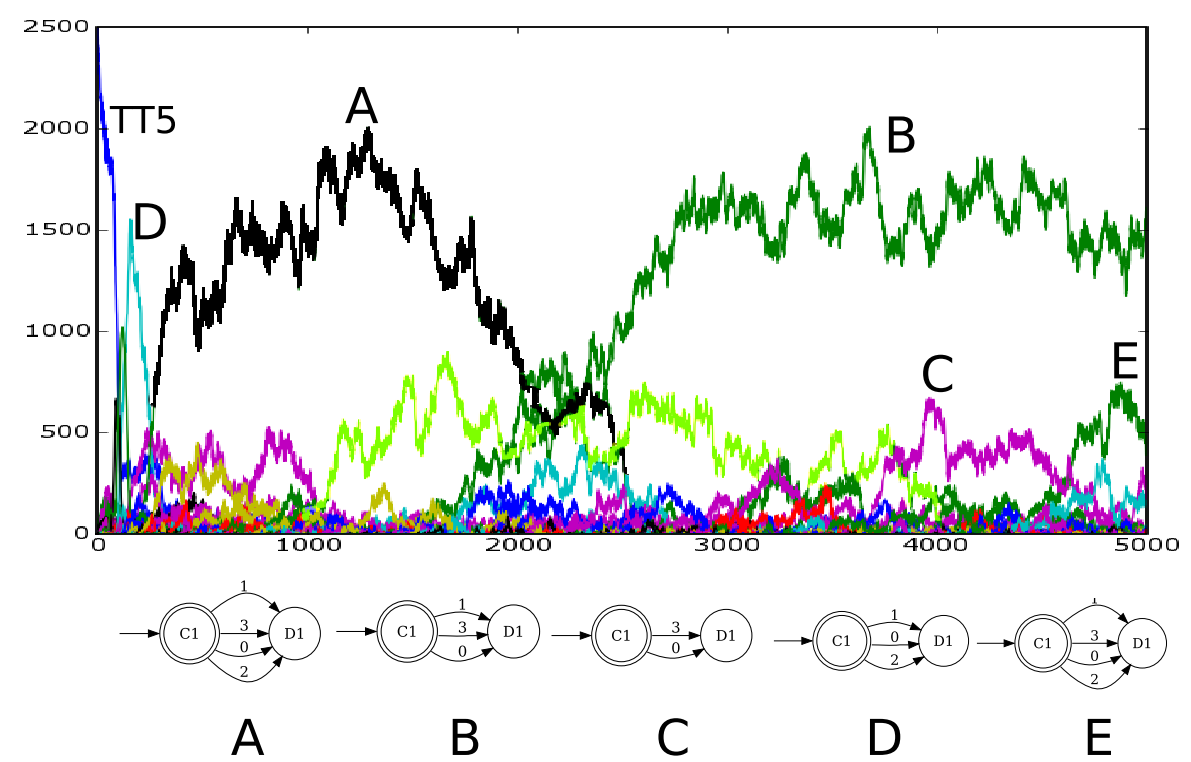

Figura 7.17: População de estratégias da simulação 2 da bateria 2 de 5000 gerações do modelo $\mathbf{J E}+\mathbf{A F}$

\begin{tabular}{|c||c|c|c|||c|c|}
\hline \multicolumn{1}{|c||}{} & \multicolumn{2}{c||}{ Bateria 1 (8000 gerações) } & \multicolumn{2}{c|}{ Bateria 2 (5000 gerações) } \\
\hline & Sim 1 & Sim 2 & Sim 3 & Sim 1 & Sim 2 \\
\hline \hline Util (média) & 439338 & 439210 & 439201 & 439891 & 437631 \\
\hline Util (desv padrão) & 13703 & 14103 & 13702 & 13262 & 13781 \\
\hline Jogs C (média) & 1715334 & 1715493 & 1715879 & 1719255 & 1718034 \\
\hline Jogs C (desv padrão) & 10436 & 10433 & 10380 & 13512 & 12223 \\
\hline Jogs D (média) & 159668 & 159505 & 159121 & 155745 & 156966 \\
\hline Jogs D (desv padrão) & 10436 & 10434 & 10381 & 13512 & 12224 \\
\hline $\begin{array}{c}\text { Gerações até sit. } \\
\text { estacionária }\end{array}$ & 1461 & 668 & 1497 & 224 & 277 \\
\hline
\end{tabular}

Tabela 7.2: Sumário dos resultados das simulações do modelo JE+AF Valores após o equilíbrio

(U na primeira bateria e TT5 na segunda bateria). De fato, a análise das estratégias mostrou que em ambas as baterias as estratégias que predominam na sociedade são aquelas da classe CDIND.

A principal diferença observada entre as simulações das duas baterias, portanto, foi na dinâmica anterior ao equilíbrio. Enquanto na bateria 1 observa-se em média mais de 1200 gerações até atingir-se o equilíbrio, nas simulações da bateria 2 este é alcançado mais rapidamente, após cerca de 250 gerações. Isso provavelmente se deve ao fato de que na primeira bateria a sociedade parte de um estado de ampla não-cooperação. Trata-se de uma situação que impede o desenvolvimento e disseminação de estratégias cooperativas que surgirem isoladamente, pois os agentes que as possuirem, como minoria, estarão em desvantagem em relação àqueles que simplesmente não cooperarem. Assim, a sociedade permanecerá não cooperando enquanto não surgir um grupo de agentes vizinhos 


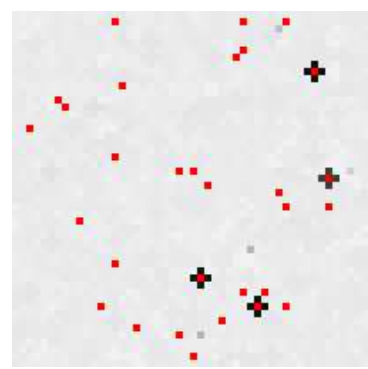

(a) Geração 2

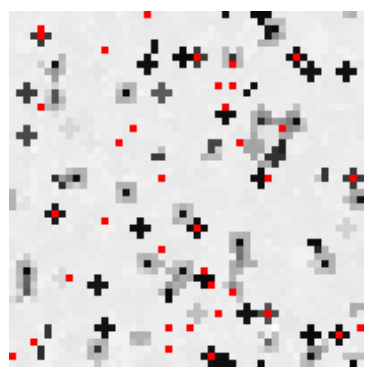

(b) Geração 26

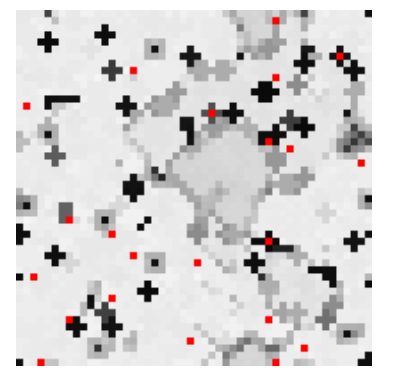

(c) Geração 48

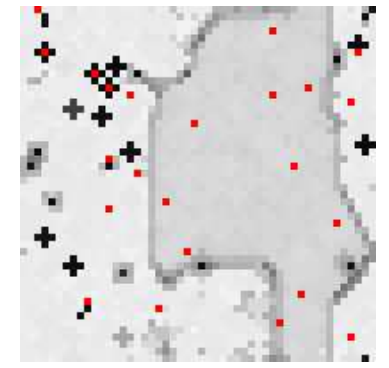

(d) Geração 100

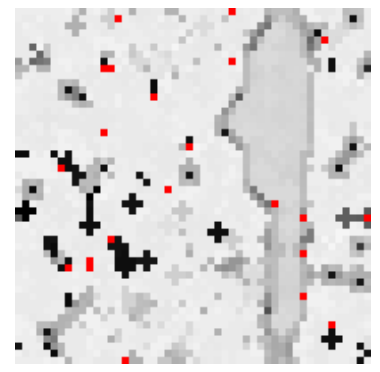

(e) Geração 136

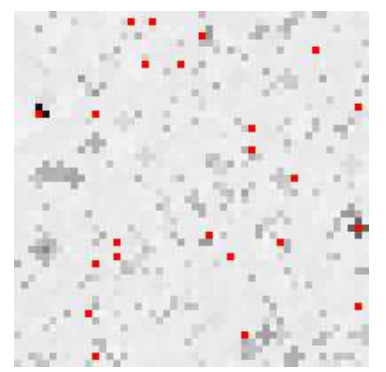

(f) Geração 224

Figura 7.18: Mapas de jogadas e da localização das mutações para a simulação 1 da bateria 2 de 5000 gerações do modelo $\mathbf{J E}+\mathbf{A F}$

que cooperem entre si em um número suficiente. A partir desse momento, assim como mostrado em (GLANCE; HUBERMAN, 1994), ocorre uma transição rápida para uma situação de ampla cooperação.

Nas simulações da bateria 2, por outro lado, os agentes já iniciam com uma estratégia que privilegia a cooperação. Dessa forma, estratégias com características cooperativas conseguem prosperar mais facilmente nesse ambiente, levando a sociedade a alcançar um equilíbrio de longo-prazo mais rapidamente.

O fato de as estratégias que predominam em ambos os casos apresentarem um comportamento que à primeira vista soa "pouco inteligente", por não possuírem uma forma de restabelecer a cooperação dentro de uma rodada múltipla, leva à conclusão de que, neste modelo, a sociedade desenvolveu um mecanismo de manutenção da cooperação baseado na sucessão de gerações. Ao invés de ainda dentro 
de uma geração apresentar mecanismos para o restabelecimento da cooperação, a manutenção da mesma é feita através das gerações, onde agentes se "sacrificam" não cooperando até o fim da geração como forma de eliminar estratégias que não cooperem. Trata-se de um resultado interessante, dado que não existe, na especificação do modelo, um benefício para os agentes decorrente de um "bem-estar social" maior. Esse resultado pode, portanto, ser visto como um comportamento emergente no modelo sob essas especificações.

\subsection{Experimentos com o modelo JE+AA}

Analogamente à abordagem adotada para o modelo $\mathbf{J E}+\mathbf{A F}$, também foram realizadas duas baterias de testes para o modelo $\mathbf{J E}+\mathbf{A A}$, cujos resultados são descritos a seguir.

\subsubsection{Primeira bateria de testes}

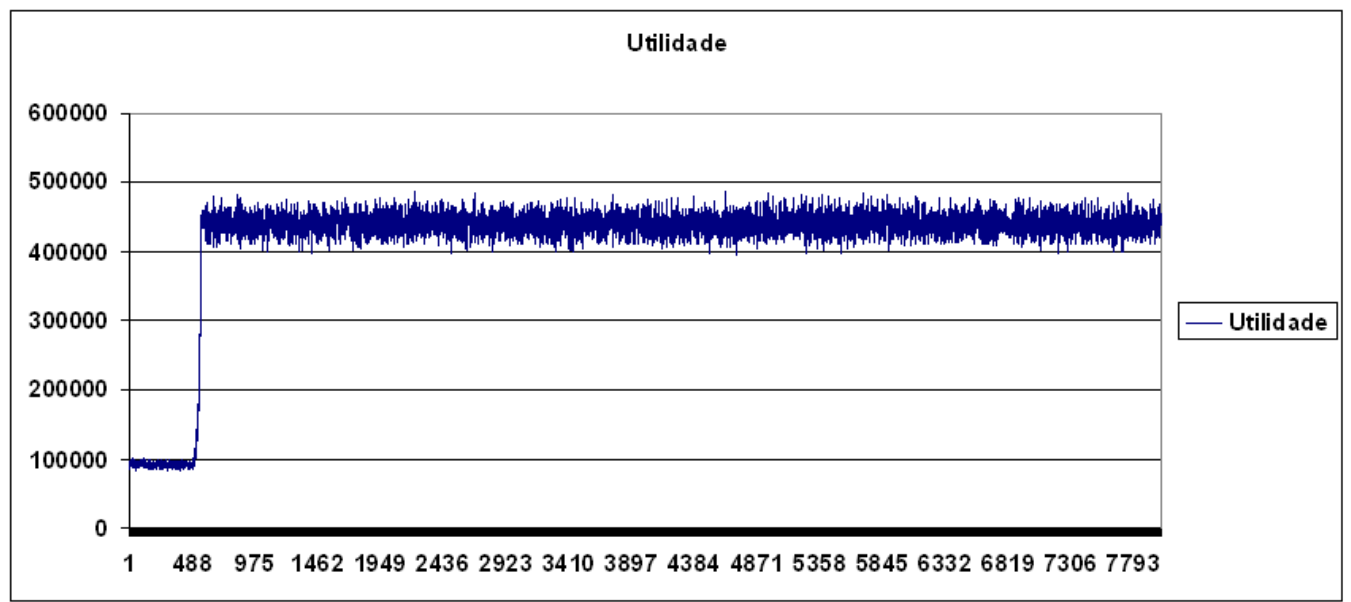

Figura 7.19: Utilidade total dos agentes para a simulação 1 da bateria 1 de 8000 gerações do modelo JE+AA

As figuras 7.19, 7.20 e 7.21 mostram os gráficos da utilidade acumulada para a primeira bateria de simulações do modelo $\mathbf{J E}+\mathbf{A A}$, composta por 8000 gerações, onde a estratégia inicial $\mathbf{U}$ dos agentes é a mesma utilizada na primeira bateria do modelo JE+AF. Nela verifica-se que os resultados são semelhantes aos das simulações anteriores: após um início com baixo nível de utilidade dos agentes, há uma rápida transição para uma situação razoavelmente estável em um nível mais alto de utilidade. Nota-se, portanto, que a utilização do modelo simplificado de AAs para a representação das estratégias dos agentes não parece ter alterado a dinâmica do modelo, ao menos na variável em consideração. A velocidade com 


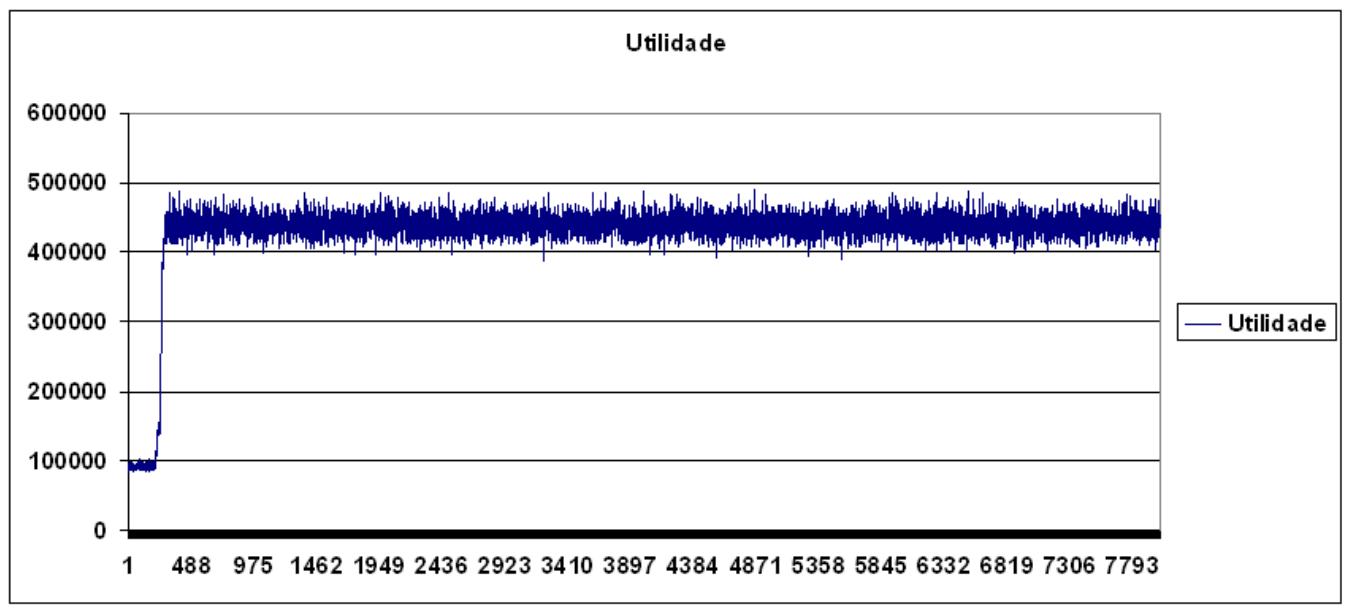

Figura 7.20: Utilidade total dos agentes para a simulação 2 da bateria 1 de 8000 gerações do modelo $\mathbf{J E}+\mathbf{A A}$

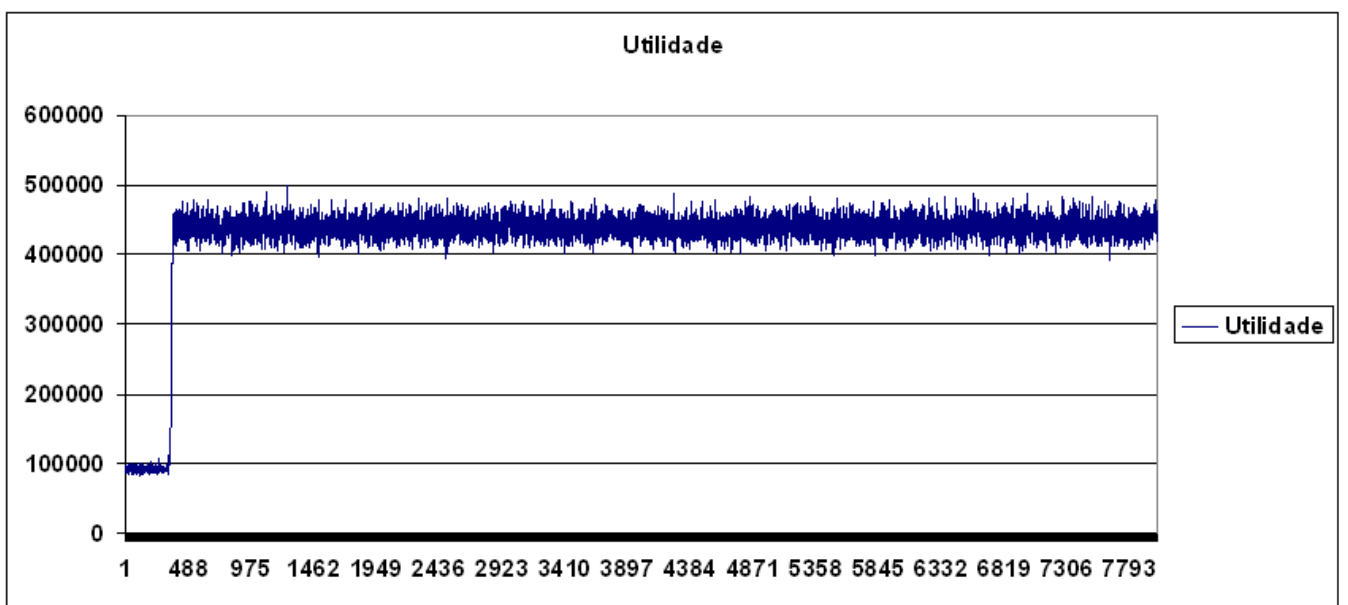

Figura 7.21: Utilidade total dos agentes para a simulação 3 da bateria 1 de 8000 gerações do modelo $\mathbf{J E}+\mathbf{A A}$

que os agentes atingem esse nível, entretando, é maior: as figuras 7.19, 7.20 e 7.21 mostram que os agentes neste modelo alcançam a cooperação mais rapidamente.

Da mesma forma, as jogadas efetuadas pelos agentes, mostradas nas figuras 7.22, 7.23 e 7.24, apresentam o mesmo comportamento: após um início onde a maioria das jogadas são $\mathbf{D}$, a sociedade passa rapidamente por uma transição onde a maioria das jogadas passam a ser cooperativas $(\mathbf{C})$.

Devido ao fato de não existir um método de minimização de AAs, não é possível traçar um gráfico de população de estratégias para o modelo JE+AA, pois nele estratégias que são na prática iguais, porém com implementação diferente, apareceriam como estratégias distintas. Optou-se então por verificar, para cada período de 1000 gerações, quais são as duas estratégias predominantes na sociedade. As representações gráficas das estrategias predominantes para cada um desses períodos nesta bateria de testes são mostradas no apêndice deste trabalho. 


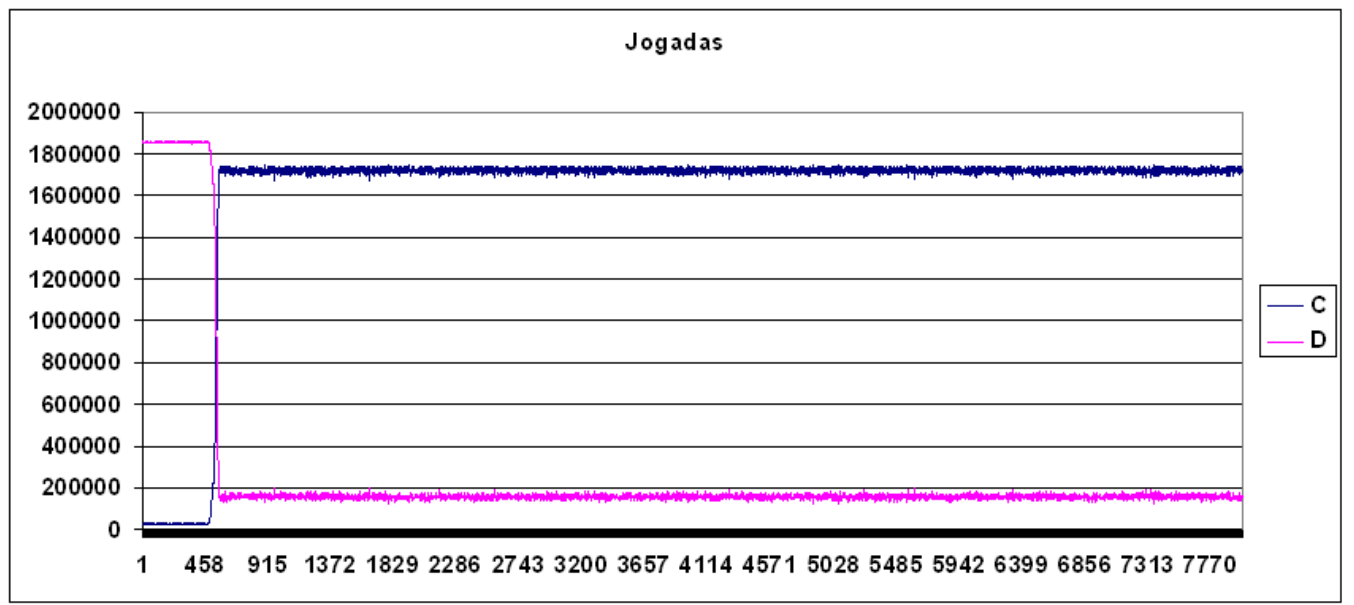

Figura 7.22: Jogadas feitas pelos agentes para a simulação 1 da bateria 1 de 8000 gerações do modelo $\mathbf{J E}+\mathbf{A A}$

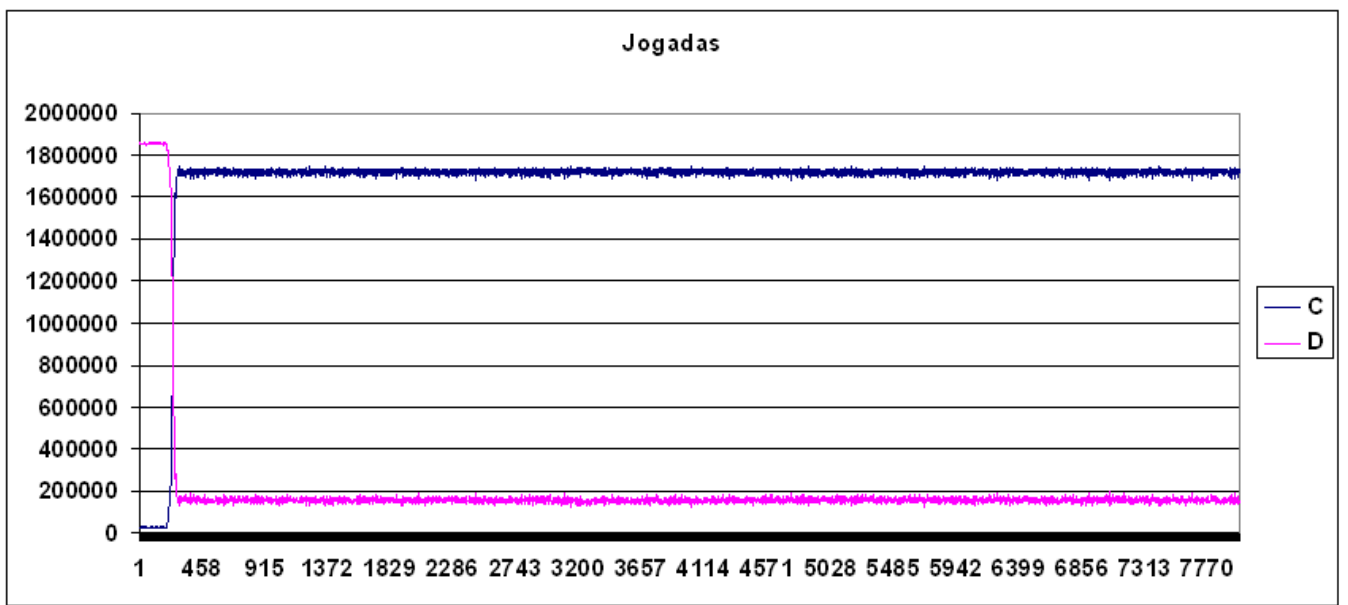

Figura 7.23: Jogadas feitas pelos agentes para a simulação 2 da bateria 1 de 8000 gerações do modelo $\mathbf{J E}+\mathbf{A A}$

A primeira observação feita foi que o uso de funções adaptativas cresce ao longo do tempo. Como o valor descontado pelo multiplicador complexityPrice depende apenas do número de estados, não há desestímulo para um agente utilizar uma estratégia que contenha várias delas, mesmo que suas ações sejam inócuas.

Ao analisar essas estratégias, é importante lembrar que a execução de uma ação adaptativa de remoção $(\mathbf{R})$ é ignorada se ela se refere a uma transição que não existe. Por exemplo, a segunda estratégia predominante na geração 2000 da simulação 1 (figura 7.25) possui a seguinte função adaptativa na transição $(C 5,2, D 2)$ :

$R(C 5,0$, C_ref2)

$R\left(D 2,3, D \_r e f 1\right)$

Como já existe a transição $(C 5,0, D 2)$, e esta não vai para um estado de tipo 


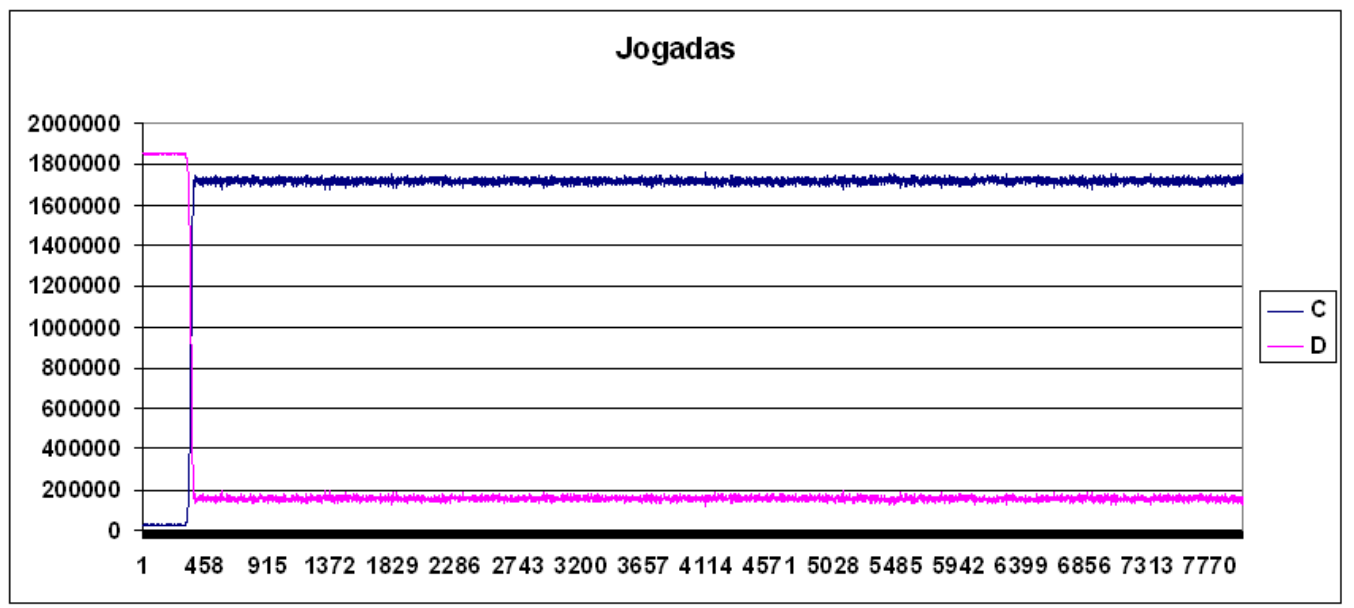

Figura 7.24: Jogadas feitas pelos agentes para a simulação 3 da bateria 1 de 8000 gerações do modelo JE+AA

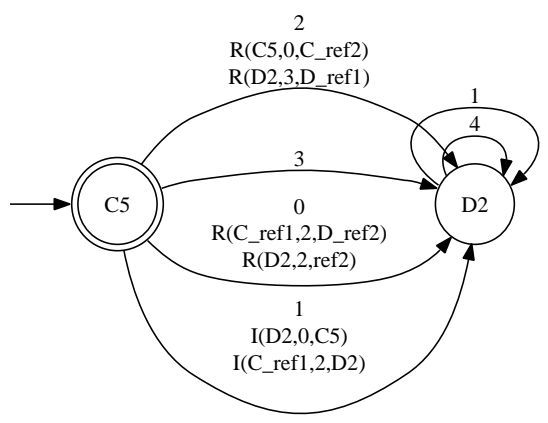

Figura 7.25: Segunda estratégia predominante na geração 2000 da simulação 1 da bateria 1 do modelo $\mathbf{J E}+\mathbf{A A}$

C, C_ref2 não recebe nenhum valor e essa ação será simplesmente ignorada. E como $(D 2,3, D 2)$ já leva para D2, a segunda ação, embora executada, não altera em nada a estrutura do autômato. A estratégia que esse autômato implementa pertence, na prática, à família CDIND.

Diferentemente das simulações feitas com o modelo $\mathbf{J E}+\mathbf{A F}$, entretanto, muitas das estratégias que predominam nas simulações do modelo $\mathbf{J E}+\mathbf{A A}$ apresentam comportamentos diferentes das estratégias da classe CDIND. A seguir são dados dois exemplos desse tipo de comportamento em estratégias que predominaram nas simulações do modelo $\mathbf{J E}+\mathbf{A A}$.

A figura 7.26 mostra a estratégia predominante ao fim da simulação 3 da primeira bateria do modelo $\mathbf{J E}+\mathbf{A A}$. De forma a analisar o comportamento da mesma, primeiro deve-se verificar quais ações adaptativas podem ser ignoradas. Para tanto, basta verificar para cada uma delas se a estrutura do autômato é de fato alterada por sua execução.

Iniciando pela função presente na transição $(C 7,4, C 7)$, verifica-se que: 


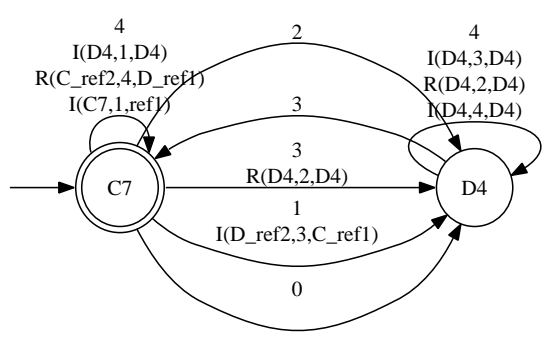

Figura 7.26: Estratégia predominante na geração 8000 da simulação 3 da bateria 1 do modelo $\mathbf{J E}+\mathbf{A A}$

- A primeira ação, I(D4,1,D4) não altera a estrutura do autômato, pois $(D 4,1, D 4)$ já está presente, e não há no autômato nenhuma outra ação que altere a transição saindo de D4 para a entrada 1. Dessa forma, essa ação pode ser ignorada.

- A segunda ação, R(C_ref2,4,D_ref1), refere-se a uma transição não existente, tanto na estrutura inicial do autômato quanto após a execução de qualquer outra ação adaptativa do mesmo. Assim, essa ação também pode ser ignorada.

- A terceira ação, I (C7, 1, ref1) tem como um dos parâmetros uma variável por referência de utilização de valor que não teve seu valor definido. Isso ocorre porque a ação anterior, onde a variável D_ref1 definiria o valor de ref1 é abortada. Como nesta ação ref1 não possui um valor definido, esta ação também será abortada.

Após aplicar esse processo para todas as funções adaptativas do autômato, concluiu-se que apenas uma ação altera funcionalmente a estrutura do autômato, presente na transição $(D 4,4, D 4)$ : I (D4, 3, D4). Isso significa que, caso o estado corrente seja $\mathbf{D} 4$ e a entrada for 4 , a transição $(D 4,3, C 7)$ é removida, de forma que não mais seria possível voltar a $\mathbf{C} 7$ estando em $\mathbf{D} 4$.

Dois exemplos de seqüência de entradas são dados a seguir para ilustrar as conseqüências desse comportamento:

\section{Exemplo 1}

Supondo que a seqüência de entradas para o autômato ao longo de quatro rodadas seja $(4,3,3,4)$, os estados correntes do autômato seguem a seqüência $(C 7, C 7, D 4, C 7, C 7)$, gerando portanto as jogadas $(C, C, D, C, C)$, sem ocorrer nenhuma alteração funcional no autômato no processo. Nota-se, portanto, que neste exemplo o possuidor da estratégia voltou a jogar $\mathbf{C}$ após ter jogado $\mathbf{D}$ e três outros jogadores jogarem $\mathbf{C}$. 


\section{Exemplo 2}

Se a seqüência, entretanto, for $(4,3,4,3)$, após a terceira entrada a função adaptativa presente na transição $(D 4,4, D 4)$ é executada, alterando a estrutura do autômato para aquela mostrada na figura 7.27. Com isso, diferentemente do primeiro exemplo, neste caso o agente não mais volta a jogar $\mathbf{C}$ quando três outros jogadores jogarem $\mathbf{C}$.

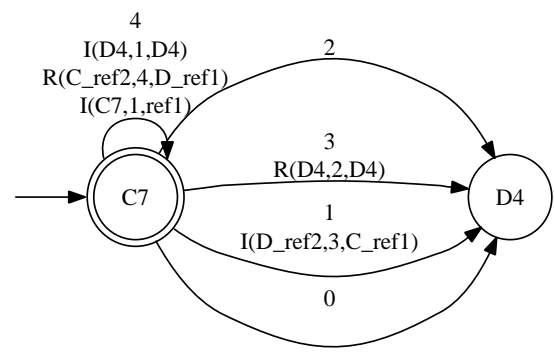

Figura 7.27: Estratégia predominante na geração 8000 da simulação 3 da bateria 1 do modelo $\mathbf{J E}+\mathbf{A A}$ após a execução da função adaptativa da transição $(D 4,4, D 4)$

A figura 7.28 mostra a estratégia predominante na geração 7000 da simulação 2 da primeira bateria do modelo $\mathbf{J E}+\mathbf{A A}$. Aplicando o mesmo processo utilizado no exemplo anterior para eliminar as ações que não alteram funcionalmente a estrutura do autômato, apenas 6 das 15 ações podem ser ignoradas:

- A ação R(C_ref2,3,C5) da transição $(C 5,4, C 5)$

- A ação R(D2, 4,C_ref2) da transição $(C 5,1, C 5)$

- As ações R(C_ref2,0,C_ref1) e R(D2,0,C5) da transição $(C 5,2, D 2)$

- As ações $\mathrm{R}(\mathrm{C} 5,1, \mathrm{D} 2)$ e $\mathrm{R}(\mathrm{D} 2,0$, ref2) da transição $(C 5,0, D 2)$

Dois exemplos de seqüência de entradas são dados a seguir para ilustrar o comportamento dessa estratégia:

\section{Exemplo 1}

Supondo que a seqüência de entradas para o autômato ao longo de quatro rodadas seja $(4,4,3,4)$, logo após a primeira rodada a estrutura do autômato é alterada para aquela mostrada na figura 7.29, permanecendo entretanto C5 como o estado corrente.

As rodadas seguintes, com entradas $(4,3,4)$, não mais alteram a estrutura do autômato, gerando a seqüência de estados correntes $(C 5, D 2, D 2)$. Nota-se, 


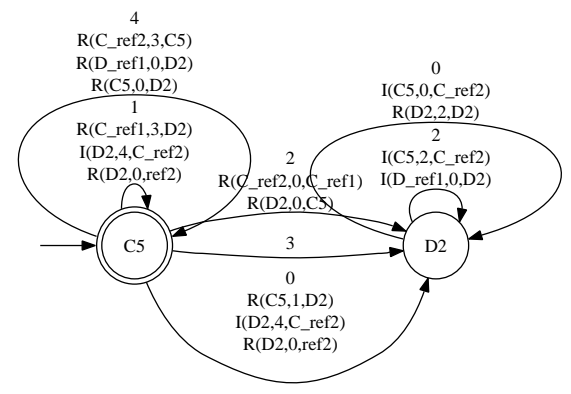

Figura 7.28: Estratégia predominante na geração 7000 da simulação 2 da bateria 1 do modelo $\mathbf{J E}+\mathbf{A A}$

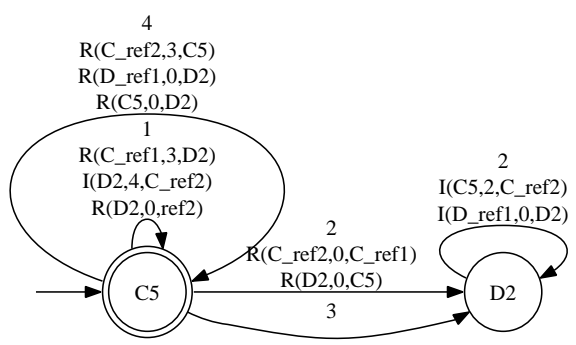

Figura 7.29: Estratégia predominante na geração 7000 da simulação 2 da bateria 1 do modelo $\mathbf{J E}+\mathbf{A A}$ após a execução da função adaptativa da transição $(C 5,4, C 5)$

portanto, que para esta seqüência de rodadas, ocorreu uma situação em que o agente estava jogando $\mathbf{D}$, todos os outros jogaram $\mathbf{C}$ e ele permaneceu jogando D.

\section{Exemplo 2}

Se a seqüência, entretanto, for $(0,4,3,4)$, verifica-se uma situação diferente. Logo após a primeira rodada a função adaptativa da transição $(C 5,0, C 5)$ é executada, alterando a estrutura do autômato para aquela vista na figura 7.30, e alterando o estado corrente para D2. É criado, portanto, um novo estado C6 que recebe a transição $(D 2,4, C 6)$. Dessa forma, o restante da seqüência de entradas leva a uma seqüência de estados correntes $(C 6, C 6, C 6)$.

Nesta última seqüência, portanto, ocorreu uma situação em que o agente em questão jogou $\mathbf{D}$, todos os outros jogaram $\mathbf{C}$ e conseqüentemente ele também passou a jogar $\mathbf{C}$.

Nota-se, portanto, que as estratégias predominantes no modelo $\mathbf{J E}+\mathbf{A A}$ apresentam comportamentos diversos e complexos. Como pôde ser visto através de análises semelhantes aos exemplos apresentados para as outras estratégias predominantes ao longo das simulações, com o tempo a maioria delas desenvolve mecanismos que possibilitam a volta à cooperação mesmo após ter efetuado jo- 


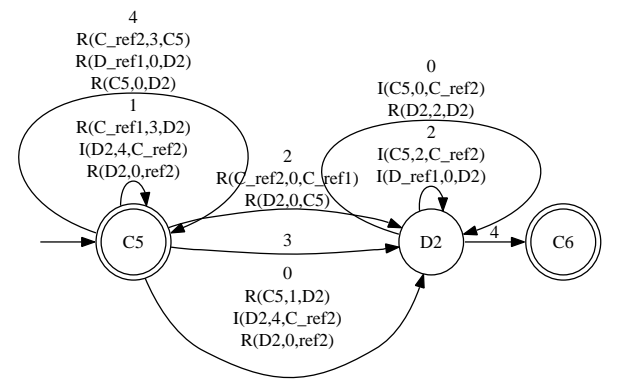

Figura 7.30: Estratégia predominante na geração 7000 da simulação 2 da bateria 1 do modelo $\mathbf{J E}+\mathbf{A A}$ após a execução da função adaptativa da transição $(C 5,0, C 5)$

gadas D, algo não observado no modelo anterior.

Essas classe de estratégias, implementadas através de AAs, que iniciam jogando $\mathbf{C}$ e podem voltar a jogar $\mathbf{C}$ quando se está jogando $\mathbf{D}$, caso seja observadas algumas seqüências específicas de jogadas por parte dos outros agentes será doravante denominada CRCDE ( inicia jogando $\mathbf{C}$, podendo ainda retornar a jogar $\mathbf{C}$ após ter jogado $\mathbf{D}$ sob condições específicas).

Os mapas de cooperação entre os agentes (figura 7.31) para a simulação 1 mostram que a forma pela qual a cooperação foi atingida e mantida espacialmente é a mesma observada no modelo $\mathbf{J E}+\mathbf{A F}$ : partindo de uma situação de baixa cooperação, estratégias com uma proporção um pouco maior de jogadas cooperativas passam a se espalhar pela sociedade. Nesse contexto, uma mutação em um grupo de agentes permite uma maior cooperação entre os agentes pertencentes a este grupo, levando-os a obter maior utilidade que seus vizinhos, e portanto disseminando estratégias que proporcionam maior cooperação entre os que a obtêm.

\subsubsection{Segunda bateria de testes}

Assim como para o modelo $\mathbf{J E}+\mathbf{A F}$, foi efetuada uma segunda bateria de testes, onde a estratégia inicial dos agentes é a CCD, detalhada na seção 5.3. Essa bateria foi composta por duas simulações de 5000 gerações. As figuras 7.32 e 7.33 mostram os gráficos das utilidades obtidas pelos agentes ao longo das gerações, e nas figuras 7.22 e 7.23 são mostrados os gráficos das jogadas efetuadas pelos agentes nesse mesmo período.

Nestes gráficos observa-se que, em ambas as simulações, há uma estabilidade tanto na utilidade total dos agentes, que permanece em um nível alto do início ao fim do período simulado, quanto nas jogadas efetuadas pelos mesmos. Como 


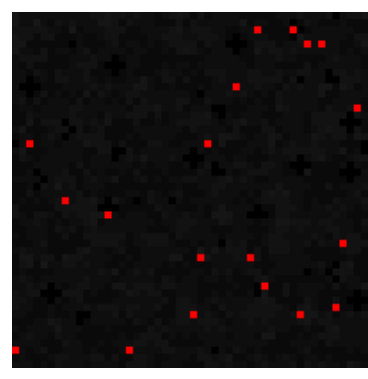

(a) Geração 1

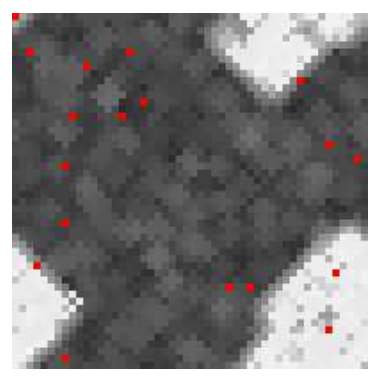

(d) Geração 530

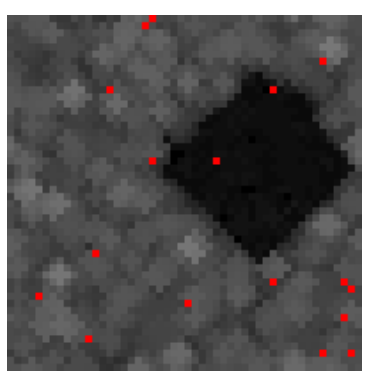

(b) Geração 516

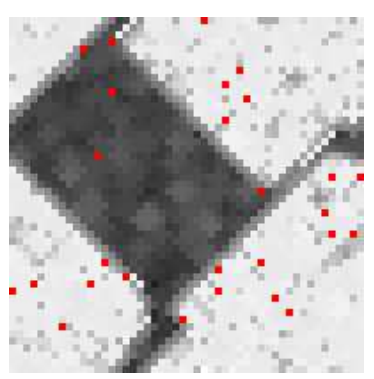

(e) Geração 542

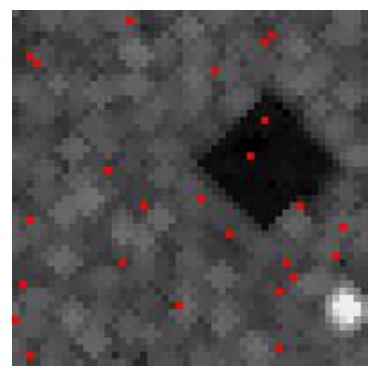

(c) Geração 520

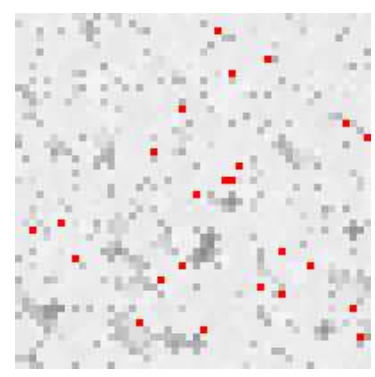

(f) Geração 560

Figura 7.31: Mapas de jogadas e da localização das mutações para a simulação 1 da bateria 1 de 8000 gerações do modelo JE+AA

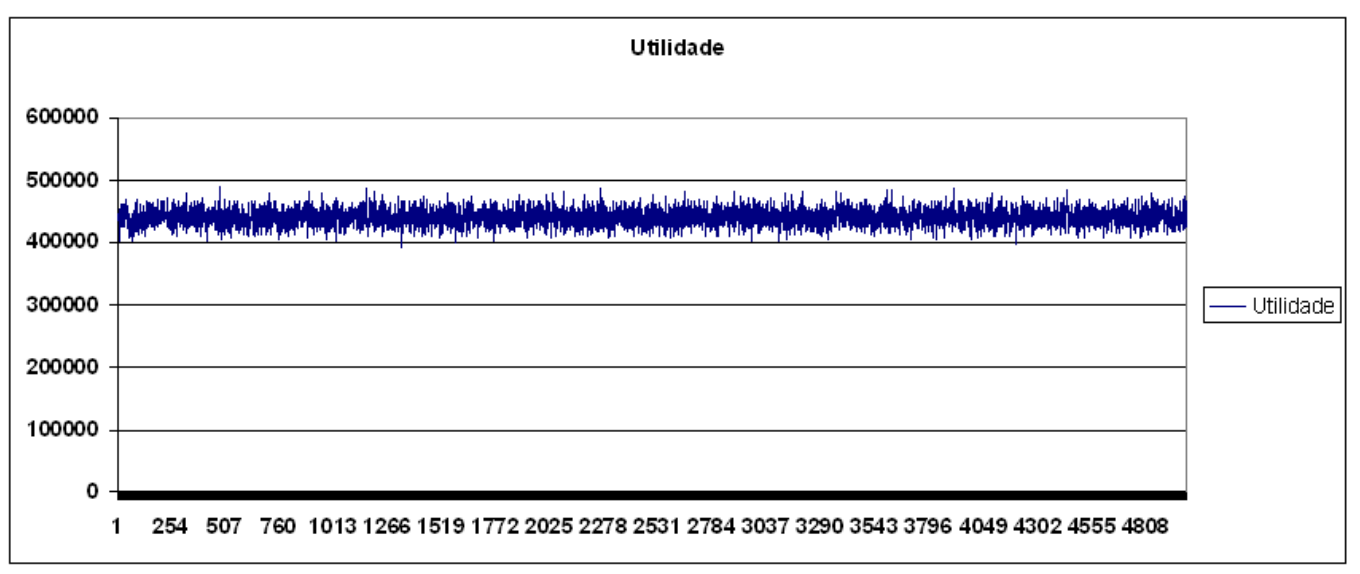

Figura 7.32: Utilidade total dos agentes para a simulação 1 da bateria 2 de 5000 gerações do modelo $\mathbf{J E}+\mathbf{A A}$ 


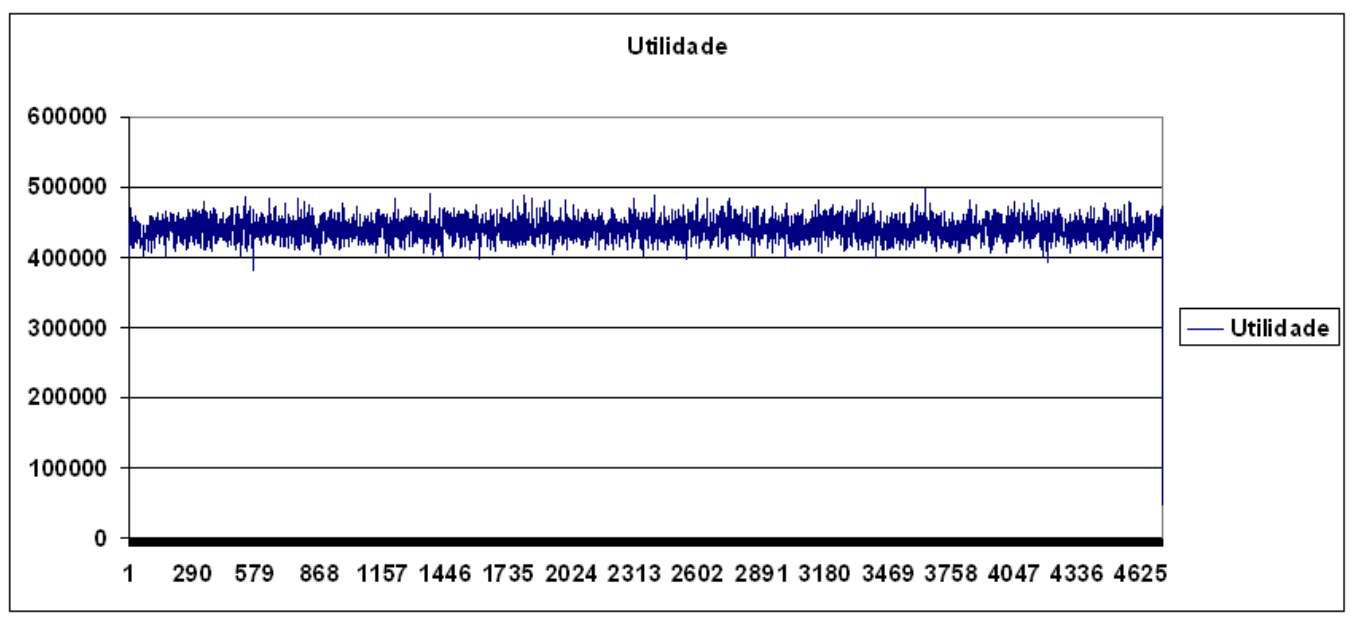

Figura 7.33: Utilidade total dos agentes para a simulação 2 da bateria 2 de 5000 gerações do modelo $\mathbf{J E}+\mathbf{A A}$

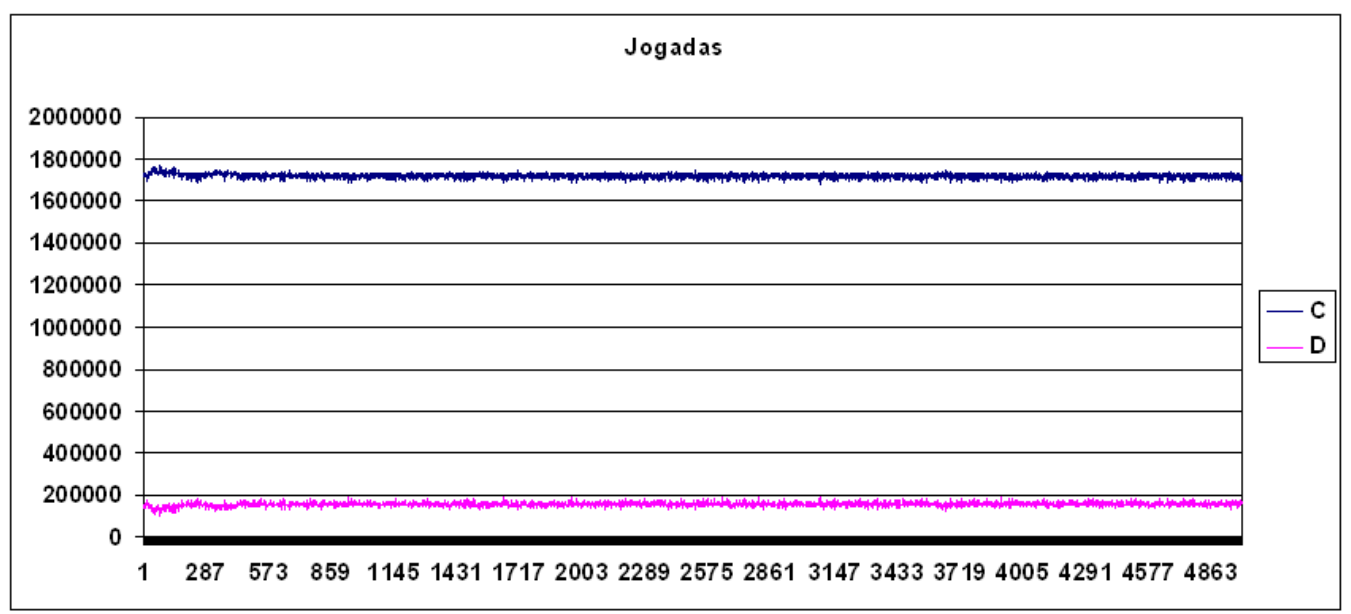

Figura 7.34: Jogadas feitas pelos agentes para a simulação 1 da bateria 2 de 5000 gerações do modelo $\mathbf{J E}+\mathbf{A A}$

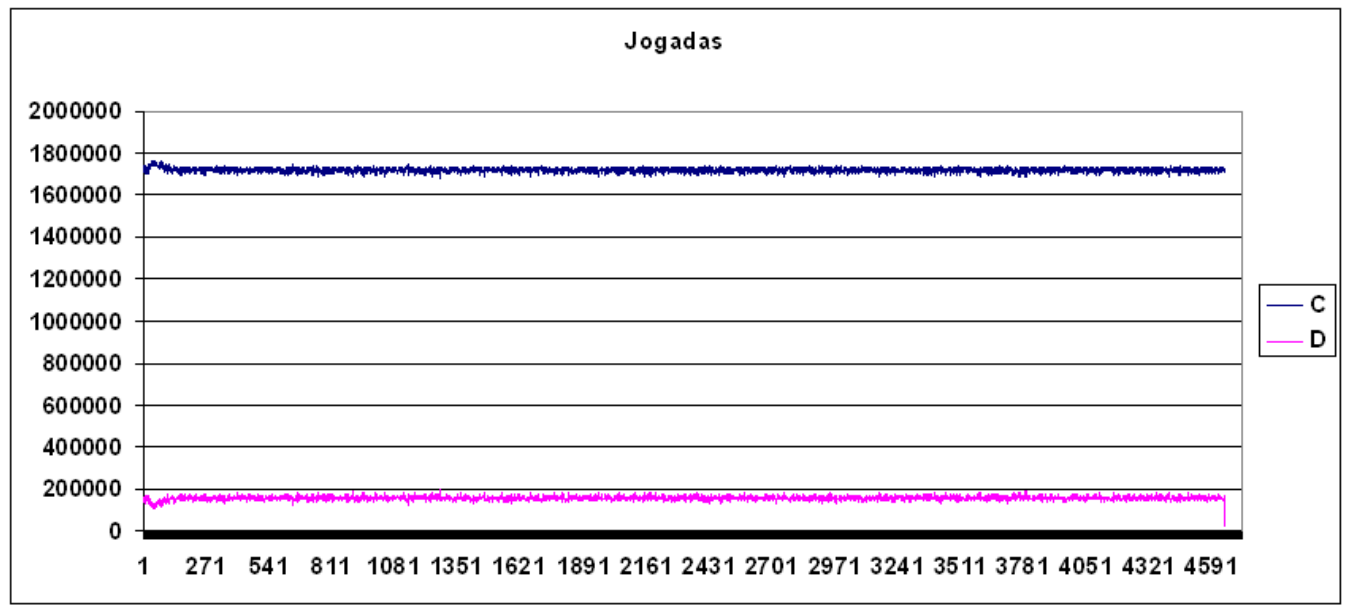

Figura 7.35: Jogadas feitas pelos agentes para a simulação 2 da bateria 2 de 5000 gerações do modelo $\mathbf{J E}+\mathbf{A A}$ 


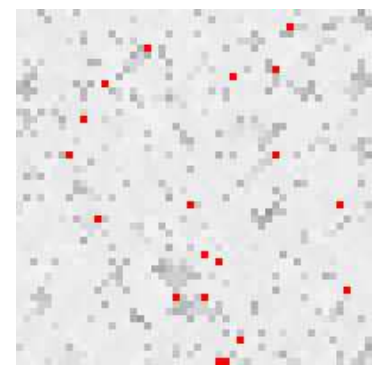

(a) Geração 1

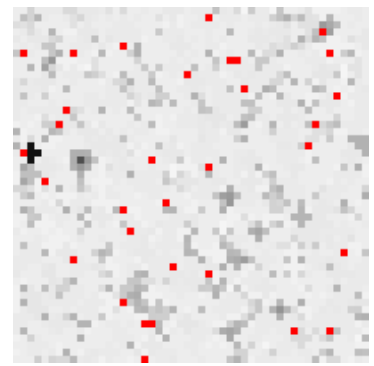

(b) Geração 500

Figura 7.36: Mapas de jogadas e da localização das mutações para a simulação 1 da bateria 2 de 5000 gerações do modelo JE+AA

a estratégia inicial tem um comportamento cooperativo que entretanto pune proporcionalmente a falta de cooperação por parte de outros agentes, a utilidade inicial dos agentes é alta e mantida ao longo do tempo.

A análise das estratégias predominantes nas simulações, entretanto, mostra que essa estratégia é substituída rapidamente por outras da classe CRCDE, assim como na primeira bateria do modelo JE+AA. Os mapas da cooperação entre os agentes não mostram dinâmicas identificáveis, permanecendo com o tipo de configuração obsevada na figura 7.36 por toda a simulação.

\subsubsection{Síntese dos resultados}

Os resultados agregados das simulações do modelo JE+AA para os dados observados após o equilíbrio estão sumarizados na tabela 7.3. Nela observa-se que, assim como no caso do modelo $\mathbf{J E}+\mathbf{A F}$, a mudança na estratégia inicial utilizada pelos agentes não resultou em diferenças nos valores de equilíbrio obtidos no longo-prazo.

A dinâmica observada até alcançar-se o equilíbrio, entretanto, é diferente. Enquanto nas simulações da primeira bateria observa-se um período de transição antes de atingir-se o equilíbrio, levando-se em média mais de 420 gerações até alcançá-lo, nas simulações da bateria 2 a sociedade já inicia no nível de equilíbrio para as variáveis.

Como foi observado na análise das estratégias predominantes, nessa segunda bateria a estratégia inicial CCD é substituída por outras da classe CRCDE. A ausência de um período intermediário com menor utilidade, entretanto, mostra que essa substituição ocorre sem que uma estratégia "oportunista" se aproveitasse de uma eventual fraqueza da CCD. Como esse resultado é observado nas duas simulações da segunda bateria, pode-se concluir que a estratégia CRCDE 


\begin{tabular}{|c||c|c|c||c|c|}
\hline \multicolumn{1}{|c||}{} & \multicolumn{2}{c||}{ Bateria 1 (8000 gerações) } & \multicolumn{2}{c|}{ Bateria 2 (5000 gerações) } \\
\hline & Sim 1 & Sim 2 & Sim 3 & Sim 1 & Sim 2 \\
\hline Util (média) & 440703 & 440997 & 440790 & 439309 & 441705 \\
\hline Util (desv padrão) & 13703 & 14103 & 13702 & 13262 & 13781 \\
\hline Jogs C (média) & 1718156 & 1718927 & 1718099 & 1718568 & 1718357 \\
\hline Jogs C (desv padrão) & 9840 & 9949 & 10015 & 10848 & 10473 \\
\hline Jogs D (média) & 156848 & 156074 & 156901 & 156432 & 156611 \\
\hline Jogs D (desv padrão) & 9837 & 9949 & 10016 & 13852 & 10672 \\
\hline $\begin{array}{c}\text { Gerações até sit. } \\
\text { estacionária }\end{array}$ & 574 & 303 & 403 & 1 & 1 \\
\hline
\end{tabular}

Tabela 7.3: Sumário dos resultados das simulações do modelo JE+AA Valores após o equilíbrio

apresenta maior robustez ao evitar a proliferação de estratégias não-cooperativas.

\subsection{Análise comparativa}

Uma grande quantidade de dados foram gerados como resultado das simulações. De forma a efetuar uma análise comparativa adequada, estes foram separados em duas categorias: dados quantitativos e dados qualitativos. Os dados quantitativos escolhidos consistem das séries temporais de utilidade global dos agentes. Já as estratégias predominantes e os mapas de jogadas configuram os dados qualitativos.

Dessa forma, a análise comparativa dos resultados das simulações foi separada em duas etapas. Em primeiro lugar, foi realizada uma análise qualitativa, onde compararam-se os comportamentos propiciados pelas estratégias predominantes nos modelos $\mathbf{J E}+\mathbf{A F}$ e $\mathbf{J E}+\mathbf{A} \mathbf{A}$, assim como a dinâmica que apresentam ao longo do tempo. Os mapas de jogadas também auxiliaram na interpretação da dinâmica dos modelos nessa etapa. Numa segunda etapa, foi efetuada uma análise quantitativa, que comparou estatisticamente os valores das séries temporais obtidas para ambas as baterias de simulações dos dois modelos.

Detalhes destas análises são apresentadas na seqüência.

\subsubsection{Análise qualitativa}

A comparação das estratégias predominantes para as baterias 1 e 2 , tanto do modelo $\mathbf{J E}+\mathbf{A F}$ quanto do $\mathbf{J E}+\mathbf{A A}$, mostraram não haver conseqüências de longo-prazo caso se adotem diferentes estratégias iniciais. Em ambos os casos, houve em todas as simulações de cada modelo uma clara convergência para o mesmo tipo de estratégias predominantes: estratégias da classe CDIND no mo- 
delo $\mathbf{J E}+\mathbf{A F}$ e da classe $\mathbf{C R C D E}$ no modelo $\mathbf{J E}+\mathbf{A A}$.

Em todas as simulações feitas com o modelo $\mathbf{J E}+\mathbf{A F}$, após um certo número de gerações todas as estratégias predominantes na sociedade possuíam o mesmo tipo de comportamento: aquele definido pela classe CDIND. Além disso, após a disseminação dessas estratégias pela sociedade, o nível de cooperação obtido permaneceu consistentemente alto e relativamente estável. O comportamento a princípio contra-intuitivo dessas estratégias se explica na idéia de que o modelo teve como resultado emergente agentes que se "sacrificam" para eliminar estratégias que não cooperem.

As estratégias predominantes no modelo $\mathbf{J E}+\mathbf{A A}$, por outro lado, apresentaram características um pouco diferentes. Na maioria delas existem situações em que um agente jogando $\mathbf{D}$ pode voltar a jogar $\mathbf{C}$. Diferentemente da estratégia TT5, entretanto, nestas essa possibilidade não depende apenas do número de outros jogadores cooperando na última rodada para que o retorno à cooperação ocorra.

Esse resultado se mostra especialmente interessante caso se considere que, dadas as mutações que podem ocorrer durante a reprodução, o surgimento de uma estratégia da classe CRCDE tem uma probabilidade maior de surgir do que uma estratégia que crie essa transição através de ações adaptativas. Esse fato é demonstrado a seguir.

Para que uma estratégia possa voltar a jogar $\mathbf{C}$ quando se está jogando D, esta deve ter um dos seguintes elementos:

- Uma transição que parte de um estado de tipo D e vai para um estado de tipo C;

- Uma ação adaptativa que crie uma transição de um estado de tipo D para um estado de tipo $\mathrm{C}$

Partindo de uma estratégia com dois estados, C1 e D1, onde não há uma transição no formato $(D 1, x, C 1)$, existem duas mutações que não envolvem funções adaptativas que podem fazer com que essa estratégia tenha uma transição de D1 para um estado do tipo C:

1. Uma primeira mutação que altere a transição $(D 1, x, D 1)$ para $(D 1, x, C 1)$;

2. Uma segunda mutação que crie um novo estado de tipo $\mathrm{C}$ que receba as transições que saem de D1. 
Como todas as escolhas aleatórias efetuadas durante a execução de uma mutação - feitas através da função escolhaAleatoria() nos algoritmos 2, 3, 4, 5, 6 e 7 da seção 5.4- são equiprováveis, pode-se calcular a probabilidade da ocorrência de uma dada mutação durante a reprodução. Por exemplo, no modelo JE+AA, a probabilidade de que um dos cinco tipos de mutações ${ }^{2}$ ocorra é de $1 / 5$, e se o autômato Automato possui apenas dois estados, a probabilidade de a função escolhaAleatoria(estadosDoAutomato(Automato)) retornar um estado específico é de $1 / 2$.

Assim, a probabilidade de que ocorra a primeira mutação consiste na combinação das seguintes probabilidades:

1. Escolher-se a mutação que altera uma transicão - $\frac{1}{5}$;

2. Escolher-se os estados D1 e $\mathbf{C} 1$ para a nova transição, nesta ordem $-\frac{1}{2} \times \frac{1}{2}=$ $\frac{1}{4}$.

A probabilidade de que ocorra a segunda mutação consiste nesta outra combinação de probabilidades:

1. Escolher-se a mutação que cria um novo estado - $\frac{1}{5}$;

2. Escolher-se D1 como o estado que irá originar a transição para o novo estado $-\frac{1}{2}$;

3. Escolher-se o tipo C para o novo estado $-\frac{1}{2}$.

A probabilidade, portanto, de surgir uma transição ligando D1 a um estado do tipo C através de mutações é, portanto:

$$
\frac{1}{5} \times \frac{1}{4}+\frac{1}{5} \times \frac{1}{2} \times \frac{1}{2}=\frac{1}{10}=10 \%
$$

Para que esse retorno à cooperação seja implementado através de uma ação adaptativa, por outro lado, deve surgir no autômato uma ação no formato I (D1 , x , y), onde $\mathrm{x}$ pode ser qualquer valor e $\mathrm{y}$ pode tanto ser C1 quanto uma variável de referência de obtenção de valor do tipo C. Assim, considerando-se o mesmo autômato inicial e a estrutura do algoritmo 7 da seção 5.4, para que em uma mutação uma ação desse tipo seja criada, a seguinte combinação de probabilidades deve ocorrer:

\footnotetext{
${ }^{2}$ Conforme descrito nas seções 4.3 e 5.4, os cinco tipos são (i) alterar o tipo de um estado, (ii) alterar uma transição, (iii) alterar o estado inicial, (iv) adicionar um novo estado e (v) associar uma nova função adaptativa a uma transição existente.
} 
1. A mutação escolhida deve ser a de associar uma função adaptativa a uma transição existente $-\frac{1}{5}$;

2. O tipo de ação deve ser de inserção (I) - $\frac{1}{2}$;

3. O primeiro parâmetro deve ser o estado D1 $-\frac{1}{2} \times \frac{1}{2}=\frac{1}{4}$;

4. O terceiro parâmetro pode tanto ser o estado C1 quanto uma variável de referência de obtenção de valor do tipo $\mathrm{C}-\frac{1}{2}$

Como uma função adaptativa pode ter até 3 ações, a probabilidade máxima de que o retorno à cooperação seja implementado através de funções adaptativas em uma mutação é:

$$
3\left(\frac{1}{5} \times \frac{1}{2} \times \frac{1}{4} \times \frac{1}{2}\right)=\frac{3}{80}=3.75 \%
$$

Nota-se portanto que o surgimento, na dinâmica do modelo $\mathbf{J E}+\mathbf{A A}$, do instrumento utilizado nas estratégias da classe CRCDE para voltar a jogar C quando se está jogando D- uma função adaptativa que propicie a criação de uma transição ligando um estado do tipo D a um do tipo C - é menos provável do que o surgimento desse comportamento por uma mutação que crie uma transição entre esses dois estados, como as presentes estratégia TT5.

Uma outra diferença verificada no modelo $\mathbf{J E}+\mathbf{A A}$ em relação ao $\mathbf{J E}+\mathbf{A F}$ é a ausência, em geral, de estratégias com forte predominância ao longo do tempo. Verifica-se, pelo contrário, um aumento constante da variedade de tipos de estratégias na população, além de um aumento também da complexidade das mesmas. Dessa forma, diferentemente do modelo $\mathbf{J E}+\mathbf{A F}$, onde quase todos os agentes possuem o mesmo tipo de estratégia, no $\mathbf{J E}+\mathbf{A A}$ estratégias com comportamentos muito mais específicos se alternam ao longo do tempo. Não é verificada nenhuma estratégia ótima, que consiga se destacar ao longo das gerações.

Observa-se, entretanto, que mecanismos que possibilitem o retorno à cooperação são presentes na maior parte dos agentes no modelo $\mathbf{J E}+\mathbf{A A}$, o que sinaliza uma diferença significativa em relação ao verificado no modelo $\mathbf{J E}+\mathbf{A F}$ : neste, a manutenção da cooperação na sociedade não se baseia apenas no processo de reprodução ao longo das gerações, mas também em mecanismos, adaptados ao longo do tempo, que possibilitam o retorno à cooperação sob certas circunstâncias. Além disto, ao contrário de estratégias que consideram apenas a última rodada para possibilitar a volta à cooperação, seqüências mais específicas de jogadas são necessárias para que isso ocorra. 
Devido à grande complexidade das interações entre os agentes com estratégias tão variadas e complexas, entretanto, é difícil estabelecer métodos de análise que ajudem na compreensão do motivo pelo qual essas seqüências específicas apresentam melhores resultados. Uma hipótese que poderia ser posteriormente analisada é a de que essas seqüências de jogadas caracterizem uma sinalização entre os agentes que, caso observada, lhes forneça alguma garantia de que poderiam cooperar com um risco menor do que se não tivessem nenhuma informação sobre qual é a estratégia dos outros participantes. Outra hipótese é de que esses mecanismos sejam uma forma de implementar estratégias onde a probabilidade de se voltar a jogar $\mathbf{C}$ quando se está jogando $\mathbf{D}$ seja menor que 1, funcionando como uma implementação rústica de estratégias probabilísticas.

\subsubsection{Análise quantitativa}

De forma a comparar as utilidades obtidas pelos agentes nos modelos $\mathbf{J E}+\mathbf{A F}$ e $\mathbf{J E}+\mathbf{A A}$, optou-se por analisar a utilidade média obtida pela totalidade dos agentes após o equilíbrio ser alcançado. Isso foi feito para que as médias de utilidade calculadas representassem os resultados no longo-prazo dos agentes, sem a interferência das transições iniciais.

Assim, utilizando-se apenas os valores de utilidade a partir da geração em que eles entram em equilíbrio (mostrados nas tabelas 7.2 e 7.3), foi escolhido o método de Tukey para múltiplas comparações (KUTNER, 2005). Esse método consiste em, dadas duas séries $Z_{i}=\zeta_{i, 1}, \ldots, \zeta_{i, n}$ e $Z_{j}=\zeta_{j, 1}, \ldots, \zeta_{j, m}$, testar para um dado nível de significância as seguintes hipóteses para todo par $\left(\zeta_{i, k}, \zeta_{j, k}\right)$ :

$$
\begin{aligned}
& H_{0}: \zeta_{i, k}-\zeta_{j, k}=0 \\
& H_{1}: \zeta_{i, k}-\zeta_{j, k} \neq 0
\end{aligned}
$$

Dessa forma, se $H_{0}$ se confirmar, pode-se dizer que a série $Z_{i}$ é equivalente à $Z_{j}$. Considerando $D=\zeta_{i, k}-\zeta_{j, k}$, e um nível de significância $\alpha$, os limites de confiança $L C$ obtidos pelo método são definidos pela seguinte fórmula:

$$
L C=\widehat{D} \quad \pm \operatorname{Ts}\{\widehat{D}\}
$$

onde: 


$$
\begin{aligned}
\widehat{D} & =\overline{Z_{i}}-\overline{Z_{j}} \\
s^{2}\{D\} & =s^{2}\left\{\overline{Z_{i}}\right\}+s^{2}\left\{\overline{Z_{j}}\right\}=\operatorname{MSE}\left(\frac{1}{n_{i}}+\frac{1}{n_{j}}\right) \\
T & =\frac{1}{\sqrt{2}} q\left(1-\alpha ; r, n_{T}-r\right)
\end{aligned}
$$

A variável $n_{T}$ da equação 7.4 indica o número total de observações em ambas as séries, $r$ o número de séries sendo comparadas, $M S E$ é o erro médio quadrático das amostras e a função $q(r, v)$ consiste numa relação chamada de studentized range, definida por:

$$
q(r, v)=\frac{\max (Z)-\min (Z)}{s}
$$

onde $s$ é a raiz da estimativa da variância $s^{2}$ de todas as observações.

Com isso, se para as séries analisadas tivermos que o valor 0 pertence ao intervalo obtido em 7.1, a hipótese $H_{0}$ é confirmada com nível de significância $\alpha$.

Como esse método supõe que as amostras analisadas são compostas por valores independentes, verificou-se a necessidade de considerar apenas os dados a cada 10 gerações, para eliminar a correlação serial presente ao considerarmos todas as observações. Caso isso não fosse feito, a aplicação do teste seria inválida. De posse desses dados, foi verificada a ausência de correlação serial para esta amostra reduzida.

Foram, portanto, feitas comparações 2 a 2 entre todas as séries de utilidade obtidas nas simulações, amostradas a cada 10 gerações. A conclusão obtida é de que ao nível de significância 5\%, há diferenças significativas entre as médias da utilidade das seguintes simulações:

- Simulação 2 da bateria 2 de 5000 gerações do modelo JE+AF com a simulação 2 da bateria 2 de 5000 gerações do modelo JE+AA

- Simulação 2 da bateria 2 de 5000 gerações do modelo JE+AF com a simulação 1 da bateria 1 de 8000 gerações do modelo JE+AA

- Simulação 2 da bateria 2 de 5000 gerações do modelo JE+AF com a simulação 2 da bateria 1 de 8000 gerações do modelo $\mathbf{J E}+\mathbf{A A}$

- Simulação 2 da bateria 2 de 5000 gerações do modelo JE+AF com a si- 
mulação 3 da bateria 1 de 8000 gerações do modelo JE+AA

A análise estatística das utilidades totais dos agentes após o equilíbrio mostra, portanto, diferenças significativas apenas entre uma instância de simulação do modelo $\mathbf{J E}+\mathbf{A F}$ e quatro instâncias do $\mathbf{J E}+\mathbf{A A}$.

Embora a diferença entre apenas uma simulação de um modelo e todas as outras de um outro modelo não possa ser considerada um resultado importante, a ausência de diferenças entre instâncias do mesmo modelo, entretanto, indica que a utilidade obtida pelos agentes de um mesmo modelo é consistente, não havendo duas simulações de um mesmo modelo que sejam consideradas diferentes por este ponto de vista.

\subsection{Considerações finais}

Embora pequena, o fato da vantagem obtida pelos agentes no modelo $\mathbf{J E}+\mathbf{A A}$ ser observada em todas as simulações efetuadas e todas serem executadas com os mesmos parâmetros (diferindo apenas na estratégia inicial ou tipo de representação de estratégias), indica que as diferenças presentes entre as estratégias predominantes podem explicar o fenômeno.

De fato, a análise das estratégias, feita nas duas seções anteriores deste capítulo, mostrou que no modelo $\mathbf{J E}+\mathbf{A A}$ a maioria das estratégias predominantes implementam critérios específicos que permitem o retorno à cooperação quando esta deixa de ocorrer. A pequena diferença observada na utilidade obtida nesse modelo, entretanto, indica que esse mecanismo é utilizado poucas vezes.

Aliando-se isso ao fato de que estratégias que retornam à cooperação através de mecanismos simples, como a versão do tit-for-tat para o DPNP utilizada como estratégia inicial na bateria 2 do modelo $\mathbf{J E}+\mathbf{A F}$, não obterem bons resultados (como visto na seção 7.2), esse resultado indica que estratégias mais conservadoras - que somente voltam a cooperar sob condições específicas - apresentam resultados ligeiramente superiores àquelas que voltam a cooperar mais facilmente.

Devido ao fato de, tanto no modelo $\mathbf{J E}+\mathbf{A F}$ quanto no $\mathbf{J E}+\mathbf{A A}$, mesmo uma diferença muito pequena na utilidade dos agentes resultar na replicação da estratégia com melhor resultado, essas estratégias conservadoras prevalecem por conseguirem sistematicamente utilidades ligeiramente superiores. 


\section{Conclusões}

Este trabalho apresentou um modelo para o estudo da evolução de estratégias para o DPNP com cinco participantes em uma população de agentes distribuídos espacialmente, e que interagem somente com seus vizinhos. Nele, as estratégias que definem como cada um deles irá se comportar são adaptadas e selecionadas ao longo do tempo por um mecanismo similar ao da seleção natural. Dois modelos de representação de estratégias foram utilizados: autômatos finitos (resultando no modelo $\mathbf{J E}+\mathbf{A F}$ ) e uma versão simplificada de autômatos adaptativos (resultando no modelo $\mathbf{J E}+\mathbf{A A})$.

Simulações efetuadas com o modelo $\mathbf{J E}+\mathbf{A F}$ corroboraram os resultados apresentados em (LINDGREN; JOHANSSON, 2003), onde estratégias da classe CDIND predominam entre os agentes e possibilitam a manutenção de um nível alto de cooperação na sociedade. Como as simulações deste trabalho foram executadas por um período maior, verificou-se a ocorência de variações no número de agentes necessários para que a não-cooperação seja iniciada, indicando a ausência de uma configuração ótima do número necessário de agentes vizinhos que jogam $\mathbf{D}$ para que se passe também a jogar $\mathbf{D}$.

Outras simulações efetuadas com o modelo $\mathbf{J E}+\mathbf{A F}$, onde a estratégia inicial dos agentes era a TT5 mostraram que estratégias da classe CDIND rapidamente substituem essas iniciais, fortalecendo a posição destas primeiras como estratégias dominantes no modelo.

A análise das estratégias predominantes em simulações do modelo $\mathbf{J E}+\mathbf{A A}$, por outro lado, mostram a predominância daquelas que implementam mecanismos que permitem o retorno à cooperação sob condições específicas, algo não observado no JE+AF. Este fato, aliado ao de estratégias que permitem o retorno à cooperação mais facilmente terem uma probabilidade maior de surgirem no modelo do que aquelas que voltam por processos mais complexos, sugerem que um comportamento mais conservador por parte dos agentes ao restabelecer a cooperação, implementado nas estratégias da classe CRCDE, pode resultar em ganhos marginais em relação àqueles obtidos através das estratégias da classe 
CDIND. Embora pequena, essa pequena vantagem obtida pelos agentes que utilizam estratégias da classe CRCDE é suficiente para transformá-las em predominantes na sociedade, dado que pela especificação dos modelos a amplitude da diferença obtida na utilidade dos agentes não altera em nenhum aspecto o processo de reprodução.

Embora as estratégias predominantes nos dois modelos tenham características distintas, essa diferença resultante na utilidade total da sociedade no longo-prazo não foi considerada estatisticamente significativa, o que indica que os ganhos proporcionados pelas estratégias dominantes do modelo $\mathbf{J E}+\mathbf{A A}$ são relativamente baixos.

Recapitulando as questões propostas na seção 1.2, as respostas resultantes dos dados obtidos nos testes realizados são as seguintes:

1. É possível haver uma cooperação no longo-prazo entre diversos agentes, onde há um estímulo individual para a não-cooperação? Como se dá, dinamicamente, esse processo?

- É possível, após um certo período de tempo, obter-se uma ampla cooperação entre agentes que participam repetidamente de situações de interação social que possam ser reduzidas a uma instância do DPNP. Para que isso ocorra, entretanto, um grupo suficientemente grande de agentes deve estar disposto em algum momento a iniciar as interações cooperando, e assim permanecer enquanto todos cooperarem. A partir do momento em que isso ocorre, o ganho obtido por esse grupo permite que nas gerações seguintes espaços vizinhos sejam ocupados por agentes com esse tipo de estratégia. Adicionalmente, a manutenção deste nível mais alto de bem-estar da sociedade depende de mecanismos de punição contra agentes que não cooperem, mesmo que isso acarrete em perdas não só para quem pune como para os agentes vizinhos.

2. Quais são as condições ambientais e institucionais que catalisam esse processo?

- Foi verificado que a presença de agentes que possuem critérios, mesmo que muito específicos, para o retorno à cooperação quando esta foi perdida, catalisam o processo, possibilitando a obtenção de um nível maior de bem-estar para a sociedade mais rapidamente. 
3. Qual o papel da limitação espacial das interações entre os agentes (em outras palavras, o fato de um agente interagir apenas com seus vizinhos) nesse processo?

- Em (LindGren; Johansson, 2003) foi feito um estudo de um modelo evolutivo do DPNP, comparando-se os resultados obtidos quando os agentes distribuídos espacialmente efetuam apenas interações locais com uma outra situação em que as interações ocorrem entre todos os agentes, desconsiderando sua proximidade. Foi verificado então que a obtenção da cooperação entre os agentes é mais difícil de ocorrer quando a interação não possui restrições espaciais. De fato, analisando o processo através do qual a cooperação entre os agentes é obtida nas simulações feitas neste trabalho, verificou-se que esta depende da formação de um grupo que interage entre si através de jogadas cooperativas. Como a probabilidade de isto ocorrer entre cinco vizinhos é muito maior do que de isto ocorrer para a maioria da população, acredita-se, portanto, que a limitação espacial seja um elemento facilitador deste.

4. Qual o papel da racionalidade nesse processo? Agentes com processos de decisão mais complexos conseguem melhores resultados individuais e/ou coletivos que aqueles com regras de comportamento mais limitadas?

- A capacidade de voltar a cooperar, quando não se está cooperando, sob critérios específicos, mostrou resultados marginalmente superiores àqueles obtidos por sociedades onde os agentes podiam implementar critérios mais simples para este retorno. Nas simulações efetuadas, a diferença total observada no bem-estar da sociedade, entretanto, foi pequena.

Adicionalmente, o desenvolvimento do simulador $\boldsymbol{S}_{\mathbf{2}} \boldsymbol{E}_{\mathbf{2}}$ pode ser considerado também uma contribuição deste trabalho. Espera-se que este possa ser extendido em outros trabalhos na mesma área.

Os resultados parciais obtidos no decorrer do trabalho foram apresentados em (Bó; SICHMAN, 2007a) e (Bó; SICHMAN, 2007b).

Diversos outros experimentos com os dois modelos analisados podem ainda ser feitos. Conforme observado nas simulações realizadas a partir do modelo $\mathbf{J E}+\mathbf{A F}$, após o equilíbrio elementos de uma mesma classe de estratégias alternamse constantemente como predominantes. Já estratégias com características in- 
crementalmente distintas são observadas nas simulações realizadas com o modelo JE+AA. Assim, justifica-se realizar simulações com um maior período de tempo, de forma a verificar se outras estratégias passam a predominar ao longo do tempo.

Por outro lado, simulações com diferentes probabilidades de erro ou falha de comunicação $\left(P_{e}\right)$ em ambos modelos são importantes para verificar a capacidade proporcionada por cada representação de estratégias face a diferentes níveis de incerteza.

A avaliação individual da utilidade proporcionada por cada estratégia, ou grupo de estratégias semelhantes, ao longo do tempo pode dar uma melhor visão do comportamento da sociedade, quando comparada à população dessas estratégias.

Finalmente, simulações onde os agentes possam identificar univocamente quais agentes vizinhos cooperaram e quais não cooperaram, podem indicar se o fato de os agentes não conhecerem quais deles cooperaram interfere em suas ações, assim como se estratégias mais complexas lidam de forma melhor com essa nova informação. Tal modificação pode ser implementado através de alterações simples na representação das estratégias.

Do ponto de vista da implementação, como discutido na seção 7.1, os tempos envolvidos numa simulação deste tipo são muito grandes. Para possibilitar a realização de experimentos futuros de forma mais eficiente, uma proposta de execução distribuída ou paralela, por exemplo em um "cluster" de máquinas, deve ser considerarda. 


\section{Apêndice A - Estratégias predominantes no modelo JE+AA}

Neste apêndice, apresentam-se as estratégias predominantes nas diferentes simulações de cada uma das baterias de testes do modelo $\mathbf{J E}+\mathbf{A A}$, amostradas em cada período de 1000 gerações. 


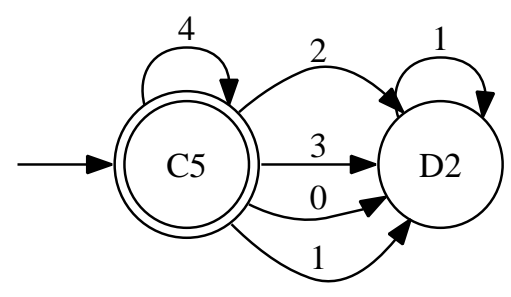

(a) Estratégia predominante na geração 1000

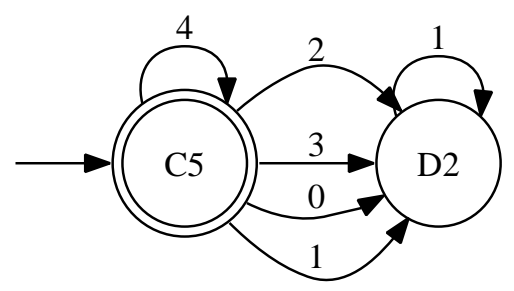

(c) Estratégia predominante na geração 2000

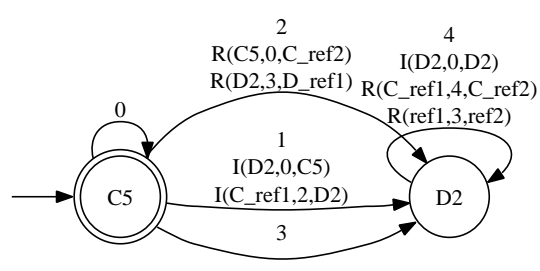

(e) Estratégia predominante na geração 3000

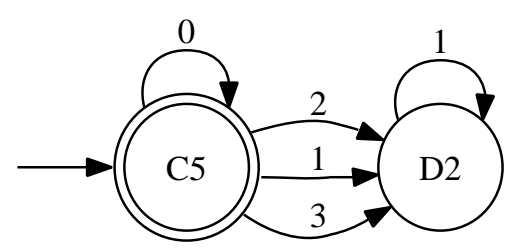

(b) Segunda estratégia predominante na geração 1000

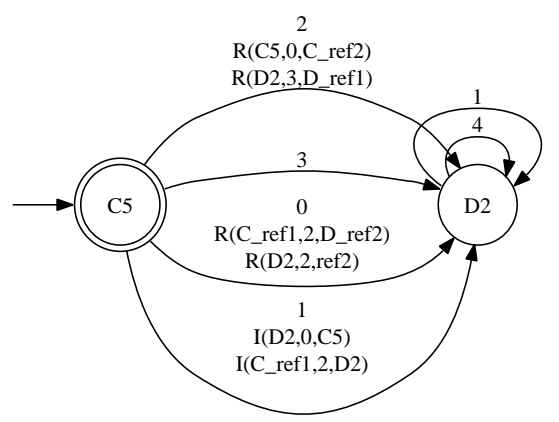

(d) Segunda estratégia predominante na geração 2000

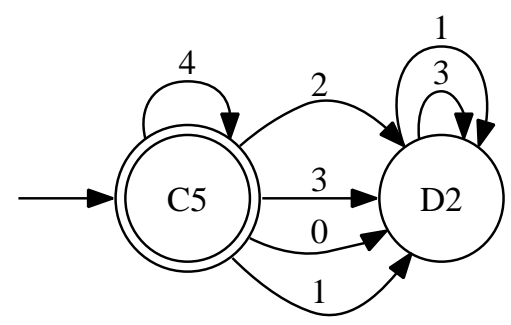

(f) Segunda estratégia predominante na geração 3000

Figura A.1: Estratégias predominantes para a simulação 1 da bateria 1, de simulações de 8000 gerações do modelo JE+AA - Parte 1 


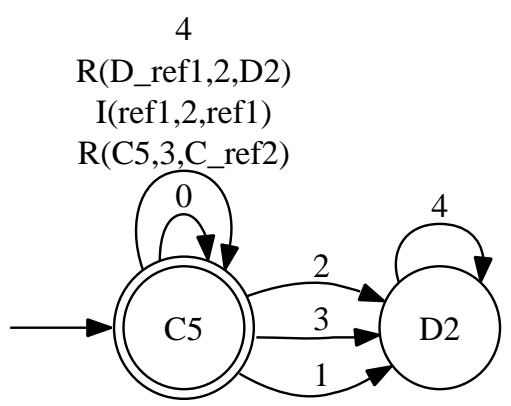

(a) Estratégia predominante na geração 4000

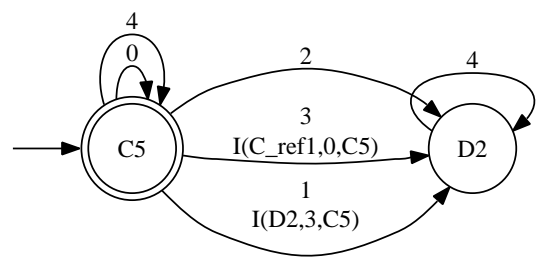

(c) Estratégia predominante na geração 5000

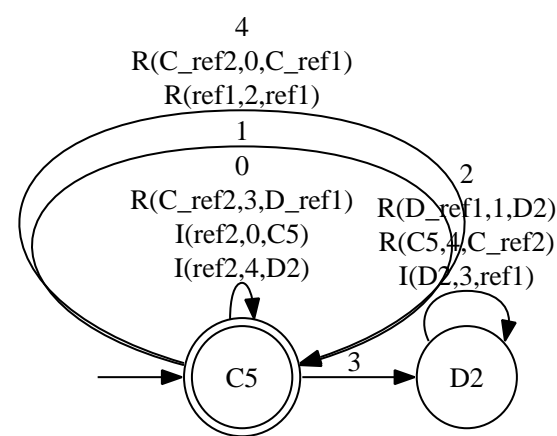

(e) Estratégia predominante na geração 6000

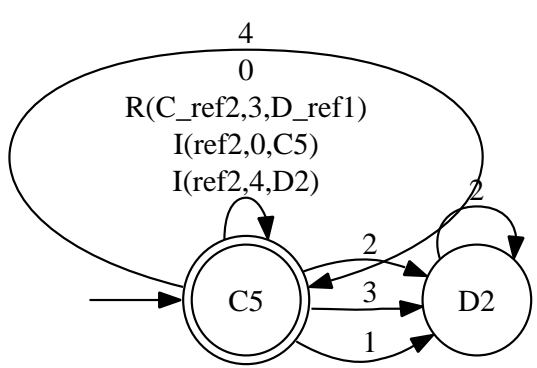

(b) Segunda estratégia predominante na geração 4000

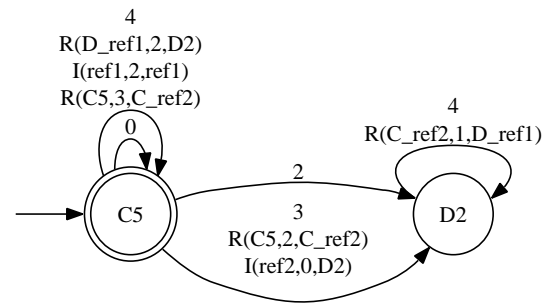

(d) Segunda estratégia predominante na geração 5000

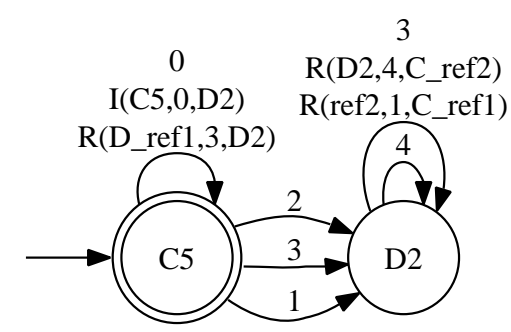

(f) Segunda estratégia predominante na geração 6000

Figura A.2: Estratégias predominantes para a simulação 1 da bateria 1, de simulações de 8000 gerações do modelo JE+AA - Parte 2 


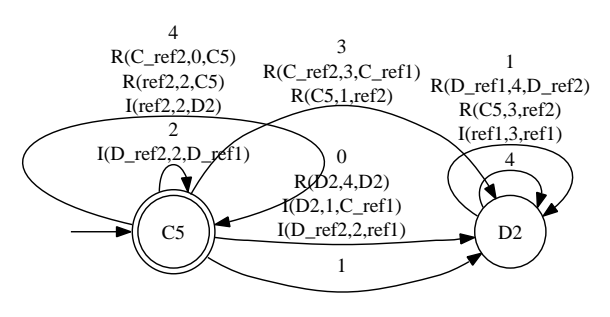

(a) Estratégia predominante na geração 7000

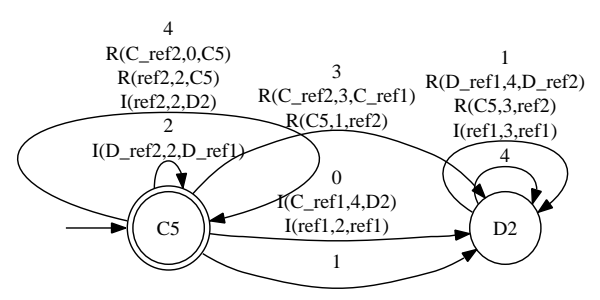

(c) Estratégia predominante na geração 8000

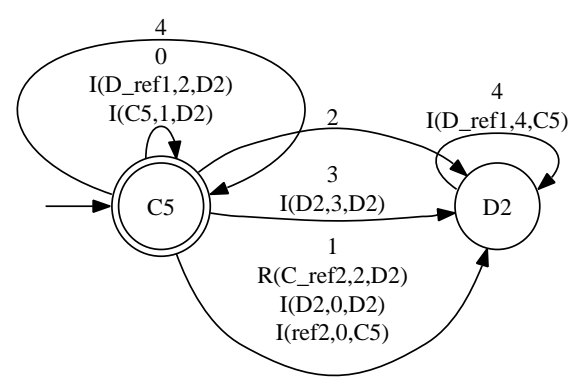

(b) Segunda estratégia predominante na geração 7000

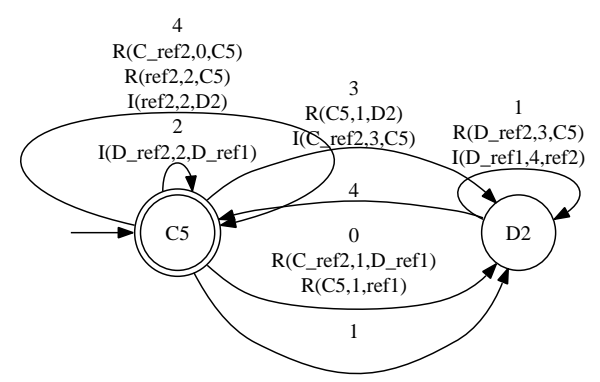

(d) Segunda estratégia predominante na geração 8000

Figura A.3: Estratégias predominantes para a simulação 1 da bateria 1, de simulações de 8000 gerações do modelo $\mathbf{J E}+\mathbf{A A}$ - Parte 3 


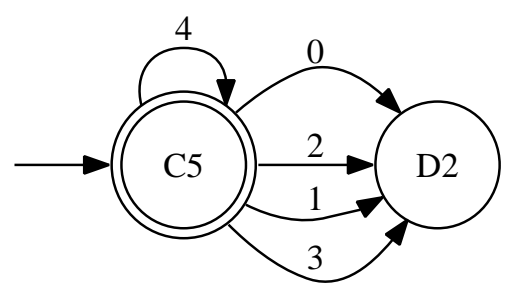

(a) Estratégia predominante na geração 1000

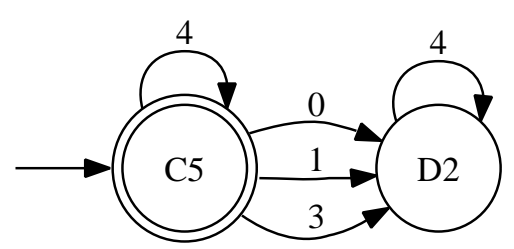

(c) Estratégia predominante na geração 2000

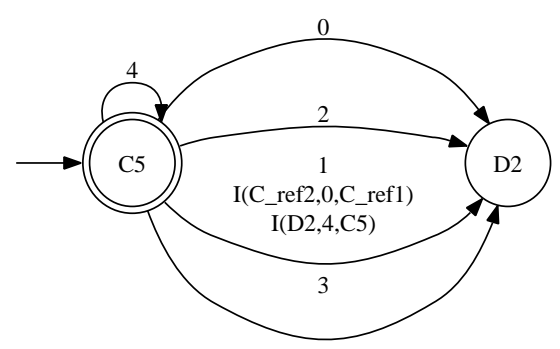

(e) Estratégia predominante na geração 3000

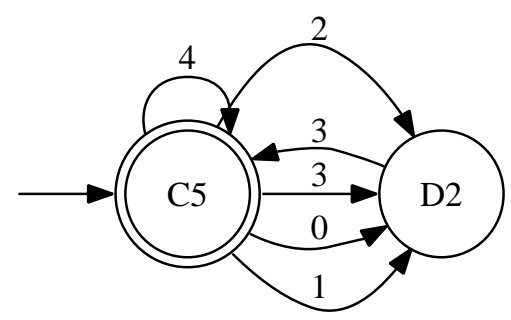

(b) Segunda estratégia predominante na geração 1000

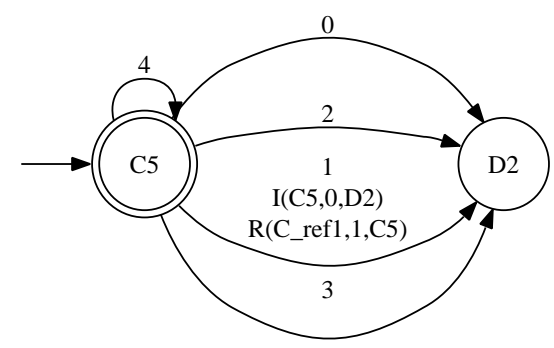

(d) Segunda estratégia predominante na geração 2000

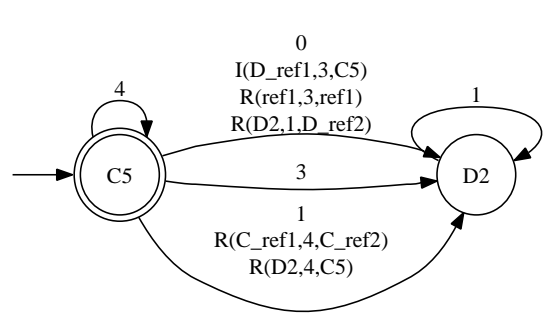

(f) Segunda estratégia predominante na geração 3000

Figura A.4: Estratégias predominantes para a simulação 2 da bateria 1, de simulações de 8000 gerações do modelo $\mathbf{J E}+\mathbf{A A}$ - Parte 1 


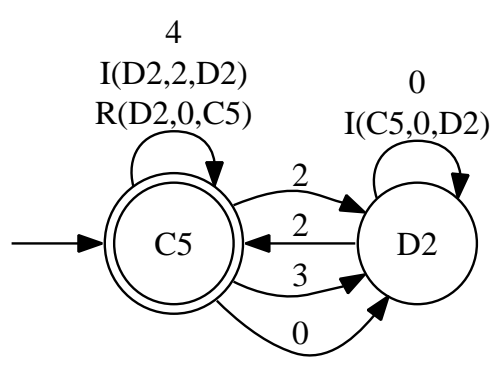

(a) Estratégia predominante na geração 4000

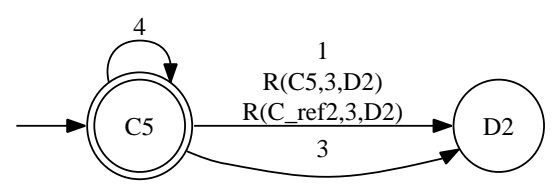

(c) Estratégia predominante na geração 5000

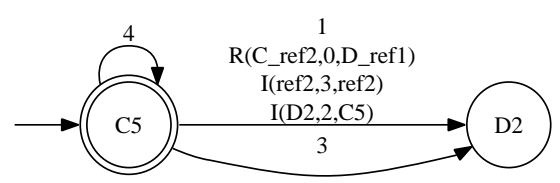

(e) Estratégia predominante na geração 6000

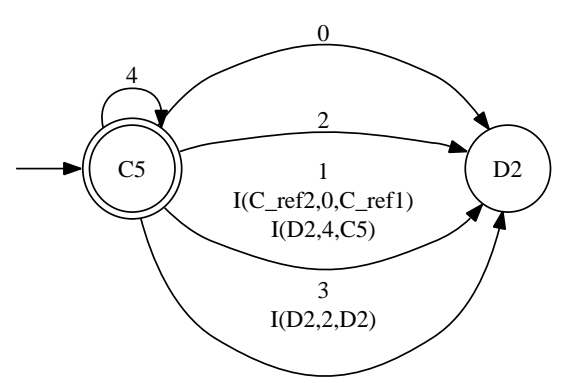

(b) Segunda estratégia predominante na geração 4000

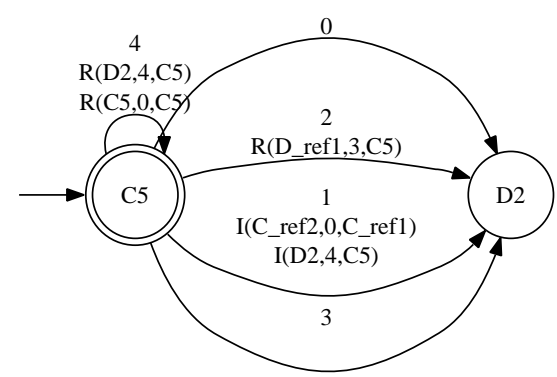

(d) Segunda estratégia predominante na geração 5000

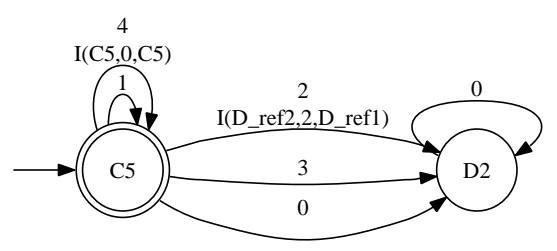

(f) Segunda estratégia predominante na geração 6000

Figura A.5: Estratégias predominantes para a simulação 2 da bateria 1, de simulações de 8000 gerações do modelo JE+AA - Parte 2 


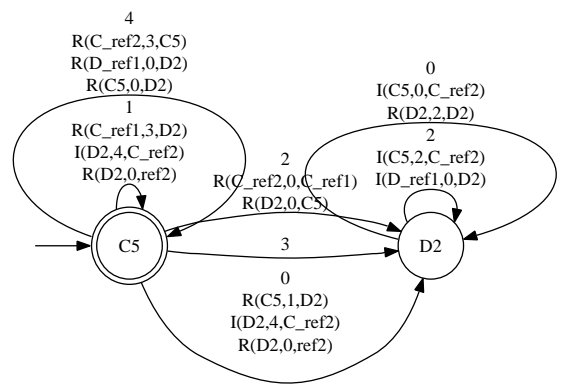

(a) Estratégia predominante na geração 7000

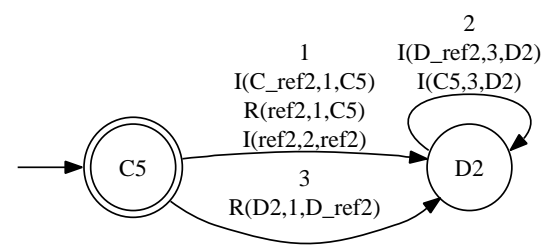

(c) Estratégia predominante na geração 8000

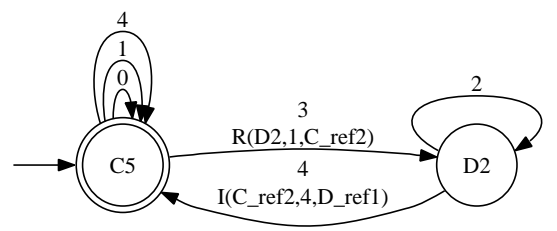

(b) Segunda estratégia predominante na geração 7000

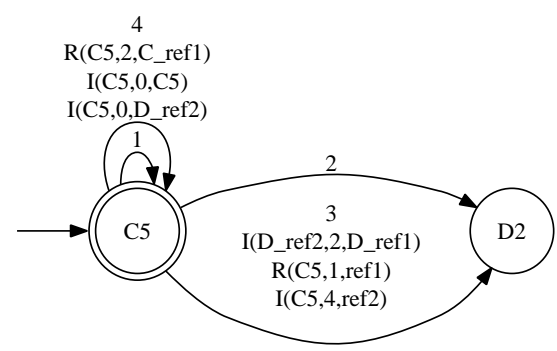

(d) Segunda estratégia predominante na geração 8000

Figura A.6: Estratégias predominantes para a simulação 2 da bateria 1, de simulações de 8000 gerações do modelo $\mathbf{J E}+\mathbf{A A}$ - Parte 3 


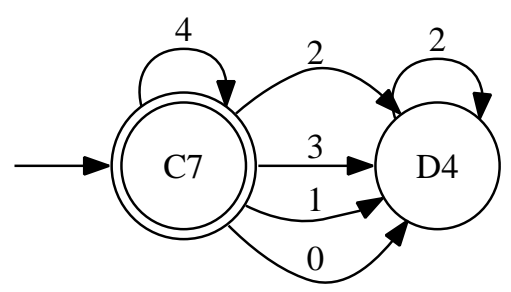

(a) Estratégia predominante na geração 1000

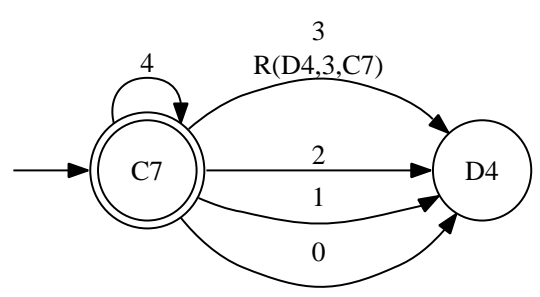

(c) Estratégia predominante na geração 2000

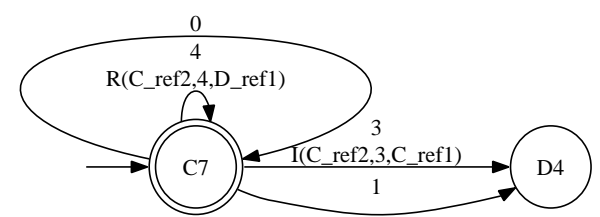

(e) Estratégia predominante na geração 3000

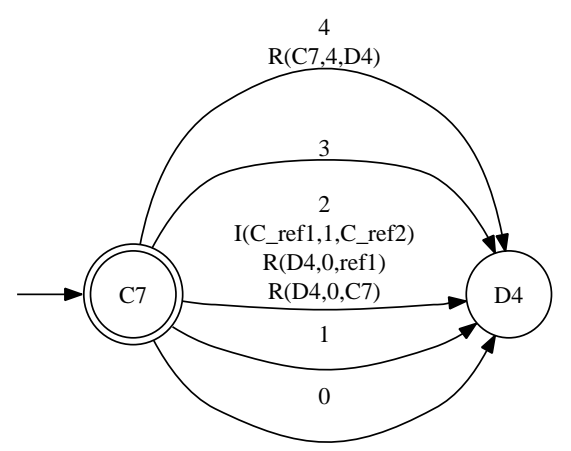

(b) Segunda estratégia predominante na geração 1000

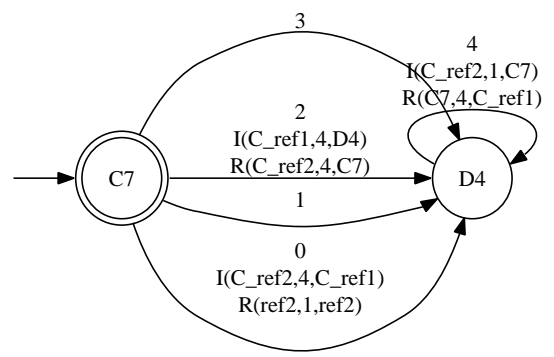

(d) Segunda estratégia predominante na geração 2000

4

I(D4,1,D4)

$$
\text { R(C_ref2,4,D_ref1) }
$$

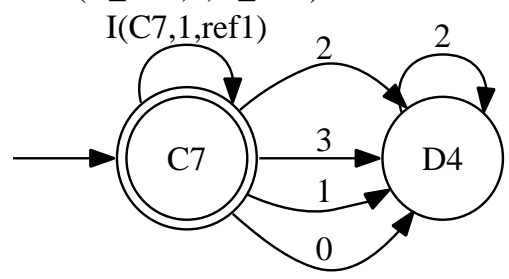

(f) Segunda estratégia predominante na geração 3000

Figura A.7: Estratégias predominantes para a simulação 3 da bateria 1, de simulações de 8000 gerações do modelo JE+AA - Parte 1 


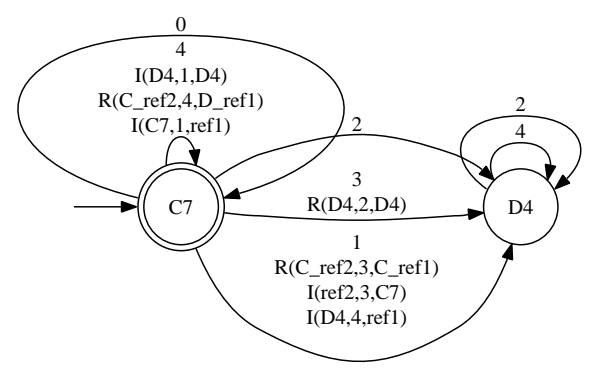

(a) Estratégia predominante na geração 4000

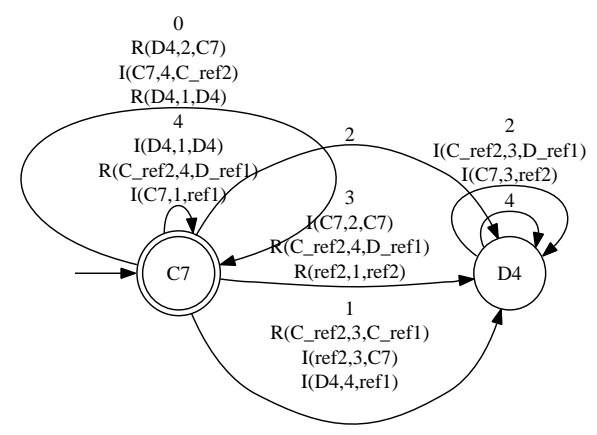

(c) Estratégia predominante na geração 5000

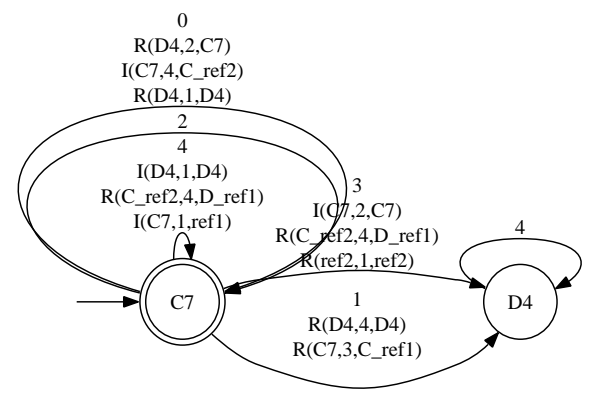

(e) Estratégia predominante na geração 6000

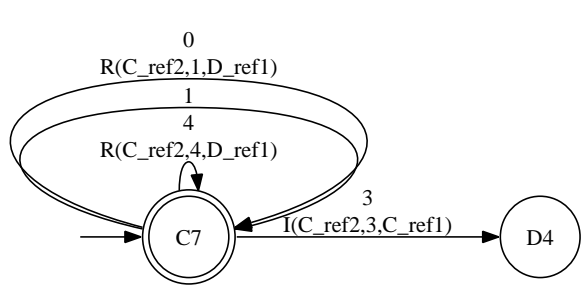

(b) Segunda estratégia predominante na geração 4000

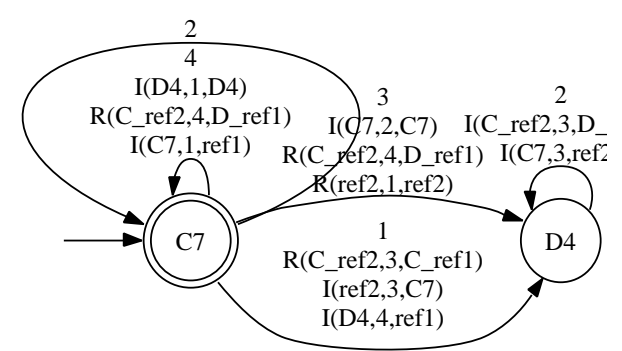

(d) Segunda estratégia predominante na geração 5000

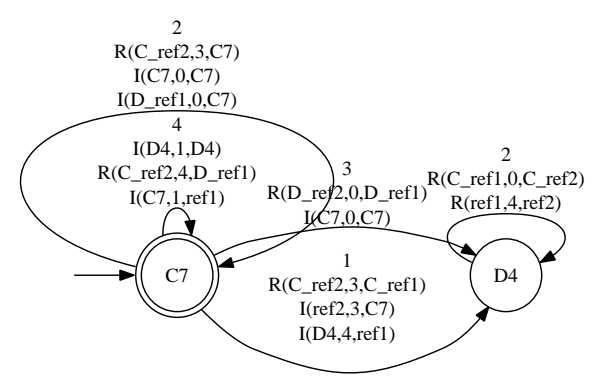

(f) Segunda estratégia predominante na geração 6000

Figura A.8: Estratégias predominantes para a simulação 3 da bateria 1, de simulações de 8000 gerações do modelo JE+AA - Parte 2 


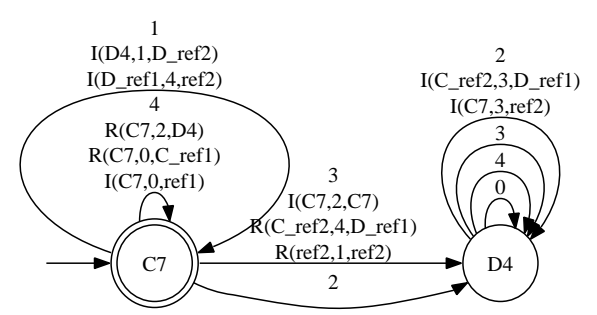

(a) Estratégia predominante na geração 7000

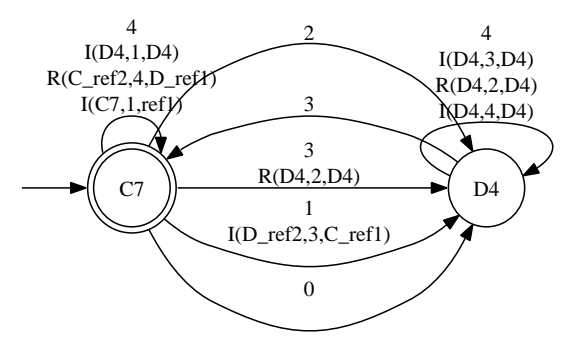

(c) Estratégia predominante na geração 8000

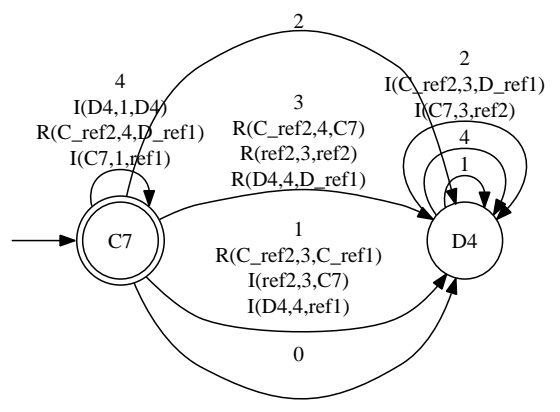

(b) Segunda estratégia predominante na geração 7000

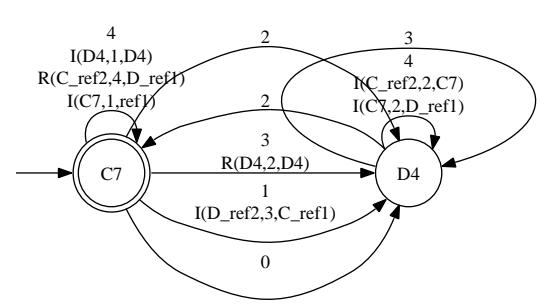

(d) Segunda estratégia predominante na geração 8000

Figura A.9: Estratégias predominantes para a simulação 3 da bateria 1, de simulações de 8000 gerações do modelo JE+AA - Parte 3 


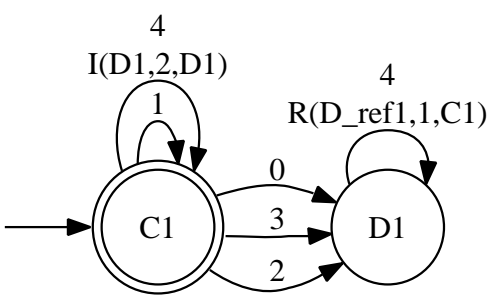

(a) Estratégia predominante na geração 1000

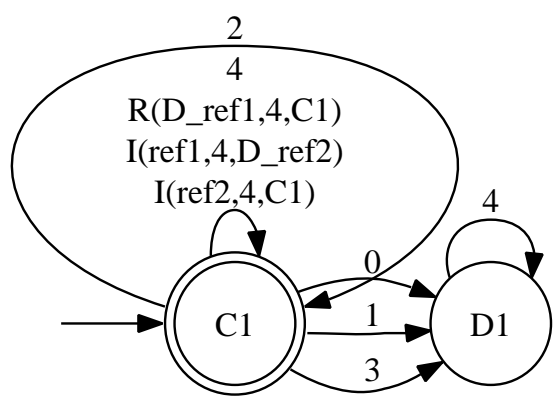

(c) Estratégia predominante na geração 2000

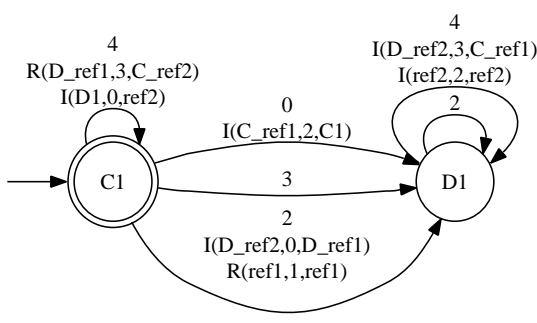

(e) Estratégia predominante na geração 3000
4

R(D_ref1,4,C1)

I(ref1,4,D_ref2)

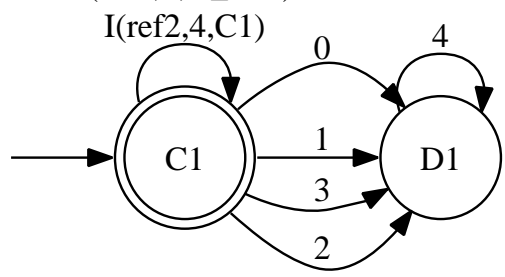

(b) Segunda estratégia predominante na geração 1000

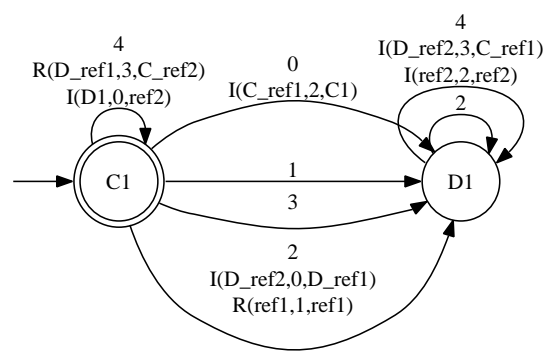

(d) Segunda estratégia predominante na geração 2000

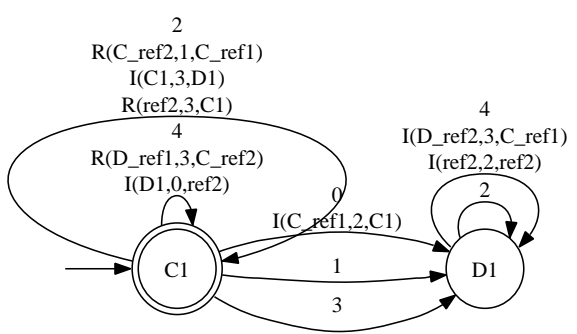

(f) Segunda estratégia predominante na geração 3000

Figura A.10: Estratégias predominantes para a simulação 1 da bateria 2, de simulações de 5000 gerações do modelo $\mathbf{J E}+\mathbf{A A}$ - Parte 1 


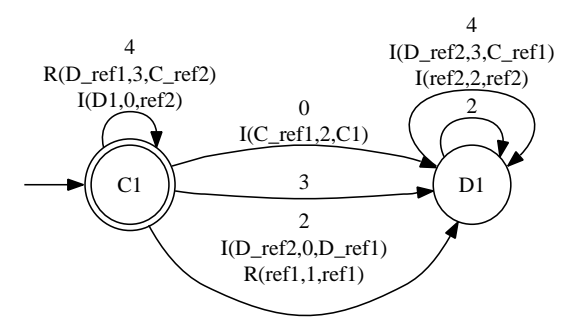

(a) Estratégia predominante na geração 4000

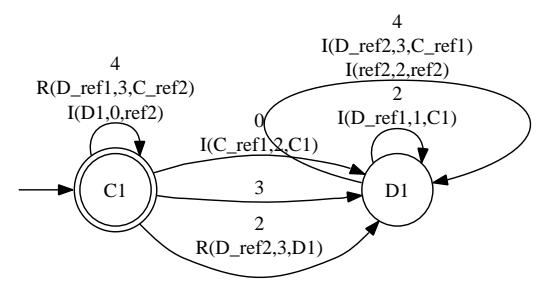

(c) Estratégia predominante na geração 5000

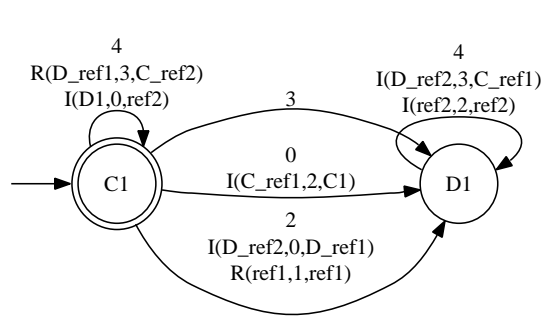

(b) Segunda estratégia predominante na geração 4000

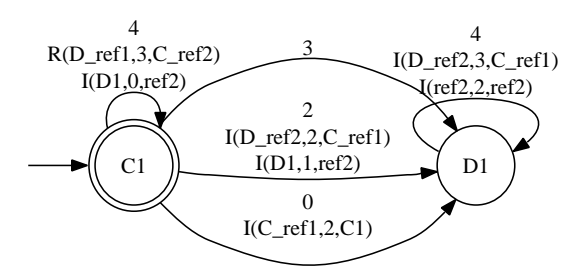

(d) Segunda estratégia predominante na geração 5000

Figura A.11: Estratégias predominantes para a simulação 1 da bateria 2, de simulações de 5000 gerações do modelo JE+AA - Parte 2 
4

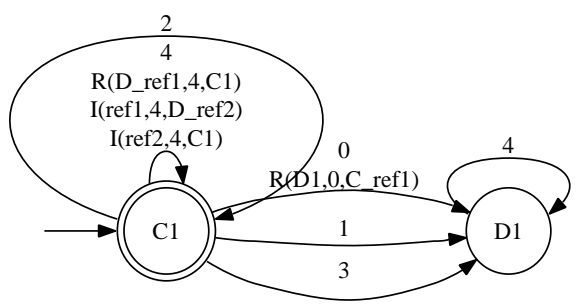

(a) Estratégia predominante na geração 1000

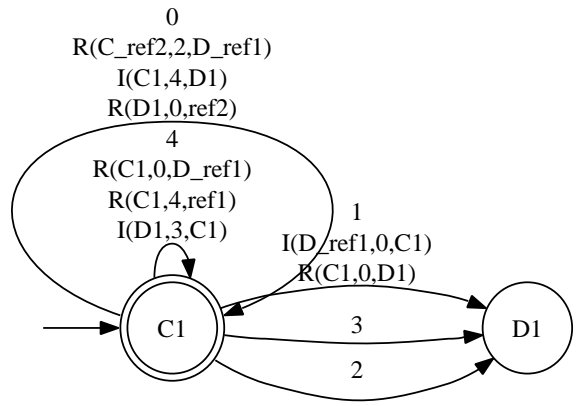

(c) Estratégia predominante na geração 2000

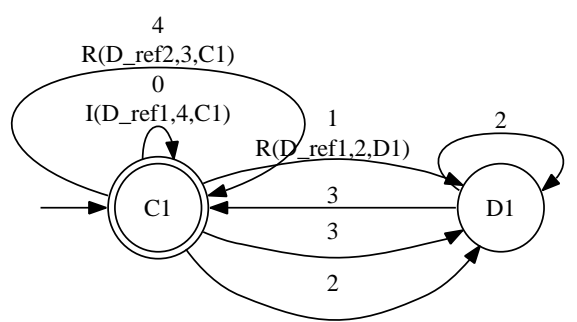

(e) Estratégia predominante na geração 3000
R(D_ref1,4,C1)

I(ref1,4,D_ref2)

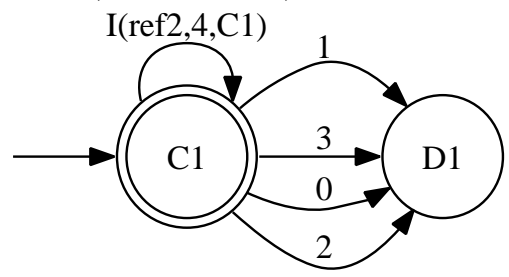

(b) Segunda estratégia predominante na geração 1000

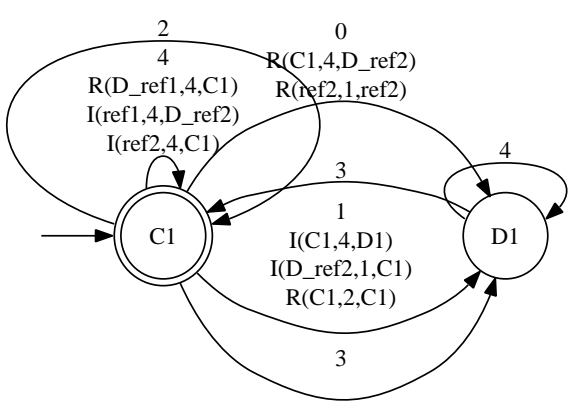

(d) Segunda estratégia predominante na geração 2000

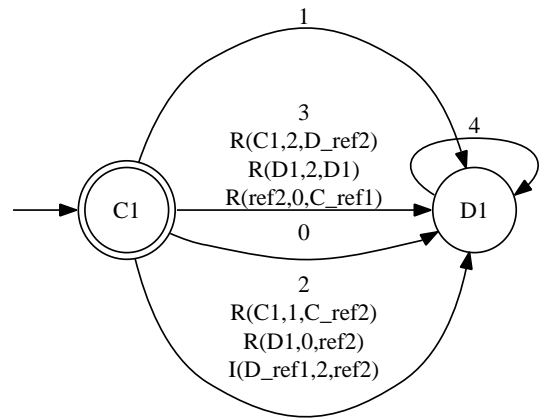

(f) Segunda estratégia predominante na geração 3000

Figura A.12: Estratégias predominantes para a simulação 2 da bateria 2, de simulações de 5000 gerações do modelo $\mathbf{J E}+\mathbf{A A}$ - Parte 1 


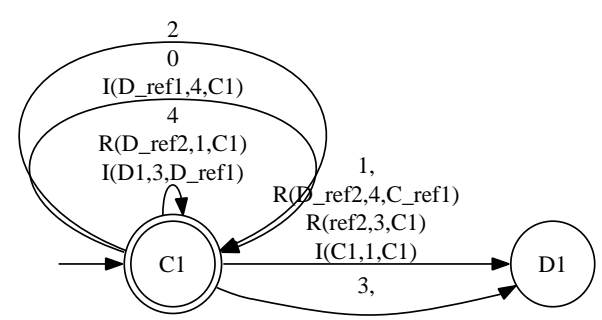

(a) Estratégia predominante na geração 4000

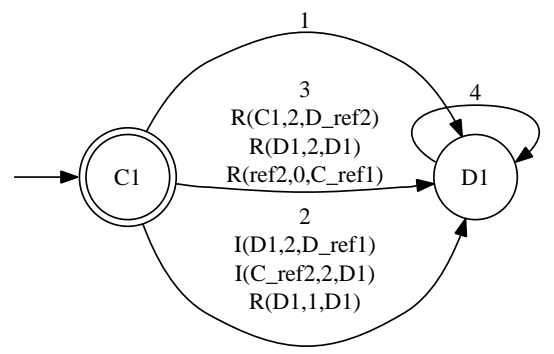

(c) Estratégia predominante na geração 5000

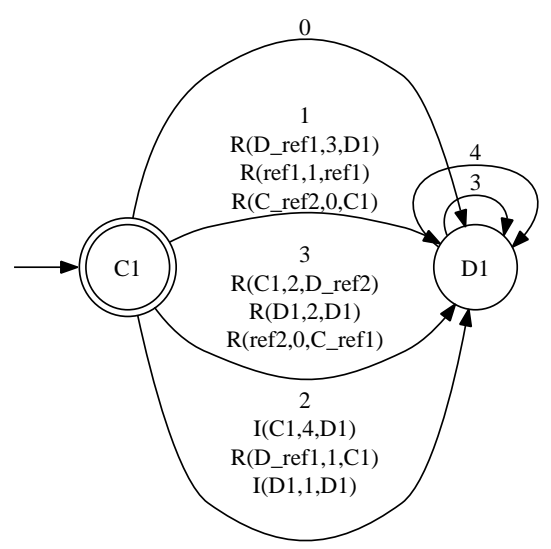

(b) Segunda estratégia predominante na geração 4000

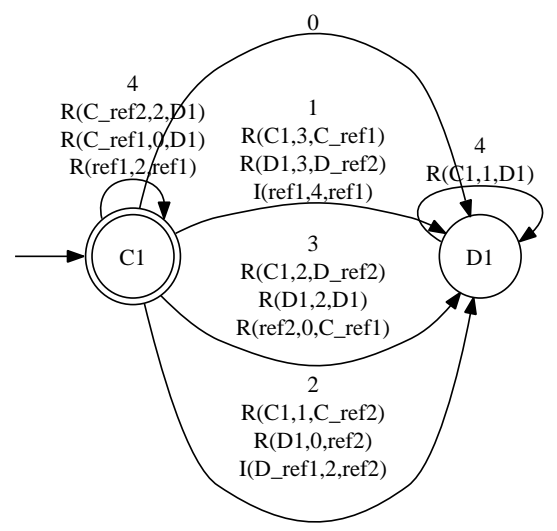

(d) Segunda estratégia predominante na geração 5000

Figura A.13: Estratégias predominantes para a simulação 2 da bateria 2, de simulações de 5000 gerações do modelo JE+AA - Parte 2 


\section{Apêndice B - Análise estatística}

\section{B.1 Análise de correlação serial das utilidades das simulações amostradas a cada 10 gerações após o equilíbrio}

As figuras B.1 a B.10 mostram, para cada simulação efetuada, a análise de correlação serial das amostras das séries de utilidade colhidas a cada 10 gerações. Nela são indicados através de barras verticais o valor da correlação para defasagens de 0, a 30. Obviamente, nota-se que a correlação com defasagem 0 tem o O valor da correlação serial de uma série $S=s_{0} \ldots s_{n}$ com defasagem $x$ indica o quanto o valor de $s_{k+x}$ está relacionado ao de $s_{k}$. Esse valor deve estar em média abaixo de 0.1 para que os dados da amostra possam ser considerados independentes.

\section{B.2 Resultado da aplicação do método de Tukey}

As tabelas das figuras B.11 a B.14 exibem os resultados da aplicação do método de Tukey para comparações múltiplas entre todas as séries de utilidade, amostradas a cada 10 gerações, dos modelos $\mathbf{J E}+\mathbf{A F}$ e $\mathbf{J E}+\mathbf{A A}$.

Nelas, as duas primeiras colunas indicam as duas séries sendo comparadas, no formato SxBymmmm, onde x é o número da simulação, y é a bateria e mmmm o modelo da série. Na terceira coluna é indicado o valor da diferença média entre as das séries. A quarta coluna apresenta o erro médio das duas séries, a quinta a significância da confirmação ou não da hipótese, e por fim as duas últimas indicam o intervalo da diferença entre as duas amostras, com 95\% de significância. Caso o valor 0 esteja nesse intervalo, as duas séries podem ser consideradas equivalentes. 
Simulação 1 Bateria 1 JE+AF

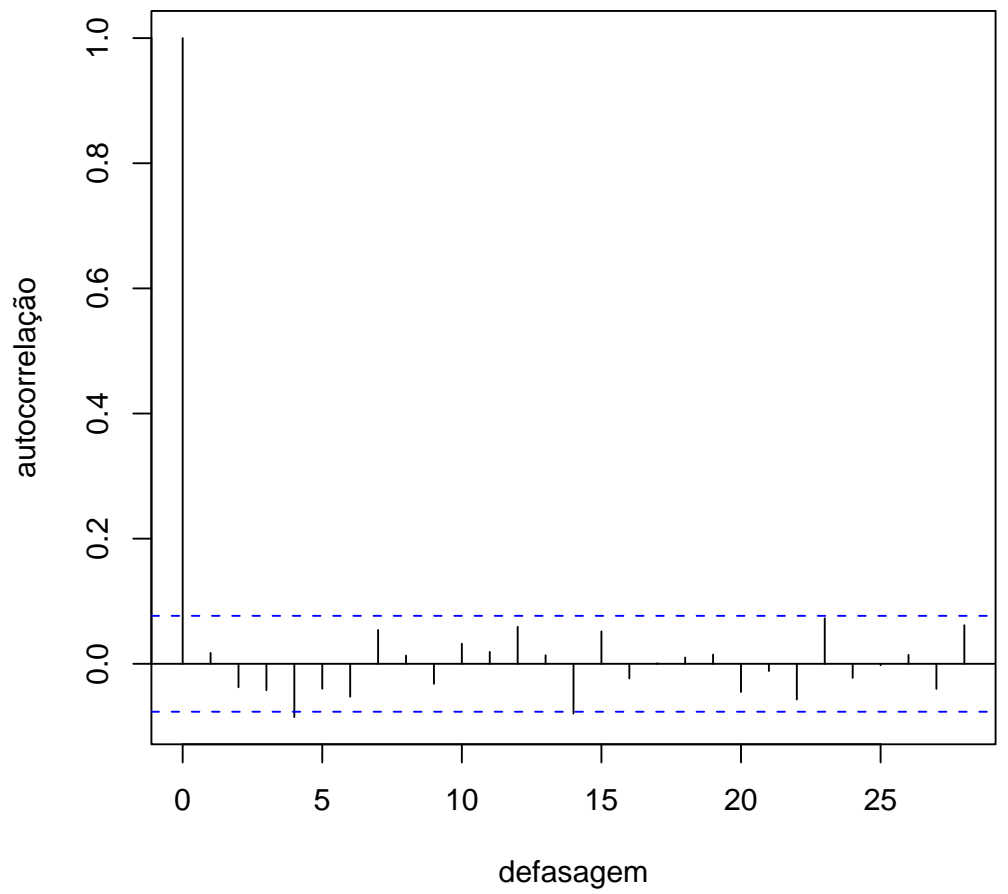

Figura B.1: Auto-correlação da utilidade para a simulação 1 da bateria 1 de simulações de 8000 gerações do modelo $\mathbf{J E}+\mathbf{A F}$ (dados colhidos a cada 10 gerações)

Simulação 2 Bateria $1 \mathrm{JE}+\mathrm{AF}$

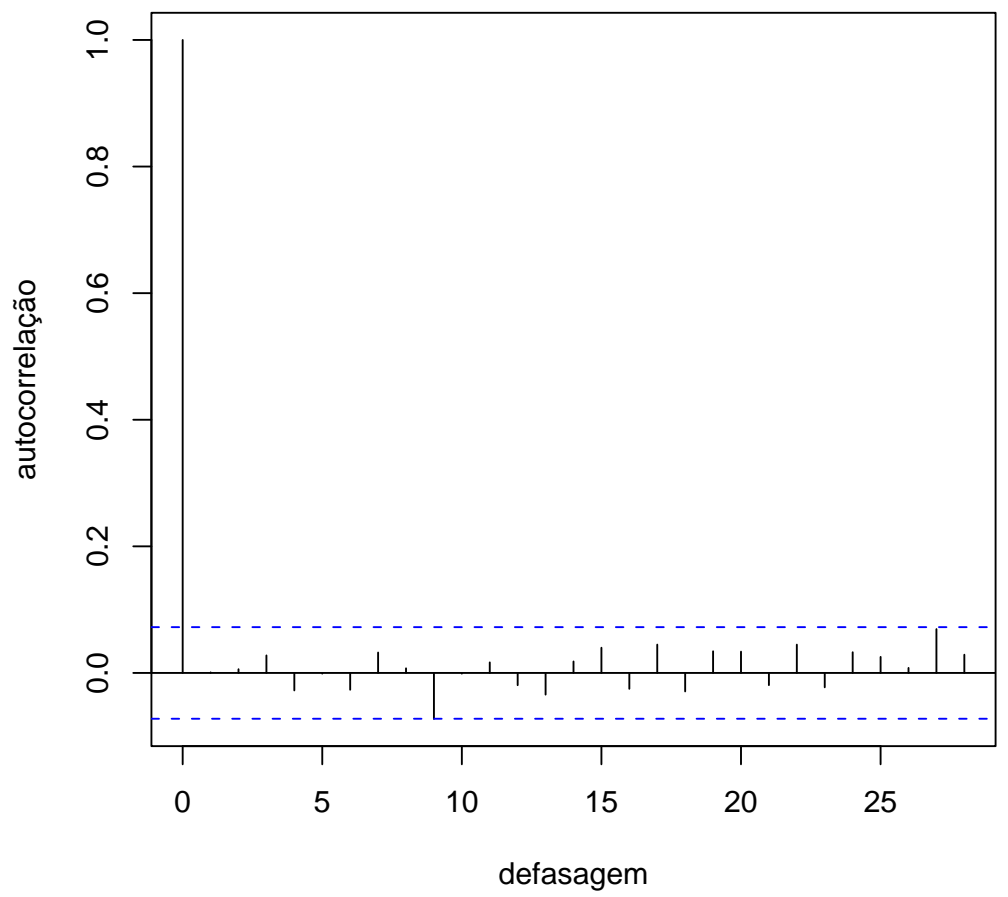

Figura B.2: Auto-correlação da utilidade para a simulação 2 da bateria 1 de simulações de 8000 gerações do modelo $\mathbf{J E}+\mathbf{A F}$ (dados colhidos a cada 10 gerações) 
Simulação 3 Bateria 1 JE+AF

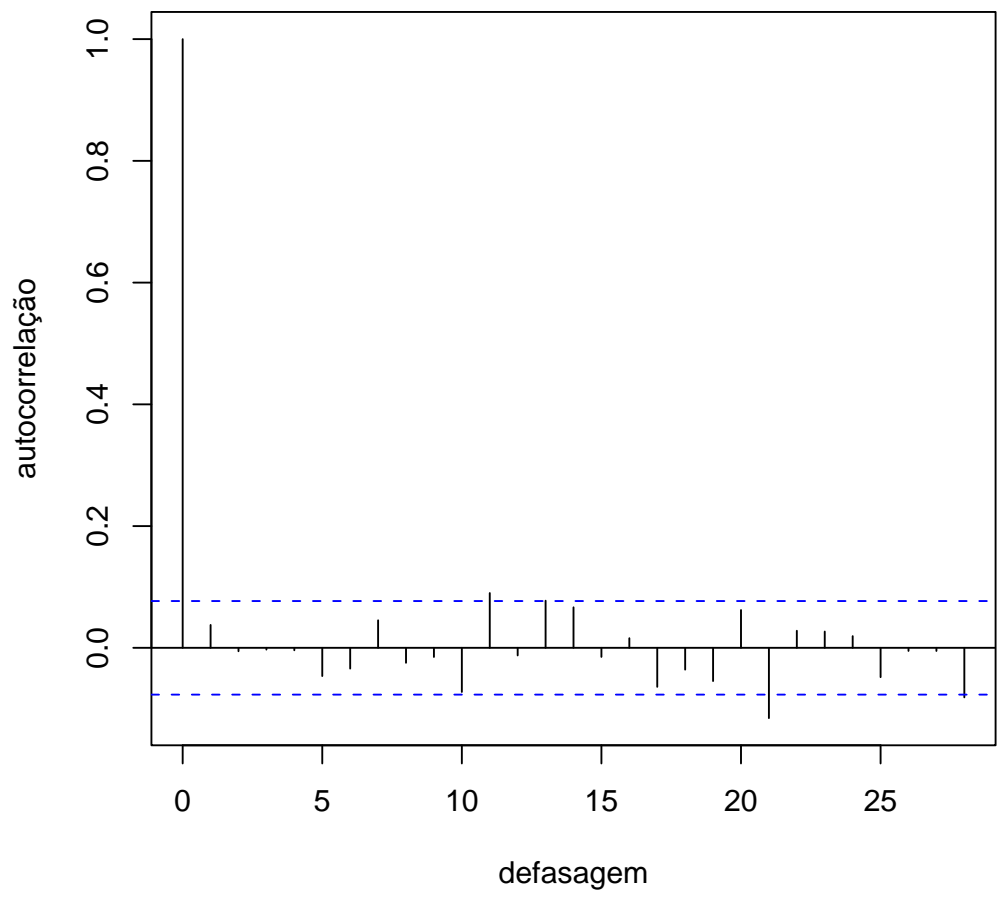

Figura B.3: Auto-correlação da utilidade para a simulação 3 da bateria 1 de simulações de 8000 gerações do modelo $\mathbf{J E}+\mathbf{A F}$ (dados colhidos a cada 10 gerações)

Simulação 1 Bateria 2 JE+AF

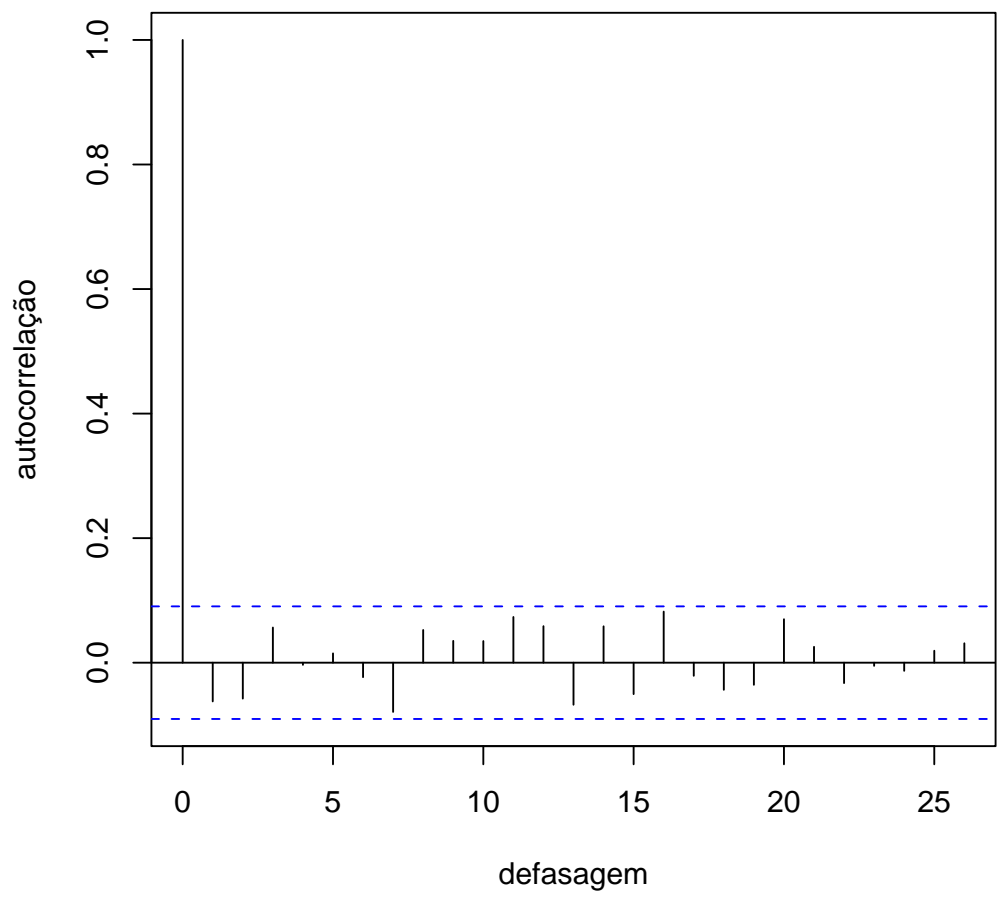

Figura B.4: Auto-correlação da utilidade para a simulação 1 da bateria 2 de simulações de 5000 gerações do modelo $\mathbf{J E}+\mathbf{A F}$ (dados colhidos a cada 10 gerações) 
Simulação 2 Bateria 2 JE+AF

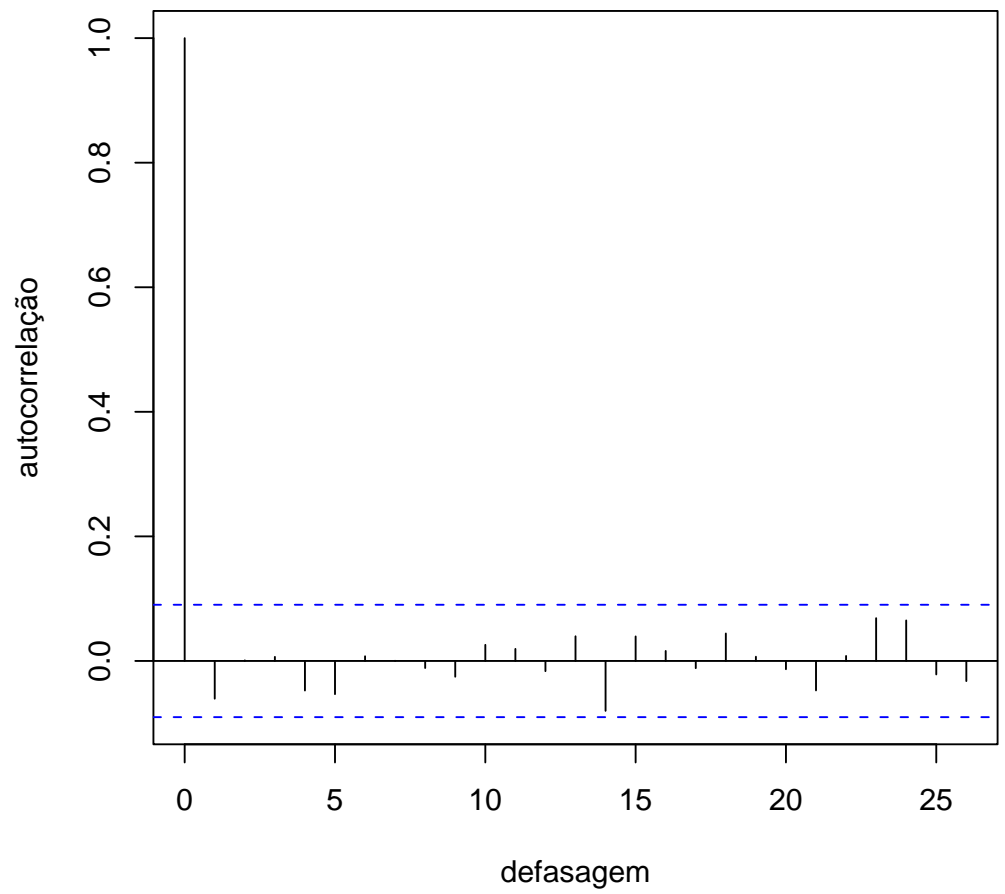

Figura B.5: Auto-correlação da utilidade para a simulação 2 da bateria 2 de simulações de 5000 gerações do modelo $\mathbf{J E}+\mathbf{A F}$ (dados colhidos a cada 10 gerações)

Simulação 1 Bateria $1 \mathrm{JE}+\mathrm{AA}$

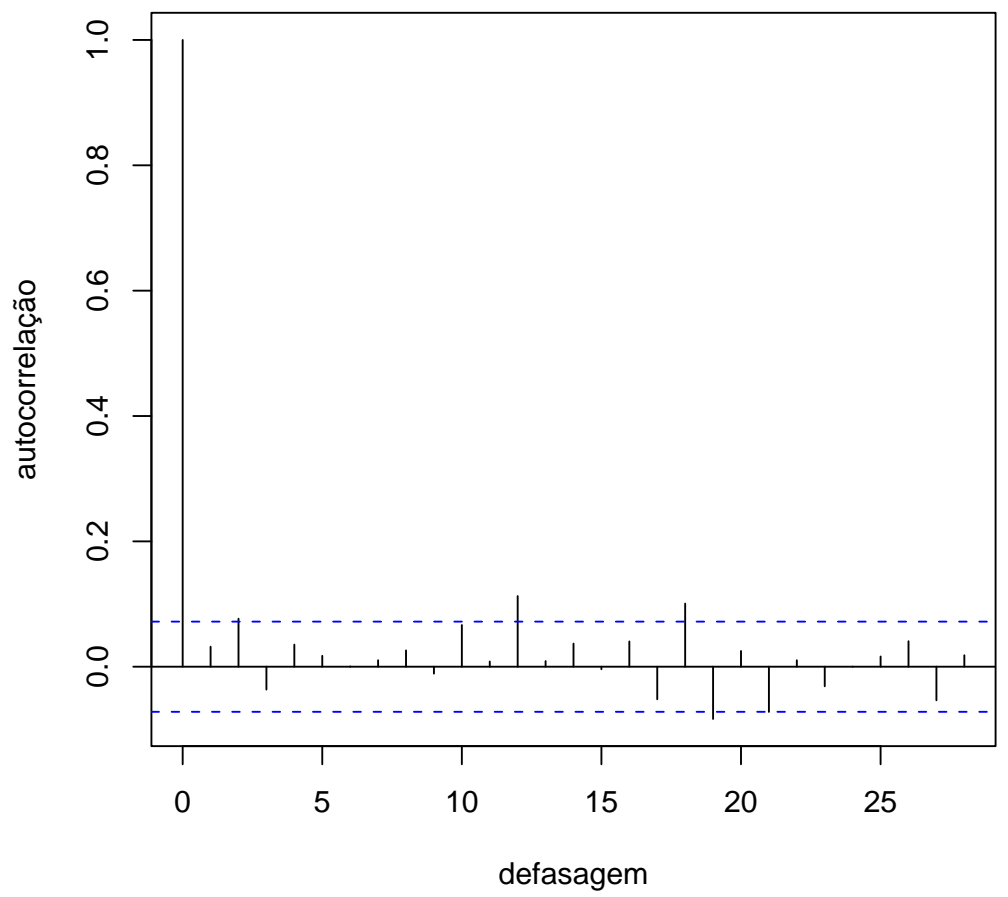

Figura B.6: Auto-correlação da utilidade para a simulação 1 da bateria 1 de simulações de 8000 gerações do modelo $\mathbf{J E}+\mathbf{A A}$ (dados colhidos a cada 10 gerações) 


\section{Simulação 2 Bateria 1 JE+AA}

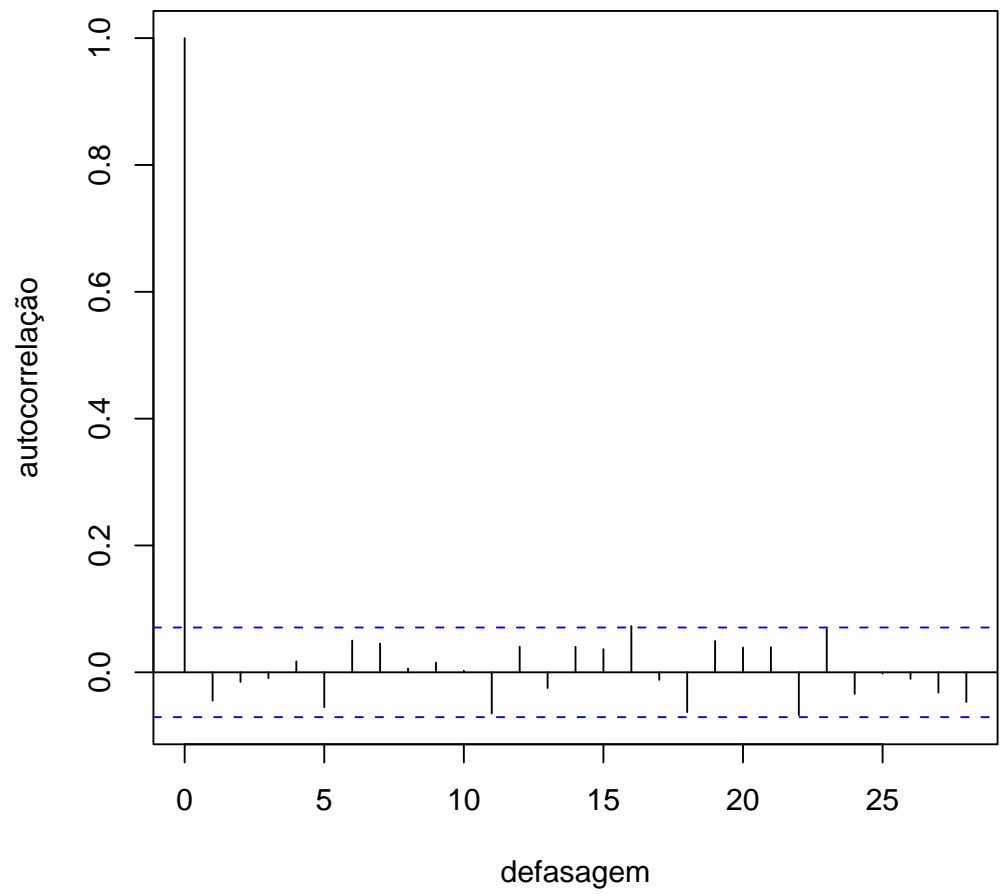

Figura B.7: Auto-correlação da utilidade para a simulação 2 da bateria 1 de simulações de 8000 gerações do modelo $\mathbf{J E}+\mathbf{A A}$ (dados colhidos a cada 10 gerações)

Simulação 3 Bateria 1 JE+AA

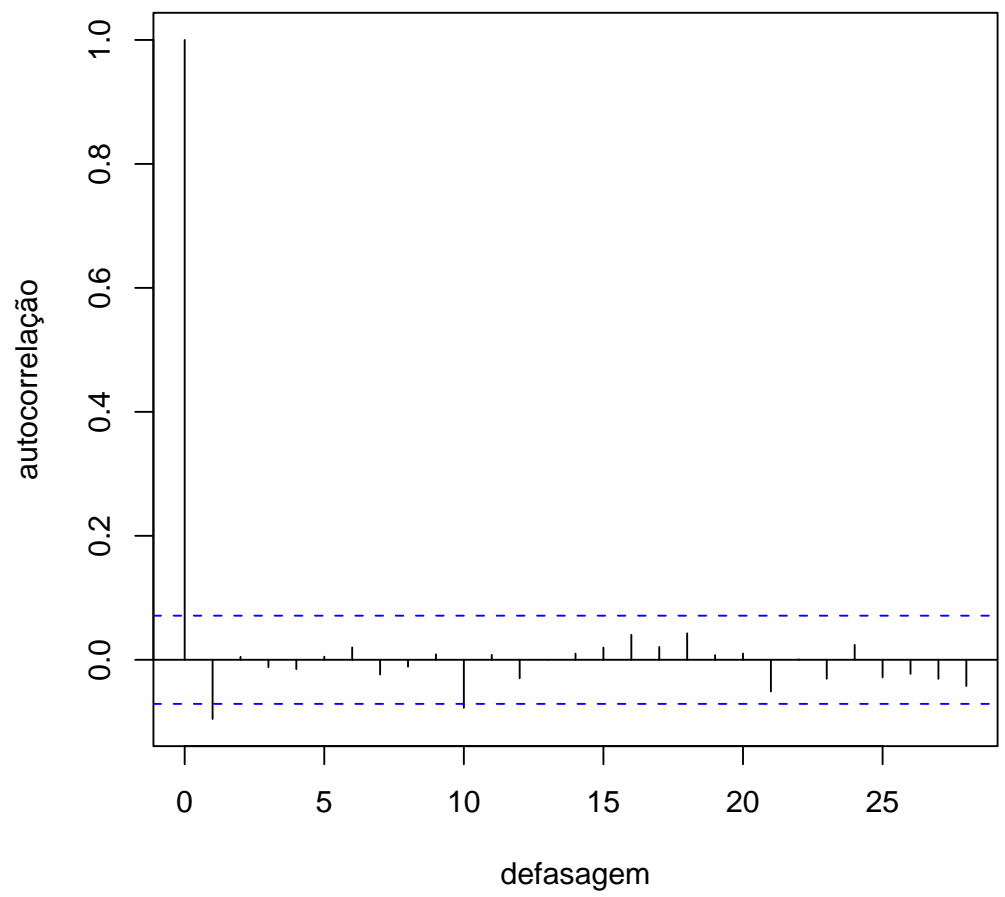

Figura B.8: Auto-correlação da utilidade para a simulação 3 da bateria 1 de simulações de 8000 gerações do modelo $\mathbf{J E}+\mathbf{A A}$ (dados colhidos a cada 10 gerações) 


\section{Simulação 1 Bateria 2 JE+AA}

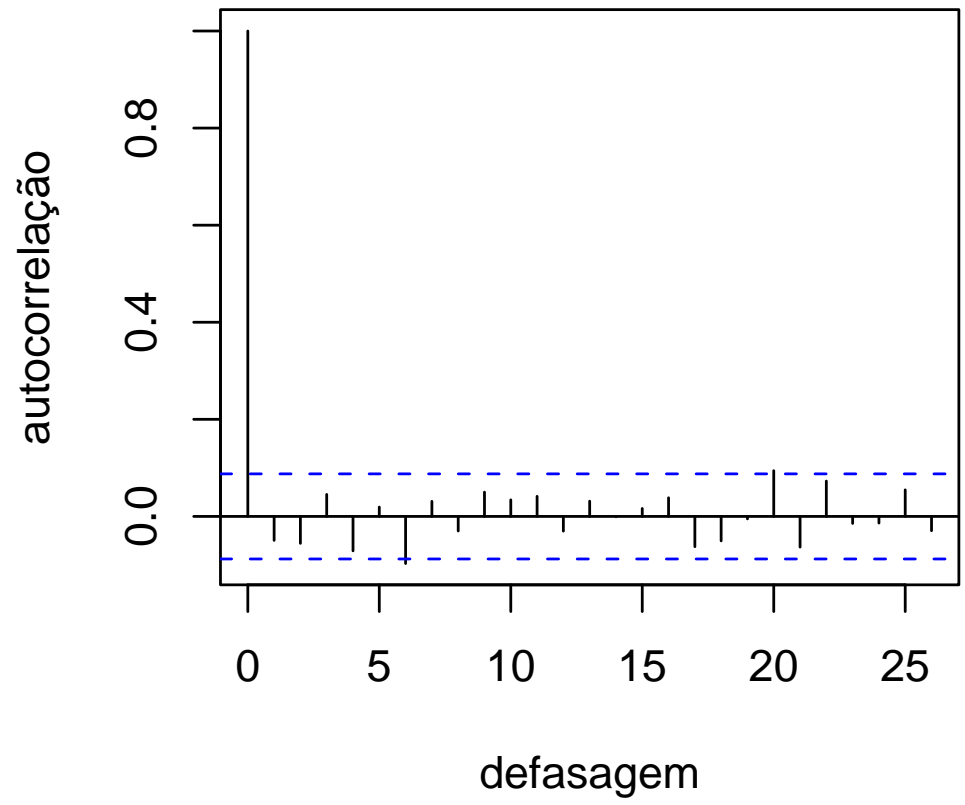

Figura B.9: Auto-correlação da utilidade para a simulação 1 da bateria 2 de simulações de 5000 gerações do modelo JE+AA (dados colhidos a cada 10 gerações)

Simulação 2 Bateria 2 JE+AF

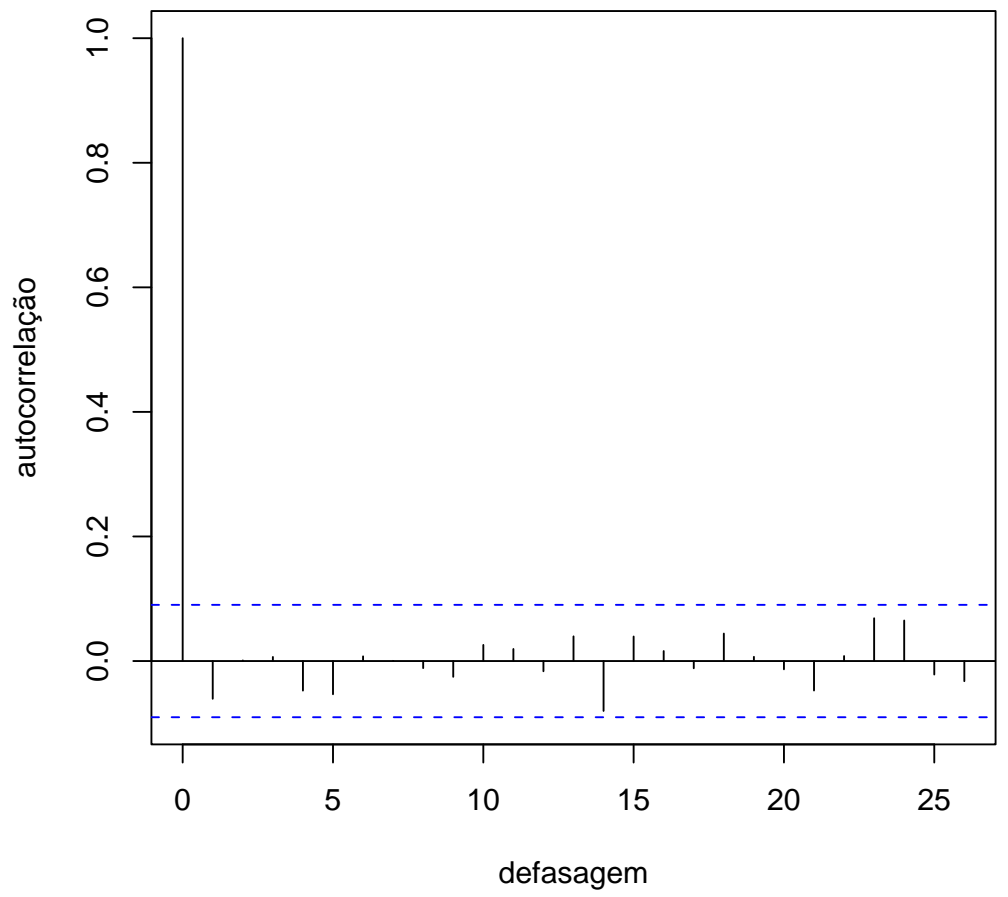

Figura B.10: Auto-correlação da utilidade para a simulação 2 da bateria 2 de simulações de 5000 gerações do modelo JE+AA (dados colhidos a cada 10 gerações) 


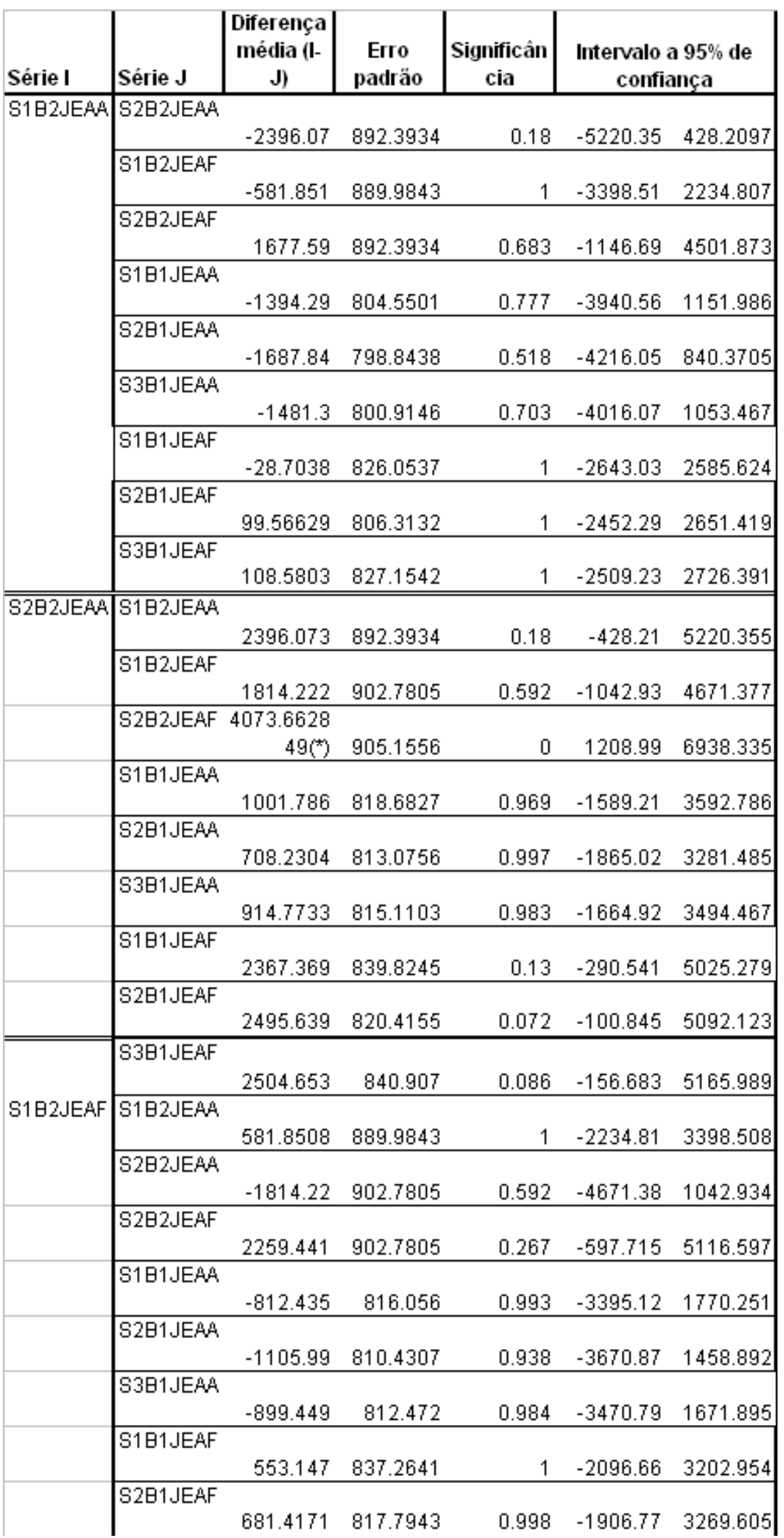

Figura B.11: Sumário dos resultados da comparação entre as séries de utilidade através do método de Tukey - Parte 1 


\begin{tabular}{|c|c|c|c|c|c|c|}
\hline & 53B1.JEAF & 690.4311 & 838.3499 & 0.998 & -1962.81 & 3343.674 \\
\hline \multirow[t]{10}{*}{ S2B2JEAF } & S1日2JEAA & & & & & \\
\hline & & -1677.59 & 892.3934 & 0.683 & -4501.87 & 1146.692 \\
\hline & S2B2JEAA & $\begin{array}{r}- \\
4073.6628 \\
49(*) \\
\end{array}$ & 905.1556 & 0 & -6938.34 & -1208.99 \\
\hline & S1日2JEAF & -2259.44 & 902.7805 & 0.267 & -5116.6 & 597.7146 \\
\hline & S1B1.JEAA & $\begin{array}{r}- \\
3071.8764 \\
80(*)\end{array}$ & 818.6827 & 0.007 & -5662.88 & -480.877 \\
\hline & S2B1JEAA & $\begin{array}{r}- \\
3365.4324 \\
53(*) \\
\end{array}$ & 813.0756 & 0.001 & -5938.69 & -792.178 \\
\hline & 53日1.JEAA & $\begin{array}{r}- \\
3158.8895 \\
82(*) \\
\end{array}$ & 815.1103 & 0.004 & -5738.58 & -579.196 \\
\hline & 51日1.JEAF & -1706.29 & 839.8245 & 0.576 & -4364.2 & 951.6162 \\
\hline & S2B1JEAF & -1578.02 & 820.4155 & 0.653 & -4174.51 & 1018.46 \\
\hline & S3B1JEAF & -1569.01 & 840.907 & 0.692 & -4230.35 & 1092.326 \\
\hline \multirow[t]{9}{*}{ S1B1JEAA } & S1B2JEAA & 1394.286 & 804.5501 & 0.777 & -1151.99 & 3940.558 \\
\hline & S2B2JEAA & -1001.79 & 818.6827 & 0.969 & -3592.79 & 1589.213 \\
\hline & S1B2JEAF & 812.4355 & 816.056 & 0.993 & -1770.25 & 3395.122 \\
\hline & S2B2JEAF & $\begin{array}{r}3071.8764 \\
80(*) \\
\end{array}$ & 818.6827 & 0.007 & 480.8767 & 5662.876 \\
\hline & S2B1JEAA & -293.556 & 715.5605 & 1 & -2558.19 & 1971.078 \\
\hline & S3B1.JEAA & -87.0131 & 717.8715 & 1 & -2358.96 & 2184.935 \\
\hline & S1B1JEAF & 1365.582 & 745.815 & 0.715 & -994.803 & 3725.968 \\
\hline & S2B1JEAF & 1493.853 & 723.8898 & 0.554 & -797.143 & 3784.848 \\
\hline & S3B1JEAF & 1502.867 & 747.0337 & 0.591 & -861.376 & 3867.109 \\
\hline \multirow[t]{8}{*}{ S2E1JEAA } & 51日2JEAA & 1687.842 & 798.8438 & 0.518 & -840.371 & 4216.055 \\
\hline & S2B2JEAA & -708.23 & 813.0756 & 0.997 & -3281.48 & 1865.024 \\
\hline & S1日2JEAF & 1105.991 & 810.4307 & 0.938 & -1458.89 & 3670.875 \\
\hline & S2B2JEAF & $\begin{array}{r}3365.4324 \\
53(*) \\
\end{array}$ & 813.0756 & 0.001 & 792.1782 & 5938.687 \\
\hline & S1B1JEAA & 293.556 & 715.5605 & 1 & -1971.08 & 2558.19 \\
\hline & S3B1.JEAA & 206.5429 & 711.4704 & 1 & -2045.15 & 2458.233 \\
\hline & S1B1JEAF & 1659.138 & 739.6558 & 0.427 & -681.754 & 4000.031 \\
\hline & S2B1JEAF & 1787.409 & 717.5423 & 0.273 & -483.498 & 4058.315 \\
\hline
\end{tabular}

Figura B.12: Sumário dos resultados da comparação entre as séries de utilidade através do método de Tukey - Parte 2 


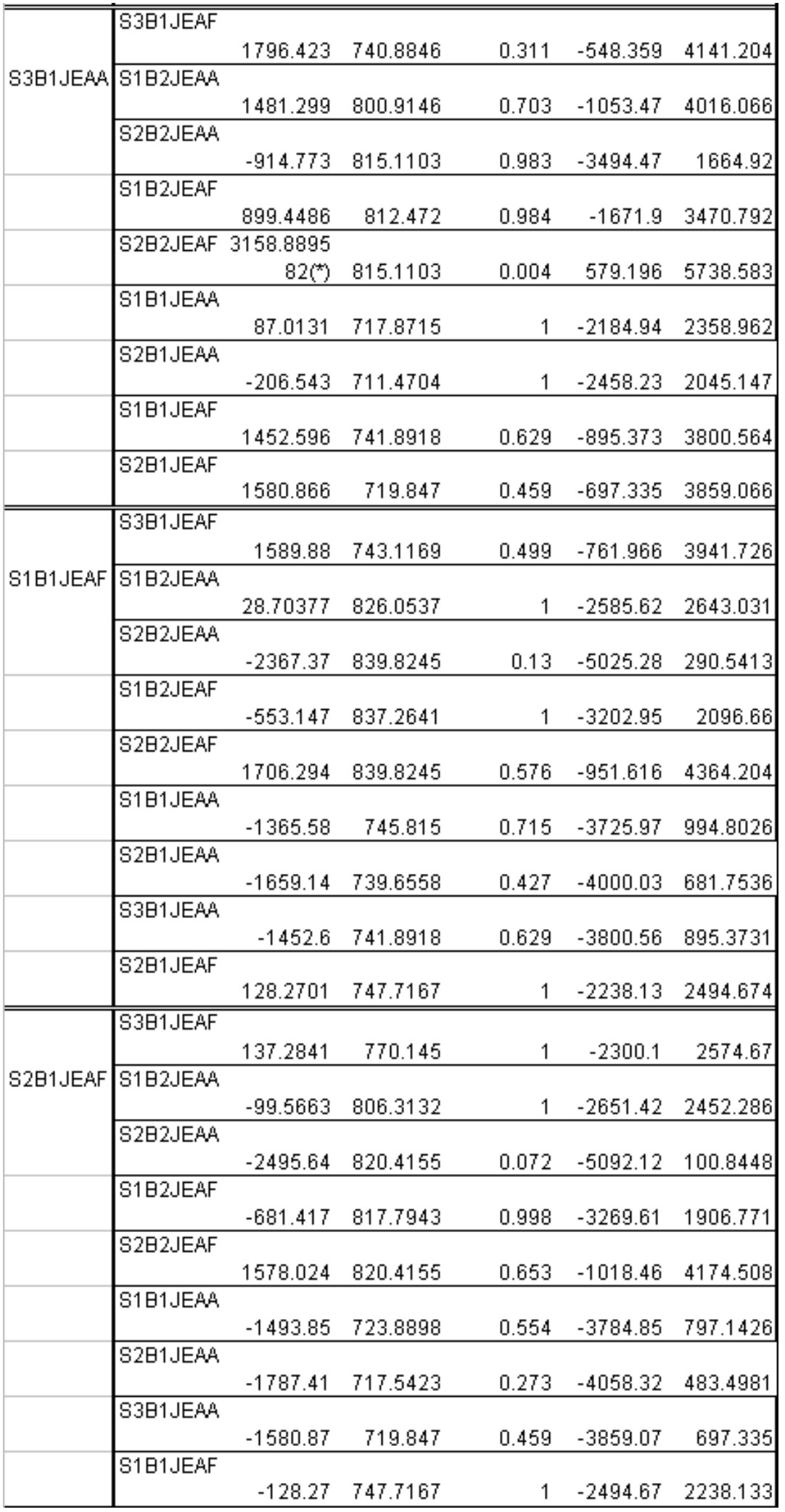

Figura B.13: Sumário dos resultados da comparação entre as séries de utilidade através do método de Tukey - Parte 3 


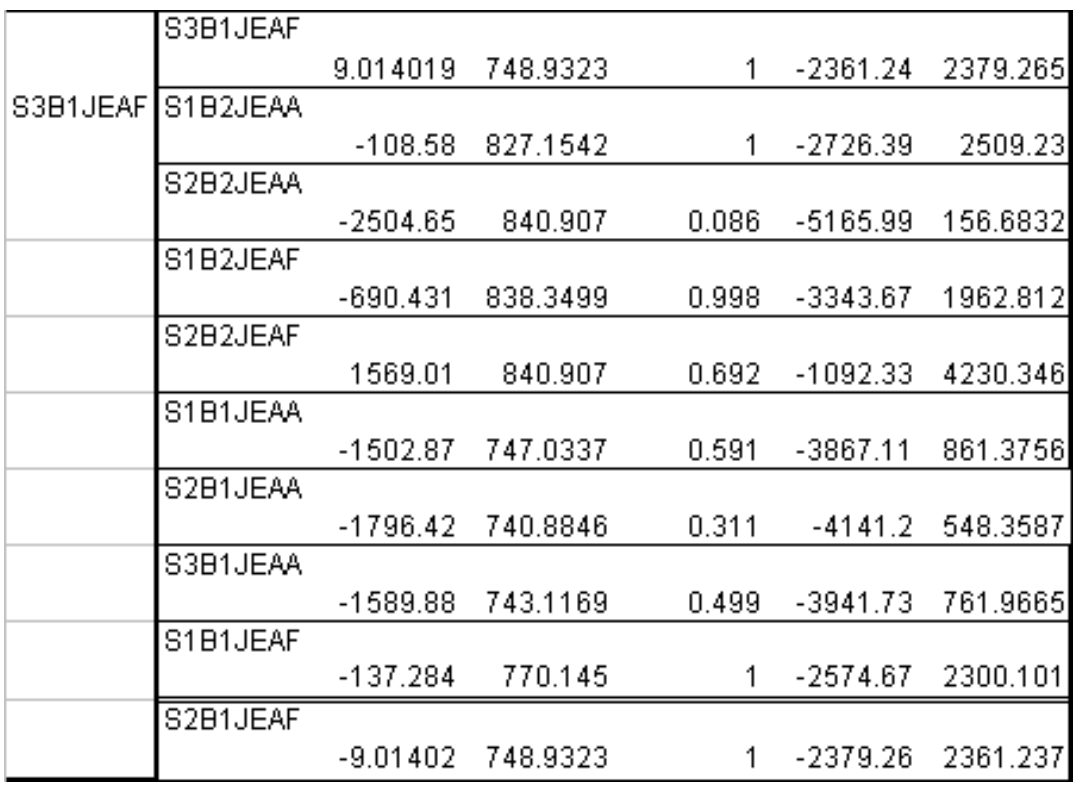

Figura B.14: Sumário dos resultados da comparação entre as séries de utilidade através do método de Tukey - Parte 4 


\section{Referências Bibliográficas}

ARAUJO, R.; LAMB, L. Towards understanding the role of learning models in the dynamics of the minority game. In: IEEE INTERNATIONAL CONFERENCE ON TOOLS WITH ARTIFICIAL INTELLIGENCE. 16. 2004, Boca Raton, FL, USA. Proceedings. New York: IEEE Computer Society. p. $727-731$

AXELROD, R. The evolution of cooperation. New York: Basic Books, 1984. 256 p.

AXELROD, R. Advancing the art of simulation in the social sciences. /Working paper/ Santa Fe, New Mexico, USA, 1997. Disponvel em: http://www.santafe.edu/research/publications/workingpapers/97-04048.pdf .Acessoem : 4dez.2007

AXELROD, R.; HAMMOND, R. The evolution of ethnocentric behavior. In: MIDWEST POLITICAL SCIENCE CONVENTION, Chicago, IL, USA. 2003.

Bó, I. G. L.; SICHMAN, J. S. An experiment on the role of cognition power on the evolution of cooperation in n-players prisioner's dilemma. In: II RESEARCH WORKSHOP ON INSTITUTIONS AND ORGANIZATIONS. São Paulo, Setembro 2007.

Bó, I. G. L.; SICHMAN, J. S. Strategy representation complexity in an evolutionary n-Players Prisoner's Dilemma model. In: SEMINARIO DE COMPUTACAO, 16. Blumenau, SC. Anais. Blumenau: 2007. p. 112-124.

BAZZAN, A. et al. Evolving populations of agents with personalities in the minority game. In: INTERNATIONAL JOINT CONFERENCE: 7th IBERAMIA AND 15th SBIA. Atibaia, SP. Proceedings. London, UK: Springer, 2000. p. 19-22.

BOYD, R.; RICHERSON, P. The evolution of reciprocity in sizable groups. Journal of Thermal Biology, v. 132, n. 3, p. 337-56, 1988.

BUSSAB, W. O.; MORETTIN, P. A. Estatística básica. São Paulo: Saraiva, 2004. $526 \mathrm{p}$.

CHROBAK, M. Minimization of finite automata. /Notas de aula/ River Side, CA.

DELAHAYE, J.; MATHIEU, P. Complex strategies in the iterated prisoner's dilemma. Chaos 6 Society, v. 94, p. 283-292, 1994.

DOEBELI, M. Spatial structure often inhibits the evolution of cooperation in the snowdrift game. Nature, v. 428, p. 643-646, 2004. 
ERIKSSON, A.; LINDGREN, K. Cooperation in an Unpredictable Environment. In: INTERNATIONAL CONFERENCE ON ARTIFICIAL LIFE. 8. Proceedings. Cambridge, MA: The MIT Press., p. 394-399, 2002.

ERIKSSON, A.; LINDGREN, K. Cooperation driven by mutations in multi-person Prisoner's Dilemma. Journal of Theoretical Biology. v. 232, n. 3, p. 399-409, 2005.

GLANCE, N.; HUBERMAN, B. The dynamics of social dilemmas. Scientific American, v. 270, n. 3, p. 76-81, 1994.

HAUERT, C.; SCHUSTER, H. Effects of increasing the number of players and memory size in the iterated prisoner's dilemma: a numerical approach. Royal Society B: Biological Sciences. v. 264, n. 1381, p. 513-519, 1997.

HELBING, D. et al. How individuals learn to take turns: Emergence of alternating cooperation in a congestion game and the prisoner's dilemma. /Working paper/ 2005. Disponvel em: http://arxiv.org/pdf/physics/0504189 .Acessoem : 4 dez. 2007

HUBERMAN, B.; GLANCE, N. Evolutionary Games and Computer Simulations. Proceedings of the National Academy of Sciences of the United States of America. v. 90, n. 16, p. 7716-7718, 1993.

IFTI, M.; KILLINGBACK, T.; DOEBELI, M. Effects of neighbourhoodsize and connectivity on the spatial Continuous Prisoner's Dilemma. Journal Theoretical Biology. Elsevier, v. 231, n. 1, p. 97-106, 2004.

KUTNER, M. e. a. Applied linear statistical models. Boston: McGraw-Hill Irwin, 2005. 1408 p.

LEWIS, H.; PAPADIMITRIOU, C. Elementos de teoria da computação. São Paulo: Bookman, 2004. 344 p.

LINDGREN, K.; JOHANSSON, J. Co-evolution of strategies in n-person Prisoner $\ll$ s Dilemma In: CRUTCHFIELD, J.; SCHUSTER, P. Evolutionary Dynamics-Exploring the Interplay of Selection, Neutrality, Accident, and Function. New York: Oxford University Press US, 2003. p. 341-360

LINDGREN, K.; NORDAHL, M. Evolutionary dynamics of spatial games. Physica D: Nonlinear Phenomena. v. 75, n. 1-3, p. 292-309, 1994.

LUKE, S. et al. MASON: A multiagent simulation environment. Simulation, v. 81, n. 7, p. 517, 2005.

MARTELLI, A. Python in a nutshell. Sebastopol, CA, USA: O'Reilly \& Associates, Inc., 2003.

MAS-COLELL, A.; WHINSTON, M.; GREEN, J. Microeconomic theory. New York: Oxford University Press, 1995.

MATSUSHIMA, M.; IKEGAMI, T. Evolution of Strategies in the three-person Iterated Prisoners Dilemma Game. Journal of Theoretical Biology. v. 195, n. 1, p. 53-67, 1998. 
MENEZES, C.; NETO, J. Um método híbrido para a construção de etiquetadores morfológicos, aplicado à língua portuguesa, baseado em autômatos adaptativos. CONFERENCIA IBEROAMERICANA EM SISTEMAS, CIBERNÉTICA E INFORMÁTICA. Anais. p. 19-21, 2002.

MILLER, J. The coevolution of automata in the repeated prisoner's dilemma. /Working paper/ Sante Fe, NM: Santa Fe Institute, (p. 89-003), 1989.

MYERSON, R. Game theory: analysis of conflict. Boston: Harvard University Press, 1991.

NETO, J. Solving complex problems efficiently with adaptive automata. Lecture Notes In Computer Science. v. 2088, p. 340-342, 2000.

NETO, J. Adaptive rule-driven devicesgeneral formulation and case study. In: INTERNATIONAL CONFERENCE ON IMPLEMENTATION AND APPLICATION OF AUTOMATA. 6. Proceedings. Pretoria-South Africa, Springer, 2001.

OWEN, G. Game Theory. 3rd. ed. Burlington, MA: Academic Press, 1995.

PISTORI, J. Adaptools: Aspectos de implementaçao e utilizaçao. Boletim tecnico PCS-USP, 2003.

PRADO, E. Dilema do prisioneiro e dinâmicas evolucionárias. Estudos Econômicos, v. 29, n. 2. p. 249-266, 1999.

ROCHA, R. da; NETO, J. Autômato adaptativo, limites e complexidade em comparação com a Máquinha de Turing. CONGRESS OF LOGIC APPLIED TO TECHNOLOGY, 2. Proceedings. p. 33-48, 2001.

SNIDAL, D. The game theory of international politics. World Politics, v. 38, p. 25-57, 1985.

TISUE, S.; WILENSKY, U. NetLogo: a simple environment for modeling complexity. INTERNATIONAL CONFERENCE ON COMPLEX SYSTEMS, 2004 .

WEIBULL, J. Evolutionary Game Theory. Cambridge, MA: MIT Press, 1995. 